\title{
If only I could tell ...
}

Citation for published version (APA):

Buskermolen, W. M. (2017). If only I could tell ...: measuring predictors for challenging behaviour in people with both intellectual disability and hearing impairment. [Doctoral Thesis, Maastricht University]. Maastricht University. https://doi.org/10.26481/dis.20170504wb

\section{Document status and date:}

Published: 04/05/2017

DOI:

10.26481/dis.20170504wb

Document Version:

Publisher's PDF, also known as Version of record

\section{Please check the document version of this publication:}

- A submitted manuscript is the version of the article upon submission and before peer-review. There can be important differences between the submitted version and the official published version of record.

People interested in the research are advised to contact the author for the final version of the publication, or visit the DOI to the publisher's website.

- The final author version and the galley proof are versions of the publication after peer review.

- The final published version features the final layout of the paper including the volume, issue and page numbers.

Link to publication

\footnotetext{
General rights rights.

- You may freely distribute the URL identifying the publication in the public portal. please follow below link for the End User Agreement:

www.umlib.nl/taverne-license

Take down policy

If you believe that this document breaches copyright please contact us at:

repository@maastrichtuniversity.nl

providing details and we will investigate your claim.
}

Copyright and moral rights for the publications made accessible in the public portal are retained by the authors and/or other copyright owners and it is a condition of accessing publications that users recognise and abide by the legal requirements associated with these

- Users may download and print one copy of any publication from the public portal for the purpose of private study or research.

- You may not further distribute the material or use it for any profit-making activity or commercial gain

If the publication is distributed under the terms of Article $25 \mathrm{fa}$ of the Dutch Copyright Act, indicated by the "Taverne" license above, 
If only I could tell...

Measuring predictors for challenging behaviour in people with both intellectual disability and hearing impairment 
(C) Willem Meindert Buskermolen, Maastricht 2017

All rights reserved. No part of this publication may be reproduced or transmitted, in any form or by any means, without the permission from the copyright owner.
Layout: $\quad$ Tiny Wouters
Cover: Tara-Lynn Voerman
Production: Ipskampprinting

ISBN: 978-94-028-0563-5

The research presented in this thesis was funded by the Stichting Vrienden van Effatha, de Gemiva-SVG-Groep, Koninklijke Kentalis, VSB fonds and Psychologen- en Pedagogenpraktijk Opmaat te Aalsmeer

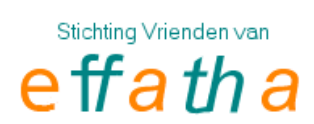

\section{VSBfonds,} iedereen doet mee

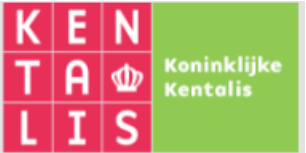

PSYCHOLOGEN- EN PEDAGOGENPRAKTIJK

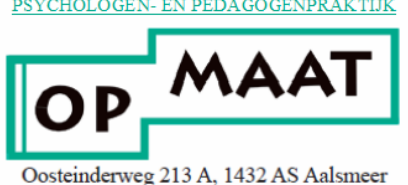

Telefoon(0297) 342636 


\title{
If only I could tell... \\ Measuring predictors for challenging behaviour in people with both intellectual disability and hearing impairment
}

\author{
Proefschrift \\ Ter verkrijging van de graad van doctor aan de Universiteit Maastricht, \\ op gezag van de Rector Magnificus, Prof. Dr. R.M. Letschert, \\ volgens het besluit van het College van Decanen, \\ in het openbaar te verdedigen \\ op donderdag 4 mei 2017 om 12.00 uur
}

door

Willem Meindert Buskermolen

Geboren op 31 maart 1956 te Leiden 


\section{Promotor}

Prof. Dr. A.P. Aldenkamp, Universiteit Maastricht

\section{Co-Promotor}

Dr. J. Hoekman, Vakgroep Orthopedagogiek, Universiteit Leiden

\section{Beoordelingscommissie}

Prof. Dr. F.R.J. Verhey (Universiteit Maastricht, voorzitter)

Dr. W.H.E. Buntinx (Gouverneur Kremers Centrum, MUMC)

Prof. Dr. C. Vlaskamp (em. Hoogleraar Orthopedagogiek, Universiteit Groningen)

Dr. S. Kef (Vrije Universiteit, Amsterdam) 


\section{Contents}

$\begin{array}{lll}\text { Chapter } 1 & \text { General Introduction and Aims } & 7\end{array}$

Chapter 2 Risk factors leading to behavioural problems in individuals 15 with hearing impairment and intellectual disabilities.

Chapter 3 Assessing challenging behaviour in people with hearing impairments and profound intellectual disabilities. The development of an Individual Behaviour Observation and Recording Scale.

Chapter 4 Assessing challenging behaviour in people with profound intellectual disabilities and hearing impairments. The inter-assessor reliability of the Individual Behaviour Observation and Recording Scale.

Chapter 5 Measuring possible environmental factors influencing challenging behaviour in people with both an intellectual disability and hearing impairment / deafness (ID - HI/D). The development of a digital program.

Chapter 6 The nature and rate of behaviour that challenges in individuals with intellectual disabilities who have hearing impairments/ deafness (ID - HI/D) (a longitudinal prospective cohort survey)

Chapter 7 Relation between environmental factors and challenging behaviour in people with both intellectual disabilities and hearing impairments/deafness (ID - HI/D). An explorative study

Chapter 8 General discussion

Summary

Samenvatting

Valorisation

Dankwoord

Curriculum vitae 

Chapter 1

GENERAL INTRODUCTION 


\section{General introduction}

Kees is a 29 year old male. He suffers from hearing loss of approximately $80 \mathrm{~dB}$, which means that Kees has severe hearing problems. His level of cognitive development can be compared with an eight-year-old child and his level of emotional development is similar to a three-year-old toddler. Moreover, Kees is diagnosed with an autism spectrum disorder. This combination of limitations means that predictability is essential for Kees. Therefore, communication with Kees should be unambiguous and clear. Kees lives in a residential home for people with an intellectual disability as well as hearing impairment/deafness and participates in a daily work and activity program. Despite the precisely arranged, pedagogic routines situations arise almost daily in which Kees hits, kicks, bites, or scratches staff. And because Kees weighs 110 kilograms and is six feet tall, this can escalate into violent situations. Very often, motives or causes for this behaviour are totally unclear.

Tessa is a young adult female of 22. She has such a profound loss of hearing that she senses only vibrations. Her cognitive level is comparable with that of a two-year-old child. Her social and emotional level is even lower. Tessa lives in a residential home for people with an intellectual disability as well as hearing impairment/deafness and participates in a daily work and activity program. Staff reports that Tessa often shows difficult behaviour during meals. She chews poorly, refuses to eat and throws with her plate. This also occurs, in other situations than meals, Tessa very often has moodswings in which she hits and punches herself. When staff tries to prevent this, Tessa's behaviour can easily worsen and very often Tessa has to be held by two staff members according to a prescribed protocol. Regularly Tessa wants to walk to and fro in the corridor. Staff does not seem to find any connection between the behaviour and certain circumstances.

My father worked as a bus-driver. He was expelled from school when he was twelve years old after the headmaster had told him that he was of no use and that it was better to look for a simple job (if possible). During early adulthood, he succeeded in getting some certificates for Dutch and English language, but that was the scope of his school and educational career. Nevertheless it was my father who got me on the track of psychology, which has led to this study. As a nine year old boy, I was sitting next to him in the dentist's waiting room. I was suffering from a terrible headache and stomach ache and was really feeling too feverish for an appointment to have my dentist check my teeth. Unfortunately I had no influence on that because this appointment had already been made. I told my father that it was odd to notice that suddenly my headache and stomache seemed to have disappeared. He smiled and said, "You see, that is what your body and brains can do to you." At that moment I didn't understand the full impact of this remarkable sentence, but from that moment I 
became fascinated by "Psychology": "Why do people act the way they do?" After graduating as a psychologist, I came to work as a staff coordinator at the Weerklank Institute, which is a residential home for people with Intellectual Disability (ID) as well as Hearing Impairment / Deafness (HI/D) in Amsterdam. In this particular home, I could abundantly utilize my fascination for my occupation.

The above described short case histories are characteristic of the problems I was confronted with at Weerklank. Every year, a multitude of incidents is reported. In Weerklank, where about forty people with both ID and HI/D live, during the year 2001, there were 868 reports of incidents,-errors and accidents, from which 706 were caused by aggression incidents (Papen \& Lansink, 2002). Yearly, after 2002, similar data were reported. We cannot find out if other homes for people with ID and HI/D are confronted with similar problems on this scale because little research has been found to date on the prevalence of behavioural problems in people with a combination of both disabilities. One exception is the study of Timehin and Timehin (2004). They reported that of 543 people with both ID and HI/D, 62\% showed problem behaviour and $34 \%$ exhibited self-harming behaviour.

However, considerable research has been done on behavioural problems of people with ID and people with HI/D separately. Behavioural problems frequently occur in people with an intellectual disability (ID) (Deb, Thomas \& Bright, 2001; Molteno, Molteno, Finchilescu \& Dawes, 2001; Emerson et al., 2001; Tyrer et al., 2006; Crocker et al., 2006; Holden \& Gitlesen, 2006). In these studies, prevalence rates varied widely, from less than $10 \%$ to over $40 \%$, depending on the definition and terminology indicating behavioural problems, the type and age of the subjects, the data collection methodology, and the psychiatric measures. For people with HI/D, similar findings for the prevalence and range of behavioural problems were reported (e.g., Vostanis, Hayes, Du Feu \& Warren, 1997; Van Eldik, Treffers, Veerman \& Verhulst, 2004; Van Gent, Goedhart, Hindley, \& Treffers, 2007).

The incidents, that are a result of behavioural problems are an important factor in the possible decrease of job satisfaction of professionals in an institution such as Weerklank and these incidents can increase the risk of absenteeism from work. In The Netherlands, of all industrial branches, healthcare is the sector in which there is the highest rate of absence due to sickness, which fluctuates at around 5\% (Ziekteverzuimpercentage; bedrijfstakken en bedrijfsgrootte, 2016), while at Weerklank this percentage (average over the years $2012-2015=7.7 \%$ ) is even higher (Beek, 2016). Nevertheless, in this residential home, well-educated professionals are continuously retrained, especially in how to interpret and understand (non-verbal) behaviour, how to deal with (threatening) aggression, and how to intervene and communicate in a respectful way.

Causes for behavioural problems such as aggression often are not clear. Although recognizing risk factors such as poor communication abilities can contribute to the understanding of behavioural problems, empirical research is needed into relations 
between behaviour and several environmental factors. When behavioural problems occur following specific environmental events, this could be an indication that this behaviour might be caused by these factors. A better insight into motives and causes will possibly lead to greater understanding of this behaviour. In addition, this could increase the possibility to anticipate and intervene in a more adequate, individually determined way.

Very few aggression incidents can be attributed to one cause. Broers en de Lange (1996) showed that in almost all aggression incidents they had studied in people with ID, a complicated combination of factors was involved. The nature of this combination of factors differs per individual, department, home and even per incident. Janssen, Schuengel and Stolk (2002) proposed that a complexity of stress factors forms the basis of the development of behavioural problems in people with ID. This makes it even more complicated to develop common guidelines to prevent aggression because professional staff very often do not see concrete relations between behaviour and causes of this behaviour.

The aim of this study is to gain more insight into internal and environmental factors that could be of any influence in developing or increasing or decreasing behavioural problems in people with both ID and HI/D. For this purpose, behaviour and environmental factors of 21 people with ID and HI/D were observed and recorded over a period of one year. Most of the people who participated in this study and are described in chapter six and seven, are residents of the Weerklank Institute, a residential home in Amsterdam, The Netherlands, for people with both ID and HI/D. The other participants are residents of two different residential homes for people with both ID and HI/D in Purmerend and Middenbeemster, The Netherlands. Several professionals such as a physical therapist, a communication teacher, a psychologist, and a psychiatrist are involved in supporting the staff who are responsible for the daily care of these people.

In the second chapter, the results from a literature review regarding the prevalence of behavioural problems in people with ID and in people with HI/D are reported. In chapter three, we investigate with which behavioural observation scale individually determined behaviour can be described, so that it could be used for the purpose of our study. We concluded that none of the scales were suitable for our study. That is why we developed our own Individual Behaviour Observation and Recording Scale (IBORS). This scale is also described in this chapter. Chapter four is a report of a study into the interassessor reliability of IBORS. In chapter five, we describe how environmental factors are defined and measured. We also describe a computer program with which these data were collected. In chapter six, possible internal factors are described based on the results we found in our participants. In chapter seven, relations between environmental factors and behaviour are reported. These results are described in 21 short case studies. In chapter eight our study is discussed. In this chapter, limitations and suggestions for further research are described as well. Finally, 
in a valorisation chapter (chapter nine), we will describe possible implications for clinical practice. 


\section{References}

Beek, M. (2016). Ziekteverzuim 2012 - 2015. Interne notitie database Kentalis Zorg. Weerklank, Amsterdam.

Broers, E. \& de Lange, J. (1996). Agressie in de Psychiatrie. Agressie tussen patienten en verpleegkundigen op gesloten afdelingen. Utrecht: NcGv

Crocker, A.G.; Mercier, C.; Lachapelle, Y.; Brunet, A.; Morin, D.; Roy, M.E. (2006). Prevalence and types of aggressive behaviour among adults with intellectual disabilities. Journal of Intellectual Disability Research, 50(9): 652-661.

Deb, S.; Thomas, M.; Bright, C. (2001). Mental disorder in adults with intellectual disability. 2: The rate of behaviour disorders among a community-based population aged between 16 and 64 years. Journal of Intellectual Disability Research, 45(6): 506-514.

Emerson, E.; Kiernan, C.; Alborz, A.; Reeves, D.; Mason, H.; Swarbrick, R.; Mason, L.; Hatton, C. (2001). The prevalence of challenging behaviors: A total population study. Research in developmental disabilities, 22(1): 77-93.

Holden, B.; Gitlesen, J.P. (2006). A total population study of challenging behaviour in the county of Hedmark, Norway: Prevalence, and risk markers. Research in developmental disabilities, 27(4): 456-465.

Janssen, C.G.C., Schuengel, C. \& Stolk, J. (2002). Understanding challenging behaviour in people with severe and profound intellectual disability:a stress-attachment model. Journal of Intellectual Disability Research, 46(6): 445-453.

Molteno, G.; Molteno, C.D.; Finchilescu, G.; Dawes, A.R.L. (2001). Behavioural and emotional problems in children with intellectual disability attending special schools in Cape Town, South Africa. Journal of Intellectual Disability Research, 45(6): 515-520.

Papen, E., Lansink, W. (2002). Jaarverslag 2001 FoBo-commissie Weerklank. Interne notitie. Amsterdam: Weerklank.

Timehin, C.; Timehin, E. (2004). Prevalence of hearing impairment in a community population of adults with learning disability: access to audiology and impact on behaviour. British Journal of learning disabilities. 32(3): 128-132.

Van Eldik, T., Treffers, P.D.A., Veerman, J.W., Verhulst, F.C. (2004). Mental health problems of deaf children as indicated by parents responses to the Child Behavior Checklist. American annals of the deaf, 148(5): 390-394.

Van Gent, T.; Goedhart, A.W.; Hindley, P.A.; \& Treffers, P.D.A. (2007). Prevalence and correlates of psychopathology in a sample of deaf adolescents. Journal of Child Psychology and Psychiatry. 48(9): 950-958.

Vostanis, P.; Hayes, M.; Du Feu, M.; Warren, J. (1997). Detection of behavioural and emotional problems in deaf children and adolescents : Comparison of two rating scales. Child care, Health and Development, 23(3): 233-246.

Ziekteverzuimpercentage; bedrijfstakken en bedrijfsgrootte. (2016, September 30). Retrieved September 30 from the website of the "Centraal Bureau voor de Statistiek":

http://statline.cbs.nl/StatWeb/publication. 
Chapter 2

\section{RISK FACTORS LEADING TO BEHAVIOURAL PROBLEMS IN INDIVIDUALS WITH HEARING IMPAIRMENTS AND INTELLECTUAL DISABILITIES}

Willem Meindert Buskermolen ${ }^{1}$, Joop Hoekman ${ }^{2}$ and Albert Pierre Aldenkamp ${ }^{3}$

1. Kentalis - Weerklank Amsterdam; the Netherlands

2. Leiden University; University of Applied Sciences Leiden; the Netherlands

3. Maastricht University; Kempenhaeghe, Heeze; the Netherlands

Published in:

International Journal on Mental Health and Deafness

2012 Volume 2 Issue 1 (33-45)

ISSN: 2226-3462 


\section{Abstract}

Background and objective

Behavioural problems in individuals with both hearing impairments ( $\mathrm{HI}$ ) and an intellectual disability (ID) are common. A literature search was conducted, focussed on the prevalence of behavioural problems in people with HI or ID and in people with both HI and ID. A special focus is on possible risk factors.

Results

Prevalence rates in both groups vary among the studies. For people with $\mathrm{HI}$, differences seem related to the composition of the samples. For people with ID, there are differences in the terminology indicating behavioural problems, type and age of the population, the methods of data collection used and the measuring instruments. In both groups an increase of behavioural problems is found when additional handicaps occur. The existence of ID in children with $\mathrm{HI}$ and conversely sensory impairment in people with ID form risk factors for behavioural problems. Understandably difficulties with communication increase the risk of developing behavioural problems.

Conclusions

We might expect prevalence rates in people with both $\mathrm{HI}$ and ID to be higher than in both groups separately. We suggest further research into the influence of external and internal factors on developing or increasing behavioural problems in people with $\mathrm{HI}$ and ID. A more precise definition of behavioural problems is also highly recommended. 


\section{Introduction}

From clinical practice it has been reported that professional carers, working with people with a Hearing Impairment (HI) as well as an Intellectual Disability (ID) are frequently confronted with behavioural problems (Nijhof \& van Overveld, 2005). In particular, aggressive incidents such as destructive behaviour aimed at objects or other people and self-harming behaviour are common problems. In the current article we use the term "Hearing Impairment" to describe those people who are deaf or hard of hearing. The Dutch classification for this is a loss of hearing from 20dB. The term "Intellectual Disabilities" is also used, which according to the American Association on Intellectual and Developmental Disabilities" (AAIDD) refers to people with "significant limitations, both in intellectual functioning and adaptive behavior as expressed in conceptual, social and practical skills which are apparent prior to the age of 18 ".

Although evidence indicates that (problem) behaviour may partly serve a self stimulatory function (Carr et al., 1999) it is a generally accepted concept that (problem) behaviour is a form of communication. Hammermeister \& Timms (1989) demonstrated the close relationship between verbal and non-verbal communication in human interaction: proximity and the use of space, bodily contact, hand gestures, head-nods, facial expression, eye contact and gaze and body movements. Brumback, Harper \& Weinberg (1996) discussed effective human communication and concluded that it consists of more than words alone. Campbell \& Fletcher (1993) examined the nonverbal behaviour of people with ID. The results indicated that individuals with ID who have no verbal skills show significantly more non-verbal behaviour intended as communication than people with verbal skills. Granlund \& Olsson (1999) state that even such behaviour as licking, squeezing, smiling, crying, hitting, or smearing with faeces should be seen as communicative signals.

People with a limited ability to express and understand verbal communication largely depend on non-verbal communication, in particular those with both HI and ID. It is conceivable that these individuals are often misunderstood or that they misinterpret situations in which they are involved. Based on this double risk, we assume that behavioural problems will occur frequently in this group.

We attempted to carry out a literature study on the prevalence of behavioural problems and incidents of aggression in people with either HI or ID and have compared this to people with both $\mathrm{HI}$ and ID. A special focus in this review was on possible risk factors leading to behavioural problems. We expected to find that communication difficulties formed the major risk factor to behavioural problems. 


\section{Methods}

The aim of our first literature search was to find prevalence rates of behavioural problems in people with both $\mathrm{HI}$ and ID. A literature search was carried out in October of 2011 in "Psychinfo" using the following search terms:

1. Hearing Impairment or Auditory Disabilities or Deaf or Deaf-Blind or Auditory Acuity or Auditory Cortex or Auditory Perception or Hearing Disorders or Partially Hearing-Impaired or Speech and Hearing Measures (30,413 publications).

2. Mental Retardation or Mild Mental Retardation or Moderate Mental Retardation or Profound Mental Retardation or Psycho-Social Mental Retardation or Severe Mental Retardation or Developmental Disabilities or Cognitive Impairment or Learning Disabilities (72,191 publications).

3. Behavior Problems or Problem Behaviour or Aggressive Behavior or Attack Behavior or Behavior Disorders or Criminal Behavior or Self Destructive Behavior or Self Injurious Behavior or Stereotyped Behavior (57,819 publications).

\section{Results}

Combining all these three groups of search terms resulted in forty results. Limited to studies on prevalence alone, thirteen studies remained. The case studies cited in these publications (Taylor, 1992; Sisson, Herson \& van Hasselt, 1993; Umbreit, 1997; Crockett \& Hagopian, 2006) were not useful for our purposes because prevalence rates were not given. Other studies (Kiani, Gangadharan \& Miller, 2007; Gordon, 2008; Kiani, Miller \& Gangadharan, 2008) focussed on the Waardenburg syndrome in which $\mathrm{HI}$ is a common co-morbidity. In these studies, no prevalence rates are mentioned either. Eventually only six studies proved to be relevant for our purposes.

Stryker (1999) concluded that although we know that ID exists in people who are deaf or hard of hearing, it is difficult to identify them. Schum (2005) confirmed these findings. Assessment of people with $\mathrm{HI}$ and such co-morbidities as epilepsy, visual impairment, ADHD or ID is very difficult because of communication problems.

Carvill \& Marston (2002) searched studies that explored the frequency of psychiatric problems amongst people with ID and sensory impairment (SI). They could not identify any studies involving people with both ID and SI.

The three remaining studies (Yeates, 1995; Timehin \& Timehin, 2004; MeuweseJongejeugd et al., 2007) explored the frequency of hearing problems in people with learning disabilities. Findings in these studies illustrated that the hearing status of people with a learning disability is commonly disregarded when the deafness is suppressed by other problems. Timehin and Timehin (2004) identified the scarcity of studies exploring the frequency of problem behaviour in people with both ID and HI. 
They also indicated that "deafness in learning disability has been described as a 'double jeopardy' because the difficulties are compounded to be more than the sum of their parts" (Timehin \& Timehin, 2004 pg 128). This was the only study to report a prevalence of behavioural problems in (British) people with both ID and HI. 62\% of these showed problem behaviour and 34\% had self-harming behaviour.

The results of our literature study suggested that people with a combination of intellectual and hearing impairment form an under-reported group. Because of the lack of results from our searches we carried out additional searches into the prevalence of behavioural problems in people with $\mathrm{HI}$ and people with ID in an attempt to reconstruct the prevalence by looking at $\mathrm{HI}$ and ID separately.

\section{Prevalence of behavioural problems in people with hearing impairment (HI)}

Studies on the prevalence of behavioural problems in people with $\mathrm{HI}$ are rare. Using "Psychinfo" the search terms in numbers 1 and 3 above produced 186 results. Limited to studies on prevalence, 18 studies remained. Only six of these were published after 2001. The results are summarized in Table 2.1 .

Table 2.1 Prevalence of behaviour problems in people with hearing impairment (HI).

\begin{tabular}{|c|c|c|c|c|c|c|}
\hline Author & Age Pop & Measuring instrument & 1 & 2 & 3 & 4 \\
\hline Rutter et al. (1970) & $5-14 y$ & Rutter Scales & 15 & & & \\
\hline Meadow (1971) & $4-20 y$ & Interview & & & 32 & \\
\hline Freeman et al. (1975) & $5-15$ y & Rutter Scales / Interview & 23 & & & \\
\hline Fundudis et al. (1979) & $7-10 y$ & Rutter Scales & 54 & & & \\
\hline Aplin (1985) & $7-15 y$ & Rutter Scales & 36 & & & \\
\hline Aplin (1987) & $7-16 y$ & Rutter Scales & 18 & & & \\
\hline Kammerer (1988) & $10-13 y$ & Parents Interview & & & 54 & \\
\hline Arnold \& Atkins (1991) & $4-10 y$ & Rutter Scales & 0 & & & \\
\hline Sinkkonen (1994) & $6-16 y$ & Rutter Scales & 19 & & & \\
\hline Hindley et al. (1994) & $11-16 y$ & $\mathrm{TCL} / \mathrm{PCL}$ & & 50 & & \\
\hline Mitchell \& Quittner (1996) & $6-14$ y & $\mathrm{CBCL} / \mathrm{TRF}$ & & $33 / 50$ & & \\
\hline Vostanis et al. (1997) & $2-18 y$ & $\mathrm{CBCL} / \mathrm{PCL}$ & & $40 / 77$ & & \\
\hline Van Eldik et al. (2004) & $4-18$ y & $\mathrm{CBCL}$ & & 41 & & \\
\hline Van Eldik (2005) & $11-18$ y & YSR & & 37 & & \\
\hline Cornes et al. (2006) & $11-18 y$ & YSR & & 43 & & \\
\hline Van Gent et al. (2007) & $13-21 y$ & $\mathrm{CBCL} / \mathrm{TRF} / \mathrm{SCICA}$ & & $11 / 27$ & & \\
\hline Hintermaier (2007) & $4-13 y$ & SDQ & & & & 36 \\
\hline Fellinger et al. (2009) & $6-16 y$ & Interview Parents & & & 33 & \\
\hline
\end{tabular}

Data are presented as percentages The columns 1-4 represent the measuring instruments: 1 Rutter scales; 2 CBCL/YSR; 3 Diagnostic Interview; 4 SDQ. 
Studies on behavioural problems in people with $\mathrm{HI}$ are concentrated on children and adolescents. From the publications mentioned in the table above, the Finnish study of Sinkkonen (1994) was the only one that did not find behavioural differences between hearing children and children with HI. Another exceptional result was reported in an Indian study by Arnold \& Atkins (1991) who found no behavioural problems in both the group people with $\mathrm{HI}$ and the control group. It is apparent that there is much variation in the prevalence found in the above mentioned studies. This was possibly due to the use of different measures.

Until 1994, the Rutter Scales (Rutter, 1967) were the most common method of measuring behavioural problems. Using his own scale along with interviews with the children tested and their parents Rutter (1970) found that $15 \%$ of a population of British school children with $\mathrm{HI}$ showed behavioural problems. His findings were confirmed by other studies which used the same scale (Freeman et al., 1975; Fundudis et al., 1979; Aplin, 1985; 1987; Sinkkonen, 1994). Psychiatric reports on interviews with parents alone were also used.

Meadow \& Schlesinger (1971) used a diagnostic interview and found that $32 \%$ of the population at an American school for deaf children were considered to be emotionally disturbed of which $12 \%$ severely. Kammerer (1988) also used diagnostic interviews with parents to discover behavioural problems among 54\% of American deaf children between the ages of 10 and 13. The more recent German study by Fellinger et al. (2009) corroborates these findings from diagnostic interviews with a prevalence rate of $33 \%$. Hintermaier (2007) is the only one who interviewed parents using the Strength and Difficulties Questionnaire (Goodman, 1997). 36\% of German children (4-13 years old) in this group displayed emotional/behavioural problems. The Child Behaviour Check List (CBCL) (Achenbach, 1991) has been used since 1991. Mitchell \& Quittner (1996) used the parent and teacher forms of the CBCL in their study on deaf American childeren. The parents' ratings indicated that half of the children with hearing impairments show externalizing behavioural problems, while the teachers' ratings indicated that one-third of the children showed significant behavioural problems. Vostanis et al. (1997) found that $40 \%$ of a sample of deaf British children scored within the clinical range of the $\mathrm{CBCL} .43 \%$ of the children scored within the clinical range on the domain "social functioning". Parents identified a much higher percentage (77\%) on the Parents Check List of the CBCL. Van Eldik (2004) studied the emotional/ behavioural problems in 238 Dutch deaf children aged from 4-18 years. The parental reports indicated that $41 \%$ showed emotional/behavioural problems. Deaf children with a relatively low intelligence showed more problems. An Australian study by Cornes et al. (2006) reported emotional/behavioural problems in $43 \%$ of adolescents. Hindley et al. (1994) used various diagnostic measures. By combining the results of interviews with British children as well as their parents with questionnaires for parents and teachers they found in their study psychiatric problems in $42 \%$ of the deaf children and in $61 \%$ of the hard of hearing children. 
However, differences in prevalence rates are also found in the above-mentioned studies in which the same instrument measure was used. Van Gent, Goedhart, Hindley \& Treffers (2007) assumed that these differences may be related to the composition of the samples. In their own study of Dutch adolescents they used a multiple informant approach, combining relevant information from parents, teachers, the children themselves, their clinicians and medical files. Despite comparable results the authors found a variation in prevalence rate.

These differences can be partially explained by the source of data collection (e.g. parents, teachers or professionals). Percentages of "Total Problems" scores in the borderline clinical range plus the clinical range, using the $\mathrm{CBCL}$, TRF and SCICA, were $28 \%, 32 \%$ and $49-63 \%$ respectively. Expert dossier ratings identified psychiatric cases in $49 \%$ and DSM classifications in $46 \%$ of the adolescents.

In summary, we may conclude that research on behavioural problems in people with $\mathrm{HI}$ is concentrated on children and adolescents. In those studies in which a hearing control group was used, higher prevalence rates of behavioural problems were reported in children with $\mathrm{HI}$. Prevalence rates of behavioural problems in the control group varied from 0 to $18 \%$. We can therefore conclude that children with $\mathrm{HI}$ show more emotional and behavioural problems than hearing children.

\section{Prevalence of behavioural problems in people with intellectual disability} (ID)

Behavioural problems such as aggression, self-harmful behaviour, destructive behaviour, outbursts of fury, hyperactivity, screaming and attention seeking is frequently seen in people with ID. The prevalence of these forms of behaviour disorders in people with ID has been studied extensively. In "Psychinfo", 4,758 search results were obtained using the above-mentioned search terms (numbers 2 and 3). When limited to articles published after 2001, a total of 1,777 search results were obtained. In 49 of these studies prevalence was mentioned. In this review, we have concentrated on the most recent articles. Furthermore, we focussed on 13 metastudies in which the main goal was research into prevalence rates.

Our literature study is summarized in Table 2.2.

The first thing that stands out in these studies is the great diversity of terms used for the behaviour studied. These terms are numbered 1 to 18 in the table above and are described below it. Further, different measures were used to examine the frequency of the problem behaviour studied. Finally, the composition of the samples differs in type and age. Rojahn \& Esbensen (2002) and Anderson (2006) also refered to these problems. Prevalence rates obtained therefore mainly depend on definition and terminology indicating behavioural problems, type and age of the population, the methods of data collection used and the psychiatric measures. Rojahn \& Meier (2009) 
concluded that some improvement regarding these problems was made in the last decade, but it still is an area of concern.

Table 2.2 Percentage behavioural problems in people with intellectual disability

\begin{tabular}{|c|c|c|c|c|c|c|c|c|c|c|c|c|c|c|c|c|c|c|c|}
\hline Author & Population & $\begin{array}{l}\text { Research } \\
\text { tool }\end{array}$ & 1 & 2 & 3 & 4 & 5 & 6 & 7 & 89 & 10 & 11 & 12 & 13 & 14 & 15 & 16 & 17 & 18 \\
\hline Dek et al (2001) & $101 ;$ adults & Disability Assessment Schedule & 23 & 29 & 36 & 38 & & & 26 & & 24 & 12 & 20 & 18 & & & & & \\
\hline $\begin{array}{l}\text { Molteno et al. } \\
\text { (2001) }\end{array}$ & 355 ; children & Developmental Behaviour Checklist & & & & & & & & & & & & & & 31 & & & \\
\hline $\begin{array}{l}\text { Emerson et al. } \\
\text { (2001) }\end{array}$ & 264; adults & Questionnaires & 7 & & & & & $10-15$ & & & 4 & 4.5 & & & & & & & $9-12$ \\
\hline Kamia (2002) & $657 ; 12-18$ seax & Questionnaires and pascbiattic evaluations & 2.4 & & & & & & & & 1,2 & & & & & & & & \\
\hline $\begin{array}{l}\text { Taanila et al. } \\
\text { (2003) }\end{array}$ & $106 ; 8$ year & Rutter scales & & & & & & & 36 & & & & & & & 44 & 21 & 18 & \\
\hline $\begin{array}{l}\text { Dekker \& Koot } \\
\text { (2003) }\end{array}$ & $474 ; 7-20$ хеax & Diagnostic Interview Schedule for Children & & & & & 25 & & & 4 & & & & & 22 & & & & \\
\hline $\begin{array}{l}\text { Jurer et al. } \\
\text { (2006) }\end{array}$ & 3065 adults & Interview & & & & & & & & & 14 & & & & & & & & \\
\hline $\begin{array}{l}\text { Crocker et al. } \\
(2006)\end{array}$ & 3165; adulta & Modified Overt Aggressive Scale & 24 & 38 & & & & & & 10 & 24 & 24 & & & & & & & \\
\hline $\begin{array}{l}\text { Lindouist et al. } \\
\text { (2006) }\end{array}$ & 107 ; childoren & Couners'parent rating scale. & & & & & & & & & & & & & & & $39-67$ & & \\
\hline $\begin{array}{l}\text { Aurbakk son } \\
\text { Ietzcaner (2008) }\end{array}$ & 140; Adel \& adulta & $A B C$ & & & & & & 20 & & & & & & & & & & & \\
\hline $\begin{array}{l}\text { Jones et al. } \\
\text { (2008) }\end{array}$ & 1023; adulta & Pavchiatrist opinion / DC.LD & & & & & & & & & & & & & & & $23 / 19$ & & \\
\hline $\begin{array}{l}\text { Cooper et al. } \\
\text { (2009A) }\end{array}$ & 651; Adults & DC.LD & & & & & & & & & 4.9 & & & & & & & & \\
\hline $\begin{array}{l}\text { Cooper et al. } \\
\text { (2009B) }\end{array}$ & 651; Adults & DCLLD & 9.8 & & & & & & & & & & & & & & & & \\
\hline
\end{tabular}

1 Physical aggression

2 Verbal aggression/screaming

3 Temper tantrum

4 Seeking attention

5 Disturbing behaviour

6 Challenging behaviour

7 Over active

8 Sexual aggression

9 Mood disorder
10 Self-injurious behaviour

11 Destructive on material

12 Compulsive on material

13 Sleeping disorder

14 Anxiety

15 Psychopathologic/Psychiatric disorder

16 Behavioural problems general

17 Emotional problems general

18 Other behavioural problems

In order to gain a better understanding a distinction was made between studies of children and those of adults. In the studies of children with ID the following results were shown.

In a population of 355 South African children with ID Molteno et al. (2001) found a prevalence rate of $31 \%$ for psychopathology. They also found that boys show more behavioural problems than girls and that behavioural problems are related to the severity of the intellectual disability. Children who depend on non-verbal communication also show more behavioural problems.

In a group of Japanese adolescents with ID Kamio (2002) compared individuals with autism to those without. The prevalence rate of self-harming behaviour was significantly higher in the group with autism. She concluded that aggressive behaviour is related to severe ID while self-harming behaviour tends to be related to autism. Taanila et al. (2003) studied 8-year-old Finnish children. This group consisted of 
children both with and without ID. They discovered that $44 \%$ of the children with ID showed probable psychiatric disturbances, $21 \%$ showed behavioural problems, $18 \%$ suffered from emotional problems and $36 \%$ were hyperactive. The prevalence rates in the group without ID were respectively $14 \%, 9 \%, 5 \%$ and $9 \%$. In both groups it appeared that boys tend to have more problems than girls, although the difference in the group of children with ID was not significant. Dekker \& Koot (2003) used the Diagnostic Interview Schedule for Children on parents of Dutch children with ID. The following prevalence rates were found: $4.4 \%$ mood disorder, $21.9 \%$ anxiety disorder and $25.1 \%$ disruptive disorder. More than half of the children who scored on these symptoms were severely impaired in daily functioning and about $37 \%$ had co-morbid disorders such as visual, auditory or physical problems and epilepsy. Lindquist et al. (2006) investigated the prevalence of behaviour problems in a group of Swedish children with hydrocephalus. They found that parents rated $67 \%$ and teachers $39 \%$ of the children as having behavioural problems.

Studies of adults with ID showed the following results: Deb, Thomas \& Bright (2001) aimed to establish the overall rate and types of behavioural disorders in a population of Welsh adults with ID. A total of 101 adults with ID were randomly selected, and prevalence rates were found for several different behavioural disorders. These varied from $12 \%$ for destructive behaviour up to $38 \%$ for attention-seeking behaviour. 23\% showed aggressive behaviour. Emerson et al. (2001) found lower rates of prevalence in a sample of 264 British people with ID of whom approximately two thirds were male and close to two-thirds were young adults: self-harming behaviour $4 \%$, aggression $7 \%$, destructive behaviour 4-5\%. Most notable is the category "other" behaviour in which $9-12 \%$ of the screened individuals scored. In this category all kinds of challenging behavioural disorders were noted, the majority of whom showed more than one form of challenging behaviour. The individuals who showed more demanding challenging behaviour were more likely in need of greater levels of assistance in their daily routine such as eating, dressing and using the toilet. These people also had more restricted expressive and receptive communication. Tyrer et al. (2006) used interview data from 3065 British adults with ID and found that 14\% were physically aggressive towards others. Over a period of one year, Crocker et al. (2006) found prevalence rates of $51.8 \%$ of aggressive behaviour in Canadian people with ID. They identified $24 \%$ property damage, 37.6\% verbal aggression, 24.4\% self-orientated aggression, 24.4\% physical aggression and 9.8\% sexual aggression. Myrbakk \& Von Tetzchner (2008) found a prevalence rate of $20 \%$ challenging behaviour in Norwegian adolescents and adults with ID living in community settings. In Scottish adults with ID, Jones et al. (2008) found a prevalence of problem behaviours of $22.5 \%$. Also in Scottish adults with ID, Cooper et al. (2009A) found prevalence rates of self-harming behaviour of $4.9 \%$ and from all types of aggressive behaviour a prevalence rate of 9.8\% (Cooper et al., 2009B).

Taking all the evidence together prevalence rates varied widely across the studies. Behavioural problems in general were mentioned as such in only three publications. 
Prevalence rates in these studies were 21\% (Taanila et al. 2003), 39-67\% (Lindquist et al. 2006) and 23/19\% (Jones et al. 2008). As mentioned above in the other studies several categories of behavioural problems were defined. This could explain the observed differences, but even within similarly defined behavioural categories differences were found. For physical aggression, prevalence rates ranged from $2.4 \%$ (Kamio 2002) to $24 \%$ (Crocker et al. 2006). Self-harming behaviour ranged from $1.2 \%$ (Kamio 2002) to 24\% (Deb, Thomas \& Bright 2001). Destructive behaviour towards objects was mentioned in three studies and prevalence rates here ranged from $4.5 \%$ (Emerson et al. 2001) to 24\% (Crocker et al. 2006). Furthermore, differences could occur owing to the fact that several psychiatric measures were used or the method by which this data was obtained.

\section{Risk factors in $\mathrm{HI}$}

A separate literature search on this subject was conducted in October 2011 in "Psychinfo", using the search terms in numbers 1 and 3 above, combined with the search term Risk Factors or Risk Assessment (18,096 publications).

A combination "and/and" of these three groups of search terms resulted in 19 publications.

Sinkkonen (1994) found that children with $\mathrm{HI}$ and additional handicaps showed more frequently disturbed behaviour. Both Vernon \& Greenberg (1999) and Miller \& Vernon (2003) studied the relationship between hearing loss and violence and discovered that people with $\mathrm{HI}$ are over-represented in the prison population in the United States. They suggest that ID, communication disorders and un- or underemployment in the deaf and hard-of-hearing population creates frustration, which tends to manifest itself in disproportionate aggression. Cappelli et al. (1995) found that Australian children with $\mathrm{HI}$ who are integrated into regular classrooms are more likely to be rejected by their peers than hearing children. This was caused by a reduced degree of competence in social skills in the children with HI. Vostanis et al. (1997) found that the use of speech in addition to sign language has a protective effect for adolescents with $\mathrm{HI}$. In their study on the relationship between parenting practice and behavioural problems Brubaker \& Szakowski (2000) concluded that there was no evidence that the greater prevalence of behavioural problems among deaf American children was the result of inadequate parenting. Van Eldik et al. (2004) found an increase in behavioural problems in Dutch children with $\mathrm{HI}$ who also had intellectual disabilities. Sarimski (2007) concluded that it is very difficult to differentiate between the various risk factors leading to mental health disorders among children and adolescents with hearing disorders, blindness, physical handicaps or intellectual disabilities. Problems in parent-child relationships and issues on the development of social competence and social participation are all possible risk factors. 
In summary, two groups of risk factors were mentioned. Firstly, co-morbidity of physical handicaps or ID form an increased risk in developing behavioural problems; secondly difficulties in communicating were also cited as a risk factor.

\section{Risk factors in ID}

A separate literature search on this subject was conducted in October 2011 in "Psychinfo", using the search terms in numbers 2 and 3 above, combined with the search term Risk Factors or Risk Assessment (18,096 publications). A combination "and/and" of these two groups of search terms resulted in 33 publications.

In some studies a gender effect was found. In general males showed more behavioural problems (Emerson et al. 2001; Molteno et al. 2001; McClintock, Hall \& Oliver 2003; Tyrer et al. 2006), although Crocker et al. (2006) did not find this difference. Deb, Thomas \& Bright (2001) found that the rate of self-harming behaviour was significantly associated with the female gender. Emerson et al. (2001) and Tyrer et al. (2006) reported an age-effect: young adults and adolescents displayed more behavioural problems. The severity of the ID was also cited as a risk factor (Deb, Thomas \& Bright 2001; Kamio 2002; McClintock, Hall \& Oliver 2001; Molteno et al. 2001; Tyrer et al. 2006). Additional problems such as sensory impairment (Besag 2003; Dekker \& Koot 2003) and autism (Matson, Boisjoli \& Mahan 2009; Kamio 2002; McClintock, Hall \& Oliver 2001) were also established as risk factors, although Tyrer et al. (2006) questioned the relationship between aggression and autism.

Chadwick et al. (2000) and Emerson et al. (2001) found a higher prevalence rate of behavioural problems when people with ID were more limited in their daily skills, such as eating and dressing. Crockett \& Hagopian (2006) found an increase in behavioural problems when people were faced with challenging situations.

Communication is often mentioned as a risk factor. Sigafoos (2000) explored the relationship between communication development and behaviour in 13 Australian preschool children with developmental disabilities. Over a period of three years, communication skills and the severity of 58 behavioural patterns were assessed every six months. A strong inverse relationship was found between communication skills and aberrant behaviour such as hyperactivity and lethargy. Molteno et al. (2001) found that children who depended on non-verbal communication had higher scores on all the subscales of psychopathology on the Developmental Behaviour Checklist. Self-harming behaviour increases significantly when people have poor communication skills (Deb, Thomas \& Bright 2001). People who show more challenging behaviour have more restricted expressive and receptive communication (Emerson et al. 2001). McClintock, Hall \& Oliver (2003) also concluded that people with restricted expressive and receptive communication showed more challenging behaviour such as self-harm. Besag (2003) investigated the relationship between epilepsy and behavioural problems and 
discovered that communication difficulties and not the epilepsy itself were responsible for the high prevalence of behavioural disturbance.

In case studies (Robinson \& Owens 1996; Frea, Arnold \& Vittimberga 2001; Durand \& Merges 2001) a decrease in behavioural problems was reported when communication capabilities increased. Others concluded that there is a decrease in behavioural problems when carers interact more with people with communicative impairment (Brusca 1989; Umbreit 1997; Bradshaw 1998).

In summary, it seems that there are several risk factors leading to developing behavioural problems. In males and young adults or adolescents the risk of developing behavioural problems is higher than in females and adults. The severity of ID was cited as another risk factor. Additional handicaps such as sensory impairment and autism also increase the chance of behavioural problems. When there are limited daily skills, such as eating and dressing or when situations are demanding, challenging behaviour is more likely to occur as well. When gender and age are not included, the abovementioned findings seem to underline problems in communication as a major risk factor.

\section{Discussion}

\section{Prevalence}

Firstly, our literature study showed that there is a scarcity of studies on people with both $\mathrm{HI}$ and ID and that in the only publication in which a prevalence rate was reported (Timehin \& Timehin 2004) high prevalence rates of behavioural problems and selfharming behaviour were found. The fact that individuals with both $\mathrm{HI}$ and ID are seldom studied as a separate group would indicate that these individuals are a negligible group. A possible explanation could be that many individuals are misdiagnosed. It is difficult to identify ID in individuals with HI. Conversely the same problem is recognized in people with ID for whom it is difficult to detect the hearing status. $\mathrm{HI}$ is often suppressed by other - more urgent - problems.

Secondly, although some improvements are being made in research on behavioural problems in people with ID, there still are differences in the terminology indicating behavioural problems, type and age of the population, the methods of data collection used and the psychiatric measuring instruments. In studies on people with $\mathrm{HI}$, behavioural problems are defined in a more general and similar way than in studies on people with ID. The most important reason for this seems to be the use of less diagnostic measures. In people with $\mathrm{HI}$ as well as in people with ID an increase in behavioural problems was found when additional handicaps occurred. 


\section{Risk factors}

It was presumed that difficulties in communicating would form a major risk factor in individuals with both $\mathrm{HI}$ and ID towards developing behavioural problems. Several risk factors were mentioned in the publications that we have identified. Communication difficulties form an important risk factor leading to behavioural problems in individuals with HI or ID. Sensory impairment in people with ID and the existence of ID in children with $\mathrm{HI}$ may increase communication difficulties and as a result form a higher risk leading to behavioural problems. All the same we would expect a higher prevalence rate of behavioural problems in people with both $\mathrm{HI}$ and ID than in either group separately. The results from the study by Timehin \& Timehin (2004) and the findings from our study on risk factors in people with $\mathrm{HI}$ and those with ID, may provide evidence for this assumption.

We can speculate about the reason that behavioural problems form ongoing difficulties. Individuals with $\mathrm{HI}$ and ID will use all their abilities to make themselves understood and to express their motives. Knowing this, it is understandable that due to difficulties in communication, these people are at higher risk of developing behavioural problems. The reasons or motives for behavioural problems are frequently not understood by carers, which can easily lead to escalating situations. Obviously, these incidents have enormous psychological and physical implications and may result in a negative effect on the quality of life of those involved. More research is therefore necessary into the causes and exacerbation of problem behaviour. When greater insight is found, programmes can be developed aimed specifically at preventing problem behaviour and intervening expeditiously.

Such programmes will be more meaningful when communication between people with $\mathrm{HI}$ and ID and carers can be improved. Special education for carers in using and understanding sign language and other forms of non-verbal communication is therefore crucial. Observation and recognition of behaviour as a means of communicating should be important topics of study.

We suggest further research into the influence of external and internal factors on developing or increasing behavioural problems in people with $\mathrm{HI}$ and ID. A more precise definition of behavioural problems is also highly recommended. 


\section{References}

Achenbach, T.M. (1991). Manual for the Child Behavior Checklist and 1991 profiles. Burlington, VT: University of Vermont Department of Psychiatry.

Anderson, G. (2006). People with intellectual disabilities who offend or are alleged to have offended. In: Hogg, J.(Ed); Langa, A.(Ed) (2005). Assessing adults with intellectual disabilities: A service providers'guide. (pp. 86-97). Malden, MA, US: Blackwell Publishing. ix, 253 pp.

Aplin, D.Y. (1985). Social and emotional adjustments of hearing-impaired children in special schools. Journal of the British Association of Teachers of the Deaf. 9, 84-94.

Aplin, D.Y. (1987). Social and emotional adjustments of hearing-impaired children in ordinary and special schools. Educational Research. 29, 56-64.

Arnold, P., \& Atkins, J. (1991). The social and emotional adjustment of primary hearing-impaired children integrated in primary schools. Educational Research. 33, 223-228.

Besag, F.M.C. (2003). Psychopathology in people with epilepsy and intellectual disability. Journal of Neurology, Neurosurgery and Psychiatry. 74(11): 1464

Bradshaw, J. (1998). Assessing and intervening in the communication environment. British Journal of Learning Disabilities. 26(2): 62-66.

Brubaker, R.G.; Szakowski, A. (2000). Parenting practices and behaviour problems among deaf children. Child and family behaviour therapy. 22(4): 13-28.

Brumback, R.A.; Harper, C.R.; Weinberg, W.A. (1996). Nonverbal learning disabilities, Asperger's syndrome, pervasive development disorder-should we care? Journal of Child Neurology. 11(6): 427-429.

Brusca, R.M.; Nieminen, G.S.; Carter, R.; Repp, A.C. (1989). The relationship of staff contact and activity to the stereotypy of children with multiple disabilities. Journal of the Association for Persons with Severe Handicaps. 14(2): 127-136.

Campbell, B.; Fletcher, D. (1993). Analysis of nonverbal behaviors as expressions of personal preference in adults with mental retardation who live in adult residential facilities. Adult Residential Care Journal. 7(2) 1993: 68-74.

Cappelli, M.; Daniels, T. ; Durieux-Smith, A. ; McGrath, P.J. ; Neuss, D. (1995). Social development of children with hearing impairments who are integrated into general education classrooms. Volta Review. 97(3): 197-208.

Carr, E.G., Horner, R.H., Turnbull, A.P., Marquis, J.G., McLaughlin, D.M., McAtee, M.L., et al. (1999). Positive behavior support for people with developmental disabilities: A research synthesis. Washington, DC: American Association on Mental Retardation.

Carvill, S.; Marston, G. (2002). People with intellectual disability, sensory impairments and behaviour disorder: a case series. Journal of Intellectual Disability Research. 46(3): 264-272.

Chadwick, O.; Piroth, N.; Walker, J.; Bernard, S.; Taylor, E. (2000). Factors affecting the risk of behaviour problems in children with severe intellectual disability. Journal of Intellectual Disability Research. 44(2): 108-123.

Cooper, S-A; Smiley, E.; Jackson, A.; Finlayson, J.; Allan, L.; Mantry D.; Morrison J. (2009a). Adults with intellectual disabilities: prevalence, incidence and remission of self-injurious behaviour, and related factors. Journal of Intellectual Disability Research. 53(3): 200-216.

Cooper, S-A; Smiley, E.; Jackson, A..; Finlayson, J.; Allan, L.; Mantry D.; Morrison J. (2009b). Adults with intellectual disabilities: prevalence, incidence and remission of aggressive behaviour and related factors. Journal of Intellectual Disability Research. 53(3): 217-232.

Cornes, A., Rohan, M.J., Napier, J. \& Del Rey, J.M. (2006). Reading the signs: impact of signed versus written questionnaires on the prevalence of psychopathology among deaf adolescents. Australian \& New Zealand Journal of Psychiatry, 40, 665-673.

Crocker, A.G.; Mercier, C.; Lachapelle, Y.; Brunet, A.; Morin, D.; Roy, M.E. (2006). Prevalence and types of aggressive behaviour among adults with intellectual disabilities. Journal of Intellectual Disability Research. 50(9): 652-661.

Crockett, J.L.; Hagopian, L.P. (2006). Prompting procedures as establishing operations for escape-maintained behavior. Behavioral Interventions. 21(1): 65-71. 
Deb, S.; Thomas, M.; Bright, C. (2001). Mental disorder in adults with intellectual disability. 2: The rate of behaviour disorders among a community-based population aged between 16 and 64 years. Journal of Intellectual Disability Research, 45(6): 506-514.

Dekker, M.C.; Koot, H.M. (2003). DSM-IV Disorders in children with borderline to moderate intellectual disability. 1: Prervalence and Impact. Journal of the American academy of child and adolescent psychiatry. 42(8): 915-922.

Durand, V.M. \& Merges, E. (2001). Functional communication training: a contemporary behavior analytic intervention for problem behaviors. Focus on autism and other developmental disabilities. 16(2): 110119.

Emerson, E.; Kiernan, C.; Alborz, A.; Reeves, D.; Mason, H.; Swarbrick, R.; Mason, L.; Hatton, C. (2001). The prevalence of challenging behaviors: A total population study. Research in developmental disabilities. 22(1): 77-93.

Fellinger, J., Holzinger, D., Sattel, H., Laucht, M. \& Goldberg, D., (2009) Correlates of mental health disorders among children with hearing impairments. Developmental Medicine \& Child Neurology, 51, 635-641.

Frea, W.D., Arnold, C.L., \& Vittimberga, G.L. (2001). A demonstration of effects of augmentative communication on the extreme aggressive behavior of a child with autism within an integrated preschool setting. Journal of positive behavior interventions. 3(4): 194-198.

Freeman, R.D., Malkin, S.F., \& Hastings, J.O. (1975). Psychological problems of deaf children and their families: A comparative study. American Annals of the Deaf. 120, 275-304.

Fundudis, T., Kolvin, I., \& Garside, R. (1979). Speech retarded and deaf children: Their psychological development. London: Academic Press.

Gordon, A.G. (2008). Is every cause of autism a definite cause of deafness? British Journal of Developmental Disabilities. 54(106): 55-57.

Goodman R. (1997). The Strengths and Difficulties Questionnaire: A Research Note. Journal of Child Psychology and Psychiatry. 55(5): 581-586.

Granlund, M. \& Olsson, C. (1999). Efficacy of communication intervention for presymbolic communicators. Augmentative and Alternative Communication. 15(1): 25-37.

Hammermeister, F.; Timms, M. (1989). Non-verbal communication: Perspectives for teachers of hearingimpaired students. Volta-Review, 91(3): 133-142.

Hindley, P.A.; Hill, P.D.; McGuigan, S.; Kitson, N. (1994). Psychiatric disorder in deaf and hearing impaired children and young people: prevalence study. Journal of Child Psychology and Psychiatry. 35(5): 917935.

Hintermair, M. (2007) Prevalence of socioemotional problems in deaf and hard of hearing children in Germany. American Annals of the Deaf, 152, 320-330.

Jones, S.; Cooper, S.; Smiley, E.; Allan, L.; Williamson, A.; Morrison, J. (2008). Prevalence of, and factors associated with, problem behaviors in adults with intellectual disabilities. Journal of nervous and mental disease. 18(9): 678-686.

Kamio, Y. (2002). Self-injurious and aggressive behavior in adolescents with intellectual disabilities: A comparison of adolescents with and without autism. Japanese Journal of Special Education. 39(6). 143154.

Kiani, R., Gangadharan, S.K. \& Miller, H. (2007). Behavioral Residential Treatment Case report: Association of Waardenburg Syndrome with intellectual disability, Autistic Spectrum Disorder and unprovoked aggressive outbursts: A new behavioural phenotype? British Journal of Developmental Disabilities. 53(104): 53-62.

Kiani, R., Miller, H. \& Gangadharan S.K. (2008). Association of sensory impairment with autism. British Journal of Developmental Disabilities. 54(106): 59-61.

Lindquist, B.; Carlsson, G.; Persson, E.K.; Uvebrant, P. (2006). Behavioural problems and autism in children with hydrocephalus: A population-based study. European Child and Adolescent Psychiatry. 15(4): 214219.

Matson, J.L.; Boisjoli, J. \& Mahan, S. (2009). The Relation of Communication and Challenging Behaviors in Infants and Toddlers with Autism Spectrum Disorders. Journal of Developmental and Physical Disabilities. 21(4): 253-261. 
McClintock, K.; Hall, S.; Oliver,C. (2003). Risk markers associated with challenging behaviours in people with intellectual disabilities: A meta-analytic study. Journal of Intellectual Disability Research. 47(6): 405416.

Meadow, K.P.; Schlesinger, H.S. (1971). The prevalence of behavioural problems in a population of deaf school children. American Annals of the Deaf. 116(3): 346-348.

Meuwese-Jongejeugd, A.; Vink, M.; van Zanten, B.; Verschuure, H.; Eichhorn, E.; Koopman, D.; Bernsen, R.; Evenhuis, H. (2006). Prevalence of hearing loss in 1598 adults with an intellectual disability: Crosssectional population based study. International Journal of Audiology. 45(11): 660-669.

Miller, K.; Vernon, M. (2003). Deaf Sex Offenders in a Prison Population. Journal of Deaf Studies and Deaf Education. 8(3): 357-362.

Mitchell, T.V. \& Quittner, A.L. (1996). Multimethod study of attention and behavior problems in hearingimpaired children. Journal of Clinical Child Psychology. 25(1): 83-96.

Molteno, G.; Molteno, C.D.; Finchilescu, G.; Dawes, A.R.L. (2001). Behavioural and emotional problems in children with intellectual disability attending special schools in Cape Town, South Africa. Journal of Intellectual Disability Research. 45(6): 515-520.

Myrbakk, E.; von Tetzchner, S. (2008). The prevalence of behavior problems among people with intellectual disability living in community settings. Journal of Mental Health Research in Intellectual Disabilities. 1(3): 205-222.

Nijhof, R. \& Van Overveld, S. (2005). FOBO Jaarverslag 2005. Amsterdam: Effatha Guyot Zorg.

Robinson, L.A. \& Owens, R.E. (1996). Functional augmentative communication and positive behavior change. Augmentative and alternative communication. 11(4): 207-211.

Rojahn, J.; Esbensen, A.J. (2002). Epidemiology of self-injurious behavior in mental retardation: A review. In: Schroeder, S.R.(Ed); Oster-Granite, M.L.(Ed); Thompson, T. (Ed). 2002. Self-injurious behavior: Genebrain-behavior relationships. (pp. 41-77) Washington,DC,US: American Psychological Association. Xiii, 405 pp.

Rojahn, J. \& Meier, L.J. (2009). Epidemiology of mental illness and maladaptive behavior in intellectual disabilities. International Review of Research in Mental Retardation. 38(38): 239-287.

Rutter, M. (1967). A children's behaviour questionnaire for completion by teachers; preliminary findings. Journal of Child Psychology and Psychiatry. 8: 1-11.

Rutter, M., Graham, P., \& Yule, W. (1970). A neuropsychiatric study in childhood. Clinics in Developmental Medicine Nos. 35/36. London: Spastics International Medical Publications.

Sarimski, K. (2007). Psychische Störungen bei Behinderten Kindern und Jugendlichen- Ubersicht und Schlussfolgerungen für die Psychodiagnostik. Zeitschrift fur Kinder- und Jugendpsychiatrie und Psychotherapie. 35(1): 19-29.

Schum, R. (2005). Psychological Assessment of Children with Multiple Handicaps Who Have Hearing Loss. Volta Review. 104(4): 237-255.

Sigafoos, J., (2000). Communication development and aberrant behavior in children with developmental disabilities. Education and Training in Mental Retardation and Developmental Disabilities. 35(2): 168176.

Sinkkonen, J. (1994). Evaluation of mental health problems among Finnish hearing impaired children. Psychiatrica Fennica. 25: 52-65.

Sisson, L.A., Herson, M. \& van Hasselt, V.B. (1993). Improving the performance of youth with dual sensory impairment: Analyses and social validation of procedures to reduce maladaptive responding in vocational and leisure settings. Behavior Therapy. 24(4): 553-571.

Stryker, D.S. (1999). Identification of learning disabilities in students who are deaf or hard of hearing: A Bayesian approach. Dissertation Abstracts International Section A: Humanities and Social Sciences. 59(9-A): 3405.

Taanila, A.; Ebeling, H; Heikura, U.; Jarvelin, M.R. (2004). Behavioural problems of 8-year-old children with and without intellectual disability. Journal of Pediatric Neurology. 1(1): 15-24.

Taylor, G. (1992). Integration: Breaking down some of the barriers. Educational and Child Psychology. 9(4): 68-74. 
Timehin, C.; Timehin, E. (2004). Prevalence of hearing impairment in a community population of adults with learning disability: access to audiology and impact on behaviour. British Journal of learning disabilities. 32(3): 128-132.

Tyrer, F.; McGrother, C.W.; Thorp, C.F.; Donaldson, M.; Bhaumik, S.; Watson, J.M.; Hollin, C. (2006). Physical aggression towards others in adults with learning disabilities: prevalence amd associated factors. Journal of Intellectual Disability Research. 50(4): 295-304.

Umbreit, J. (1997). Eliminating challenging behaviors in multiple environments throughout the entire day. Education and Training in Mental Retardation and Developmental Disabilities. 32(4): 321-330.

Van Eldik, T., Treffers, P.D.A., Veerman, J.W., Verhulst, F.C. (2004). Mental health problems of deaf children as indicated by parents responses to the Child Behavior Checklist. American annals of the deaf. 148(5): 390-394.

Van Gent, T.; Goedhart, A.W.; Hindley, P.A.; \& Treffers, P.D.A. (2007). Prevalence and correlates of psychopathology in a sample of deaf adolescents. Journal of Child Psychology and Psychiatry. 48(9): 950-958.

Vernon, M.; Greenberg, S. (1999). Violence in deaf and hard-of-hearing people: A review of the literature. Aggression and violent behavior. 4(3): 259-272.

Vostanis, P.; Hayes, M.; Du Feu, M.; Warren, J. (1997). Detection of behavioural and emotional problems in deaf children and adolescents: Comparison of two rating scales. Child: Care, Health and Development. 23(3): 233-246.

Yeates, S. (1995). The incidence and importance of hearing loss in people with severe learning disability: The evolution of a service. British Journal of Learning Disabilities. 23(2): 79-84. 


\title{
Chapter 3
}

\author{
ASSESSING CHALLENGING BEHAVIOUR IN PEOPLE WITH \\ HEARING IMPAIRMENTS AND PROFOUND INTELLECTUAL \\ DISABILITIES, THE DEVELOPMENT OF AN INDIVIDUAL \\ BEHAVIOUR OBSERVATION AND RECORDING SCALE
}

Willem Meindert Buskermolen ${ }^{1}$, Joop Hoekman ${ }^{2}$ and Albert Pierre Aldenkamp ${ }^{3}$

1. Kentalis - Weerklank Amsterdam; the Netherlands

2. Leiden University; University of Applied Sciences Leiden; the Netherlands

3. Maastricht University; Kempenhaeghe, Heeze; the Netherlands

Published in:

International Journal on Mental Health and Deafness

2013 Volume 3 Issue 1 (30-40)

ISSN: 2226-3462 


\section{Abstract}

Background and objective

Studies on people with both Hearing Impairments (HI) and an Intellectual Disability (ID) are rare, although in clinical practice aggressive incidents such as destructive behaviour aimed at objects or other people and self-harming behaviour are mentioned as common problems. In studies into people of both groups of people seperately prevalence rates of behavioural problems vary widely and many risk factors for developing behavioural problems are mentioned. Although recognizing risk factors can contribute to the understanding of behavioural problems, empirical research is needed into relations between behaviour and several external factors to gain more insight into direct causes of behavioural problems. The aim of this article is to detect a scale with which behaviour of individuals with both ID and $\mathrm{HI}$ can be observed and recorded in order to study relationships between behaviour and several external factors. Six conditions for such a scale are defined.

Results

Regrettably, none of the scales we studied meets all our conditions and are therefore not suitable for our study. Because of this shortage we developed our own Individual Behaviour Observation and Recording Scale (IBORS) which is based on eight dimensions of behaviour and five levels of severity which results in a unique behavioural repertoire of each individual person.

\section{Conclusions}

Although we succeeded in the construction of a scale which meets our conditions, some remarks can be made. The construction of an individual behaviour repertoire is an extensive process in which several familiar people should be involved. Secondly, the classification of eight dimensions of behaviour was not based on a scientific theory or construct. It is recommended to do further research on these topics and especially on the psychometric properties of IBORS. 


\section{Introduction}

Professionals working with people with both an Intellectual Disability (ID) and Hearing Impairments (HI) have frequently reported confrontations with behavioural problems (Nijhof \& van Overveld, 2005). In particular, aggressive incidents such as destructive behaviour aimed at objects or other people and self-harming behaviour are mentioned as common problems.

Little research on behavioural problems in people with a combination of both disabilities has been found (Buskermolen, Hoekman, \& Aldenkamp, 2012). An exception is the study of Timehin and Timehin (2004). They report that of 543 people $62 \%$ shows problem behaviour and $34 \%$ exhibits self-harming behaviour.

Much research has been done into people with ID. In this group behavioural problems frequently occur (Deb, Thomas \& Bright, 2001; Molteno, Finchilescu \& Dawes, 2001; Emerson et al., 2001; Tyrer et al., 2006; Crocker et al., 2006; Holden \& Gitlesen, 2006). Prevalence rates varied from less than $10 \%$ to over $40 \%$. These results depend on the definition and terminology used to indicate behavioural problems, background and age of the population, methods of data collection used and psychiatric scales employed. Several risk factors for these behavioural problems are reported. Some studies found a gender effect in which males exhibited more behavioural problems than females (Emerson et al., 2001; Molteno et al., 2001; McClintock, Hall \& Oliver, 2003); Tyrer et al., 2006). On the contrary, Deb, Thomas \& Bright (2001) found that the rate of self-harming behaviour was significantly associated with the female gender. Emerson et al. (2001) and Tyrer et al. (2006) reported an age effect; adolescents and young adults showed more behavioural problems than other age groups. The severity of the ID is also mentioned as a risk factor by several studies (Deb, Thomas \& Bright, 2001; McClintock, Hall \& Oliver, 2001; Molteno et al., 2001; Tyrer et al., 2006). Additional problems such as sensory impairment (Besag, 2003; Dekker \& Koot, 2003) and autism (McClintock, Hall \& Oliver, 2001; Kamio, 2002; Matson, Boisjoli \& Mahan, 2009) are also found as risk factors. Chadwick, Piroth, Walker, Bernard \& Taylor (2000) and Emerson et al. (2001) found a higher prevalence of behavioural problems when people were limited in such daily skills as eating and dressing. Crockett and Hagopian (2006) found an increase in behavioural problems when people were challenged by demanding situations. In several meta analyses (Sigafoos, 2000; Molteno, Finchilescu \& Dawes, 2001; Deb, Thomas \& Bright, 2001; Emerson et al., 2001; McClintock, Hall \& Oliver, 2003; Besag, 2003) and in case studies (Brusca, 1989; Robinson \& Owens, 1996; Umbreit; 1997; Bradshaw, 1998; Frea, Arnold \& Vittimberga, 2001; Durand \& Merges, 2001) communication is mentioned as a risk factor.

In people with $\mathrm{HI}$ similar findings were reported for the prevalence and distribution of behavioural problems (Hindley, Hill, McGuigan \& Kitson, 1994; Mitchell \& Quittner, 1996; Vostanis, Hayes, Du Feu \& Warren, 1997; Van Eldik, Treffers, 
Veerman \& Verhulst, 2004; Van Gent, Goedhart, Hindley, \& Treffers, 2007). Prevalence rates also vary from less than $10 \%$ to over $40 \%$. In these studies however, the concept of behavioural problems is defined in a more general and uniform way than in studies in people with ID. The most important reason for this seems to be the use of only two diagnostic scales in studies on people with HI: the Rutter scale (Rutter, 1967) and the CBCL (Achenbach, 1991).

Several risk factors for developing behavioural problems in people with $\mathrm{HI}$ are mentioned as well. Sinkkonen (1994) found that children with $\mathrm{HI}$ and additional handicaps showed more behaviour problems than children with $\mathrm{HI}$ alone. Two studies (Vernon \& Greenberg (1999); Miller \& Vernon (2003)) examined the relationship between hearing loss and violence and discovered that people with $\mathrm{HI}$ are overly represented in the prison population. They hypothesize that ID, communication disorders, unemployment and underemployment in people with $\mathrm{HI}$ create frustration, which tends to manifest itself in disproportionate aggression. Cappelli et al. (1995) found that children with $\mathrm{HI}$ who are integrated into regular classrooms are more likely to be rejected by their peers than normally hearing children. It was hypothesized that this could be caused by a reduced degree of competence in social skills in children with HI. Vostanis, Hayes, Du Feu \& Warren (1997) found that the use of speech in addition to sign language has a positive effect on social skills in adolescents with HI. Van Eldik, Treffers, Veerman \& Verhulst (2004) reported an increase of behavioural problems in people with $\mathrm{HI}$ who also have intellectual disabilities. Brubaker and Szakowski (2000) conclude in their study on the relation between parenting practice and behavioural problems that there is no evidence that the greater prevalence of behavioural problems among deaf children is a result of inadequate parenting. Sarimski (2007) studied several risk factors and found that problems in parent-child relations, the development of social competence and social participation are all possible risk factors. It was concluded that it is very difficult to differentiate between the various risk factors for mental health disorders among children and youth with hearing disorders, blindness, physical handicaps or intellectual disabilities.

From the results of the studies mentioned above we conclude that in people with ID and also in people with $\mathrm{HI}$ an increase of behavioural problems is found when additional handicaps occur. It is plausible that the prevalence rates of behavioural problems in people with both ID and $\mathrm{HI}$ are higher than in both groups seperately. Furthermore it is plausible that communication difficulties form an important risk factor leading to behavioural problems in individuals with ID or HI.

Unfortunately we did not find any study on causal relations between risk factors and behavioural problems. Although recognizing risk factors can contribute to the understanding of behavioural problems, empirical research is needed into relations between behaviour and several external factors to gain more insight into direct causes of behavioural problems. When behavioural problems occur following specific external events, this could be an indication that this behaviour might be caused by these 
factors. In order to gain more insight into the relations between behaviour and external factors, it is necessary to use a scale with which behaviour can be observed and recorded. In this article we will first review existing behaviour observation and recording scales and check for their suitability of using them for studying individuals with ID and HI.

Our research questions are:

1. Which conditions are required for a behaviour observation and recording scale for individuals with both ID and HI?

2. Are there scales with which behaviour of individuals with both ID and $\mathrm{HI}$ can be observed and recorded?

3. Which scale can be used in a study to find relationships between behaviour and several external factors?

Because we did not find any suitable scales for our study, we describe the development of an Individual Behaviour Observation and Recording Scale (IBORS) in the second part of this article.

\section{Methods}

\section{The required conditions of a behaviour observation and recording scale}

The aim of our study is to detect certain relations between behavioural problems and external factors. Therefore it is necessary to collect observations of specific defined behaviour as well as descriptions of circumstances in which this behaviour occurs. In this article we concentrate on the description of (problem) behaviour.

Our research will take place in institutional settings for people with both ID and HI. These people are needy and dependent in their daily care because of the complexity of their handicaps. They do not have the ability to communicate verbally and depend on non-verbal communication. Moreover, they are not able to read or write. They are assisted by several familiar carers throughout the day for their daily care. In the interaction between carers and people with ID and $\mathrm{HI}$ carers have to be able to determine and interpret the non-verbal communication of their pupils. Watzlawick, Beavin and Jackson (1967) describe several dimensions of human communication. Communication is not only what we say but rather what we don't say. In their first axioma they formulate that it is impossible to not communicate. Every act, including doing "nothing" has a certain influence on the environment. Every behaviour is a form of communication. Granlund \& Olsson (1999) state that even such behaviour as licking, squeezing, smiling, crying, hitting, or smearing with faeces should be seen as communicative signals. These communicative signals have been developed as a result 
of a combination of an individual's predispositions (nature) and learning experience (nurture).

As a part of their daily routine, professional carers of people with ID and $\mathrm{HI}$ have to observe and record behaviour of their pupils. Therefore, it is necessary to use a scale in which non-verbal signals can be observed and recorded if we want to study the behaviour of this group. Several studies (Mackintosh, Knight \& Kumar, 1986; Sappington et al., 1989; Isogai et al., 1998; Cascella, 2005; Vlaskamp, 2005, Petry \& Maes, 2006), conclude that it is possible to determine and interpret motives of people who depend on non-verbal communication by using systematic observation of nonverbal signals.

With the experience of daily practice, combined with the first axioma of Watzlawick, beavin and Jackson we might be able to give an answer to our question "Which conditions are required for a behaviour observation and recording scale for individuals with both ID and HI?"

\section{Results}

Our first condition is that it is necessary to observe and record a variety of (non-verbal) behaviour. It is our purpose to study a wide range of behaviour and do not focus on specific aspects of behaviour.

Our second condition is related to the fact that each person tends to react in an individually determined way based on his personal history, limitations and abilities. In a recording scale of behaviour which is suitable for our study there should be room for measuring specific behavioural patterns that are characteristic of and personal to the individual. So we must be able to personalize the recording scale.

The third condition for our scale is to differentiate between degrees of severity of problem behaviour. Because the purpose of our study is to gain insight into relations between behavioural problems and external factors it is necessary to make quantitative records of the severity of behaviour which is defined as a behavioural problem. It is also necessary to make records of behaviour of the same individual which is not experienced as a behavioural problem. This will make it possible to draw conclusions about circumstances in which behavioural problems do and do not occur and to which extent they occur.

Our fourth condition is that it should be possible to carry out several daily recordings of observed behaviour during a specific period. This could increase the possibility of gaining insight into specific relations between behaviour and external factors.

A fifth condition is that it enables each professional carer to use the scale. First of all, it is not likely that people with ID and $\mathrm{HI}$ are able to read and write or to make 
records of their own behaviour. Secondly, if outsiders were to do the recording it could disrupt the daily routine, especially because it is our aim to collect records over an extended period of time. It would require a lot of time to have outsiders make these recordings. A third argument in favour of letting the carers do the recording for our study is that they are quite able to recognise behavioural patterns because they are familiar with the participant.

A final condition is that such a scale should not be highly time consuming. Because carers are on duty, it is not acceptable for them to invest more than five minutes in recording behaviour. With the use of a scale which fullfills these conditions, it will be possible to determine differences in behaviour over a period of time in order to relate them to changing circumstances.

In summary, the observation and recording scale should meet the following conditions:

1. A variety of non-verbal behavioural aspects must be measurable;

2. There must be room for individual behavioural descriptions;

3. The severity of problem behaviour must be measurable;

4. There should be room for several records per day;

5. It should be filled in by professional carers;

6. It must be efficient and easy to use for every carer;

\section{Method}

With these six conditions in mind we have searched for suitable scales.

A literature study was carried out in March 2013 using "PsychInfo", "Medline" and "Web of Science" with the following search terms and limited to publications after 1999:

1: Questionnaires or Observation Methods or Diagnostic interview Schedule

2: Behaviour or Behavioural assessment.

3: The combination and/and of the two groups of search terms.

\section{Results}

This resulted in 169 publications in which was referred to behaviour description scales, questionnaires, observation methods or diagnostic interview schedules. After initial inspection, this resulted in 27 different scales. Our first condition is that it is necessary to observe and record a variety of non-verbal behaviour. Some of these scales however are used to diagnose psychiatric disturbances and are therefore not suitable: Psychopathology checklist for Adults with Intellectuel Disability (P-AID; Hove \& Havik, 
2008), Psychopathology Inventory for Mentally Retarded Adults (PIMRA; Matson, 1988), Gedye's Compulsive Behaviour Checklist (Gedye, 1992), Diagnostic Criteria for Psychiatric Disorders in Adults with MR/Learning Disorders (DC-LD; Clarke, Cooper, Holland, Matthews \& Simpson, 2000), Clinical Global Impression: (CGI; National Institute of Mental Health, 1985), The scale for Assessing Severity of the psychopathology in children (SSPC; Grigoroiu-Serbănescu, 1989), A scale for evaluating emotional disorders in severely and profoundly mentally retarded persons (DASH; Matson, Gardner, Coe \& Sovner, 1991), Psychiatric Assessment Schedule for Adults with a Developmental Disability (PAS-ADD; Moss, Prosser, Costello, Simpson, Patel, Rowe, Turner \& Hatton (1998) Reiss Screen (Reiss, 1988), Brief Symptom Inventory, (Derogatis \& Melisaratos 1983).

Another group of behavioural observation scales is not suitable because these scales are aimed at specific aspects of behaviour such as motivation (Motivation Assessment Scale (MAS) Durand \& Crimmins, 1988), depression (Clinical Behavior Checklist for Persons with Intellectual Disabilities (CBCPID), Tsiouris, 2003), social skills (Social Skills Rating System, Gresham \& Elliot, 1990), playing skills (SNap, Hughes, Oksanen, Taylor, Jackson, Murray, Caspi \& Moffitt 2002) anxiety (RCMAS, Reynolds, \& Richmond, 1978) or temperament (Toddler Behaviour Assessment Questionnaire, Goldschmidt, 1996); Rutter Children's Behaviour Questionnaire, Rutter, 1967).

After this selection ten scales remained. Unfortunately, in none of these scales is there room for individual behavioural descriptions, which is our second condition. We may already assume that a scale which meets all our conditions does not seem to exist. Yet we will review our other conditions and assess the ten remaining scales. Some of these scales take a lot of time for carers to complete (Condition 6). Examples are The Aberrant Behaviour Checklist (ABC; Aman, Singh, Stewart \& Field, 1985), the Child Behaviour Checklist (CBCL; Achenbach \& Edelbrock, 1981), Developmental Behaviour Checklist (DBC; Einfeld \& Tonge, 1992), Child Behaviour Rating Form and Nisonger (CBRF-A; Aman, Tassé, Rojahn \& Hammer, 1996). Some of these scales are not appropriate to our study because recording should not be done by professional carers (Condition 5). The Self-Efficacy Questionnaire for Children (SEQ-C; Muris, 2001) is a self-evaluating method and the Children's Global Assessment Scale (CGAS; Shaffer, Gould, Brasic, Ambrosini, Fisher, Bird \& Aluwahlia, 1983) should be used by doctors and clinicians.

Four scales remained: The Behaviour Problems Index or BPI, (Peterson \& Zill, 1986), Strengths and Difficulties Questionnaire or SDQ, (Goodman, 1996), Storend Gedragschaal voor Zwakzinnigen (Disturbed Behaviour Scale for the Mentally Handicapped) (SGZ; Kraijer \& Kema, 1977) and Questions About Behavioral Function or QABF (Matson \& Vollmer 1995). These four scales all measure a certain degree of severity of problem behaviour, which is our third condition. These scales all are designed to identify aberrant behaviour and develop hypotheses about its function. As a result it should be possible to formulate and carry out suitable interventions in order 
to decrease the occurence of this behaviour while increasing adaptive skills to increase more desirable behaviour. To complete the BPI, SDQ, SGZ and QABF however, the informant has to make judgements about behavioural aspects during the most recent months. In Condition 4, we formulated that it should be possible to make several records per day. Making several records with these scales will not increase the possibility of gaining insight into specific relations between behaviour and external factors.

We thus come to the conclusion that none of the scales are suitable for our study. Our main objections are that there does not seem to be a questionnaire in which there is room for individual behavioural descriptions and that making several records per day does not give extra information. These conditions are essential if we want to draw conclusions about circumstances in which individuals behave in a specific way.

\section{Behaviour description plans}

Nowhere in our search in the above-mentioned databases did we find any scale that is suitable for our study. Therefore we explored behaviour observation scales that are not internationally published, but already used in (Dutch) clinical practice. One of the scales we found is "behaviour description plans" which is commonly being used in several psychiatric hospitals. This method was originally presented by Van der Werf, Goedhart and Huiberts (1998). Basically this scale is meant as an intervention method. The main aim of this method is to make plans jointly with the client, enabling carers to intervene appropriately in critical situations. In order to decide which intervention is the most applicable, carers must be able to recognise warning signals, or behavioural patterns of a client. As a result, carers can offer the conditions needed to decrease tension within the client. The premise of this method is that behavioural patterns of each individual vary with one's state of mind. Behavioural patterns are therefore described in several different moods, representing different states of mind. These states of mind are rated in levels varying from relaxation to loss of control. For every person an individual behavioural repertoire is described with which it is possible to make judgements on an individual's mood at any given time. In the method of Van der Werf, Goedhart and Huiberts it is possible to describe a variety of non-verbal behavioural aspects (Condition 1). This method is intended to define individual determined behaviour (Condition 2) in which it is possible to describe the severity of (problem) behaviour (Condition 3). With this method it is possible to make several records per day (Condition 4), it is suitable to be filled in by carers (Condition 5) and it is not too timeconsuming and therefore efficient and easy to use (Condition 6). In the next section we will assess the possibility of using this method as a behaviour observation and recording scale for our study. 
The construction of an Individual Behaviour Observation and Recording Scale (IBORS)

The method of Van der Werf, Goedhart and Huiberts distinguishes levels of behaviour. In constructing our Individual Behaviour Observation and Recording Scale (IBORS), several steps were taken. Parents of people with ID and HI, who all live in a specialised residential setting in Amsterdam, the Netherlands, were invited to contribute in this process. Fifteen of them cooperated. These parents were asked to describe specific behaviour of their child in different moods, from relaxation to loss of control. The same was asked of professionals of different disciplines (staff, communication therapist, physiotherapist, psychologist) who were familiar with these people. Most contributers recognised five different levels of behaviour in all individuals. These levels were defined as "relaxation", "slight restlessness", "tension", "threat" and "loss of control". This first step in the process resulted in very divergent descriptions. The next step was to divide these behaviour descriptions of all fifteen people into a few behaviour categories. After studying these descriptions professionals agreed to distinguish eight dimensions of behaviour: "making sounds", "locomotion", "facial expression", "object manipulation", "body manipulation", "concentration", "expressive communication" and "receptive communication". The third step was to combine each of the eight dimensions of behaviour with the five different levels of behaviour as above. By following this step forty unique behavioural descriptions of each individual are needed to fill the scale (see Table 3.1).

Behaviour in Level 1 is described in terms of relaxation. Some examples are: "makes adequate contact, communicates in sign language, plays with his toys". In the second level restless behaviour is described. Some examples are: "wants to arrange all his toys, communicates only in sentences of two signs, claims attention, stands up from his chair while having dinner but returns of his own accord, laughs extra loudly, walks restlessly in circles, rubs toys softly against his face, shows some stereotypical movements". In Level 3 behaviour is described as tense. This behaviour becomes problematic because it requires active intervention of the carers in order to prevent further escalation. Examples are: "hits himself, spits and smears, steals food, is continuously making screaming sounds, is frequently and compulsively going to the bathroom, is tearing up magazines, is insistent upon making eye contact, pinches himself, hits himself on the chest and head, smears with faeces". In Level 4 behaviour represents a threatening escalation. Examples are: "hits himself in the belly and face, occasionally beats his head against the wall, pokes his finger hard into his nose, throws himself deliberately onto the ground, threatens to hit, kick or bite others, hits windows and doors with force, ignores all communication". 


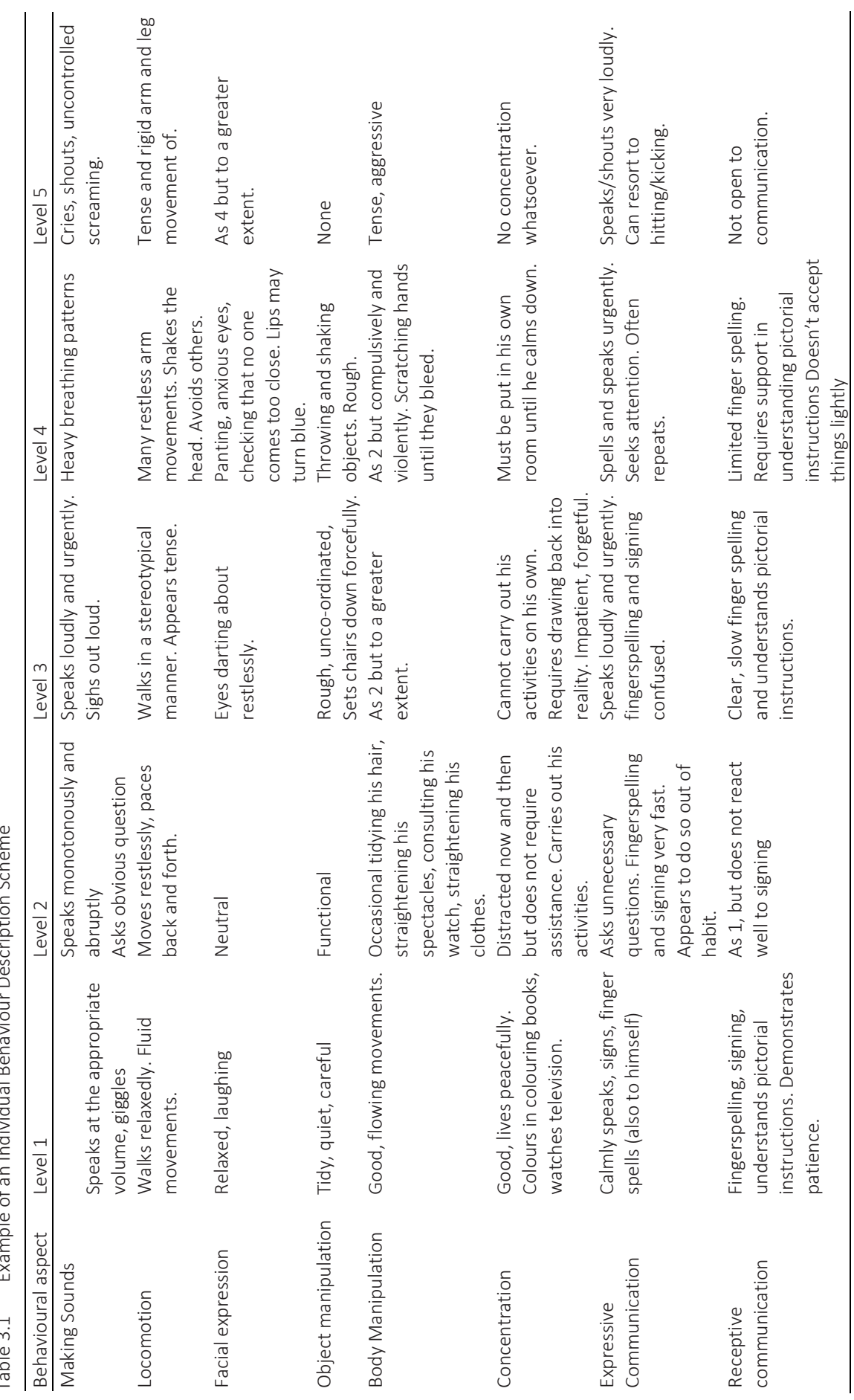


Level 5 behaviour reflects a highly escalated situation. Examples are: "tears his fingernails until they bleed, throws objects at others, bites himself hard in the arms, beats his head constantly against the wall, is unapproachable, bites, hits and kicks wildly, is incessantly destructive". Behaviour at Level 3 or higher requires active intervention by carers. We therefore agree with Emerson et al (2001) and Holden and Gitlesen, (2006) in using the term "challenging behaviour" for describing behavioural problems and propose to define behaviour representing Level 3 or higher as challenging behaviour.

\section{Discussion}

This article describes how we endeavoured to find a behaviour observation and recording method suitable for use in people with ID and $\mathrm{HI}$ that can be used to relate behaviour to several external factors and (challenging) behaviour. To gain insight into this topic, it was necessary to use a method with which individually determined behaviour could be recorded. We defined conditions for such a method but none of the 27 scales we evaluated fullfilled all six conditions. Because we did not find any suitable method, we explored the possibility of using an Individual Behaviour Observation Recording Scale (IBORS) based on the intervention method of behaviour description plans (van der Werf, Goedhart \& Huiberts, 1998). We described above the development of IBORS. IBORS does fullfill our six conditions for a behaviour observation and recording scale. There are however several remarks to be made.

A first remark concerns the construction of an individual behaviour repertoire. This is an extensive process in which several people familiar to each individual should be involved. A second remark can be made about the eight behaviour categories. These categories are chosen after gathering and combining several behavioural descriptions and are not based on a scientific theory or construct. The most important critical remark on this topic concerns the psychometric properties of IBORS. The development of a behaviour observation and recording scale is not the main goal of our future research, which is aimed on relationships between challenging behaviour and internal and external factors. It is however necessary to achieve an indication of the reliability and validity of IBORS if we are planning to use it in order to do our research. Therefore we will focus on that topic in future research. 


\section{References}

Achenbach, T. M. (1991). Manual for the Child Behaviour Checklist and 1991 profiles. Burlington, VT: University of Vermont Department of Psychiatry.

Aman, M. G., Singh, N. N., Stewart, A. W., Field, C. J. (1985). The Aberrant Behavior Checklist: A behavior rating scale for the assessment of treatment effects. American Journal on Mental Deficiency, 89: 485-491.

Aman, M. G., Tassé, M. J., Rojahn, J., Hammer, D. (1996). The Nisonger CBRF: A Child Behavior Rating Form for children with developmental disabilities. Research in Developmental Disabilities. 17: 41-57.

Besag, F. M. C. (2003). Psychopathology in people with epilepsy and intellectual disability. Journal of Neurology, Neurosurgery and Psychiatry. 74(11): 1464.

Bradshaw, J. (1998). Assessing and intervening in the communication environment. British Journal of Learning Disabilities. 26(2): 62-66.

Brubaker, R. G. \& Szakowski, A. (2000). Parenting practices and behaviour problems among deaf children. Child and family behaviour therapy. 22(4): 13-28.

Brusca, R. M., Nieminen, G. S., Carter, R., Repp, A. C. (1989). The relationship of staff contact and activity to the stereotypy of children with multiple disabilities. Journal of the Association for Persons with Severe Handicaps. 14(2): 127-136.

Buskermolen, W. M., Hoekman, J., Aldenkamp A. P. (2012). Risk factors leading to behavioural problems in individuals with profound intellectual and hearing impairments disabilities. International Journal on Mental Health and Deafness. 1(2): 33-45.

Cappelli, M., Daniels, T., Durieux-Smith, A., McGrath, P. J., Neuss, D. (1995). Social development of children with hearing impairments who are integrated into general education classrooms. Volta Review. 97(3): 197-208.

Cascella, P. W. (2005) Expressive communication strenghts of adults with severe to profound intellectual disabilities as reported by group home carers. Communication Disorders Quarterly. 26(3): 156-163.

Chadwick, O., Piroth, N., Walker, J., Bernard, S., Taylor, E. (2000). Factors affecting the risk of behaviour problems in children with severe intellectual disability. Journal of Intellectual Disability Research. 44(2): 108-123.

Clarke, D., Cooper, S. A., Holland, A. J., Matthews, H., Simpson, N. (2000). Practical interactive experience of using the DC-LD to diagnose psychiatric disorders in adults with moderate to profound intellectual disabilities. Journal of Intellectual Disability Research. 44(3-4): 238-239.

Crocker, A. G., Mercier, C., Lachapelle, Y., Brunet, A., Morin, D., Roy, M. E. (2006). Prevalence and types of aggressive behaviour among adults with intellectual disabilities. Journal of Intellectual Disability Research. 50(9): 652-661.

Crockett, J. L. \& Hagopian, L. P. (2006). Prompting procedures as establishing operations for escapemaintained behavior. Behavioral Interventions. 21(1): 65-71.

Deb, S., Thomas, M., Bright, C. (2001). Mental disorder in adults with intellectual disability. 2: The rate of behaviour disorders among a community-based population aged between 16 and 64 years. Journal of Intellectual Disability Research. 45(6): 506-514.

Dekker, M. C., \& Koot, H. M. (2003). DSM-IV Disorders in children with borderline to moderate intellectual disability. 1: Prevalence and Impact. Journal of the American academy of child and adolescent psychiatry. 42(8): 915-922.

Derogatis, L. R., \& Melisaratos, N. (1983). The Brief Symptom Inventory: An introductory report. Psychological Medicine. 13: 595-605.

Durand, V. M., \& Crimmins, D. B. (1988). The Motivation Assessment Scale. Topeka: Monaco \& Associates.

Durand, V. M. \& Merges, E. (2001). Functional communication training : a contemporary behavior analytic intervention for problem behaviors. Focus on autism and other developmental disabilities. 16(2): 110119.

Einfeld S. L., Tonge B. J. Manual for the developmental behaviour checklist. Monash University Centre for Developmental Psychiatry and School of Psychiatry, University of N.S.W.; Melbourne and Sydney: 1992. 
Emerson, E., Kiernan, C., Alborz, A., Reeves, D., Mason, H., Swarbrick, R., et al. (2001). The prevalence of challenging behaviours: A total population study. Research in developmental disabilities. 22(1): 77-93.

Frea, W. D., Arnold, C. L., Vittimberga, G. L. (2001). A demonstration of effects of augmentative communication on the extreme aggressive behavior of a child with autism within an integrated preschool setting. Journal of positive behavior interventions. 3(4): 194-198.

Gedye, A. (1998). Behavioural Diagnostic Guide for Developmental Disabilities. Vancouver: Diagnostic Books.

Goldsmith, H. H., (1996). Studying Temperament via Construction of the Toddler Behavior Assessment Questionnaire. Child Development. 67: 218-235.

Goodman R. (1997). The Strengths and Difficulties Questionnaire: a research note. Journal of Child Psychology and Psychiatry. 38(5): 581-586.

Granlund, M. \& Olsson, C. (1999). Efficacy of communication intervention for presymbolic communicators. Augmentative and Alternative Communication. 15(1): 25-37.

Gresham, F. M., \& Elliot, S. N. (1990). Social skills rating system manual. Circle Pines, MN: American Guidance Service.

Grigoroiu -Serbănescu M. A. (1989) Rating scale for the severity of psychopathology in children. Neurologie et psychiatrie. 27(3): 201-208.

Hindley, P. A., Hill, P. D., McGuigan, S., Kitson, N. (1994). Psychiatric disorder in deaf and hearing impaired children and young people: prevalence study. Journal of Child Psychology and Psychiatry. 35(5): 917935.

Holden, B. \& Gitlesen, J. P. (2006). A total population study of challenging behaviour in the county of Hedmark, Norway: Prevalence, and risk markers. Research in developmental disabilities. 27(4): 456465.

Hove, O \& Havik, O. E. (2008). Psychometric properties of Psychopathology checklists for Adults with Intellectual Disability (P-AID) on a community sample of adults with intellectual disability. Research in developmental disabilities. 29(5): 467-482.

Hughes, C., Oksanen H., Taylor A., Jackson J., Murray L., Caspi A. et al. (2002). 'I'm gonna beat you!' SNap!: an observational paradigm for assessing young children's disruptive behaviour in competitive play. Journal of Child Psychology and Psychiatry. 43(4): 507-516.

Isogai, J., Sato, S., Koike, T., Katada, A. (1998). Evaluation of a program for training teachers to understand non-verbal requests of children with severe mental retardation. Japanese Journal of Special Education. 36(2): 43-52.

Kamio, Y. (2002). Self-injurious and aggressive behavior in adolescents with intellectual disabilities: A comparison of adolescents with and without autism. Japanese Journal of Special Education. 39(6): 143154.

Kraijer, D. W. \& Kema, G. N. (1994). Storend Gedragsschaal voor Zwakzinnigen, SGZ. Handleiding (3e herziene en uitgebreide uitgave). Lisse: Swets \& Zeitlinger.

Mackintosh, J. H., Knight, R., Kumar, R. (1986). Ethiological studies of depressed patients. Schweizer archiv fur neurology und psychiatrie. 137(5): 165-170.

Matson, J.L. (1988). The Psychopathology Instrument for Mentally Retarded Adults: Test Manual. Orland Park, IL: International Diagnostic Systems.

Matson J. L., Gardner W. I., Coe D. A., Sovner R. (1991). A scale for evaluating emotional disorders in severely and profoundly mentally retarded persons. Development of the Diagnostic Assessment for the Severely Handicapped (DASH) scale. British Journal of Psychiatry. 159: 404-409.

Matson, J. L., \& Vollmer, T. R. (1995). The Questions About Behavioral Function (QABF) user's guide. Baton Rouge, LA: Scientific Publishers Inc.

Matson, J. L., Boisjoli, J., Mahan, S. (2009). The Relation of Communication and Challenging Behaviors in Infants and Toddlers with Autism Spectrum Disorders. Journal of Developmental and Physical Disabilities. 21(4): 253-261.

McClintock, K., Hall, S., Oliver, C. (2003). Risk markers associated with challenging behaviours in people with intellectual disabilities: A meta-analytic study. Journal of Intellectual Disability Research. 47(6): 405416.

Miller, K. \& Vernon, M. (2003). Deaf Sex Offenders in a Prison Population. Journal of Deaf Studies and Deaf Education. 8(3): 357-362. 
Mitchell, T. V. \& Quittner, A. L. (1996). Multimethod study of attention and behaviour problems in hearingimpaired children. Journal of clinical child psychology. 25(1): 83-96.

Molteno, G., Molteno, C. D., Finchilescu, G., Dawes, A. R. L. (2001). Behavioural and emotional problems in children with intellectual disability attending special schools in Cape Town, South Africa. Journal of Intellectual Disability Research. 45(6): 515-520.

Moss S. C., Prosser H., Costello H., Simpson N., Patel P., Rowe S., et al. (1998). Reliability and validity of the PAS-ADD Checklist for detecting psychiatric disorders in adults with intellectual disability. Journal of Intellectual Disability Research. 42: 173-183.

Muris, P. (2001) A Brief Questionnaire for Measuring Self-Efficacy in Youths. Journal of Psychopathology and Behavioral Assessment. 23: 145-149.

National Institute of Mental Health (1985). Clinical Global Impression) Scale. Psychopharmacological Bulletin. 21: 839-843.

Nijhof, R. \& Van Overveld, S. (2005). FOBO Jaarverslag 2005. Amsterdam: Effatha Guyot Zorg.

Peterson, J. L., \& Zill, N. (1986). Marital disruption, parent-child relationships, and behavior problems in children. Journal of Marriage and Family. 48: 295-307.

Petry, K., \& Maes, B. (2006). Identifying expressions of pleasure and displeasure by persons with profound and multiple disabilities. Journal of intellectual and developmental disability. 31(1): 28-38.

Reiss, S. (1988). Reiss Screen for Maladaptive Behavior: Test manual (2nd ed.) Orland Park, IL: International Diagnostic Systems.

Reynolds, C., \& Richmond, B. (1978). What I think and feel: A revised measure of children's anxiety. Journal of Abnormal Child Psychology. 6: 271-280.

Robinson, L. A. \& Owens, R. E. (1996). Functional augmentative communication and positive behavior change. Augmentative and alternative communication. 11(4): 207-211.

Rutter M. (1967). A children's behaviour questionnaire. Journal of Child Psychology and Psychiatry. 8: 1-11.

Sappington J., Reedy S., Welch R., Hamilton J. (1989): Validity of Messages from Quadriplegic Persons With Cerebral Palsy. American Journal on Mental Retardation. 94(1): 49-52.

Sarimski, K. (2007). Psychische Störungen bei Behinderten Kindern und Jugendlichen- Ubersicht und Schlussfolgerungen für die Psychodiagnostik. Zeitschrift fur Kinder- und Jugendpsychiatrie und Psychotherapie. 35(1): 19-29.

Shaffer D., Gould M. S., Brasic J., Ambrosini P., Fisher P., Bird H. et al. (1983) A children's global assessment scale (CGAS). Archives of General Psychiatry. 40: 1228-1231.

Sigafoos, J., (2000). Communication development and aberrant behavior in children with developmental disabilities. Education and Training in Mental Retardation and Developmental Disabilities. 35(2): 168176.

Sinkkonen, J. (1994). Evaluation of mental health problems among Finnish hearing impaired children. Psychiatrica Fennica. 25: 52-65.

Timehin, C., \& Timehin, E. (2004). Prevalence of hearing impairment in a community population of adults with learning disability: access to audiology and impact on behaviour. British Journal of learning disabilities. 32(3): 128-132.

Tsiouris J. A., Mann R., Patti P. J., Sturmey P. (2003). Challenging behaviours should not be considered as depressive equivalents in individuals with intellectual disability. Journal of Intellectual Disability Research. 47(1): 14-21.

Tyrer, F., McGrother, C. W., Thorp, C. F.; Donaldson, M.; Bhaumik, S.; Watson, J. M. et al. (2006). Physical aggression towards others in adults with learning disabilities: prevalence and associated factors. Journal of intellectual disability research. 50(4): 295-304.

Umbreit, J. (1997). Eliminating challenging behaviors in multiple environments throughout the entire day. Education and Training in Mental Retardation and Developmental Disabilities. 32(4): 321-330.

Van der Werf, L. J., Goedhart, A. W., Huiberts, S. (1998). Signaleringsplannen, naar minder agressie en dwang in de psychiatrie. Lisse: Swets \& Zeitlinger.

Van Eldik, T., Treffers, P. D. A., Veerman, J. W., Verhulst, F. C. (2004). Mental health problems of deaf children as indicated by parents responses to the Child Behavior Checklist. American annals of the deaf. 148(5): 390-394. 
Van Gent, T., Goedhart, A. W., Hindley, P. A., Treffers, P. D. A. (2007). Prevalence and correlates of psychopathology in a sample of deaf adolescents. Journal of Child Psychology and Psychiatry. 48(9): 950-958.

Vernon, M. \& Greenberg, S. (1999). Violence in deaf and hard-of-hearing people: A review of the literature. Aggression and violent behavior. 4(3): 259-272.

Vlaskamp, C. (2005). Interdisciplinairy assessment of people with profound intellectual and multiple disabilities. In: Hogg, J. (Ed.) \& Langa, A. (Ed.)Assessing adults with intellectual disabilities: A service providers' guide. (pag. 39-51) Malden, MA, US: Blackwell Publishing.

Vostanis, P., Hayes, M., Du Feu, M., Warren, J. (1997). Detection of behavioural and emotional problems in deaf children and adolescents : Comparison of two rating scales. Child: care, Health and Development. 23(3): 233-246.

Watzlawick, P., Beavin, J., Jackson, D. D. (1967). Pragmatics of Human Communication A Study of Interactional Patterns, Pathologies, and Paradoxes. New York: W. W. Norton and Co. 


\title{
Chapter 4
}

\author{
ASSESSING CHALLENGING BEHAVIOUR IN PEOPLE \\ WITH PROFOUND INTELLECTUAL DISABILITIES AND \\ HEARING IMPAIRMENTS: THE INTER-ASSESSOR \\ RELIABILITY OF THE INDIVIDUAL BEHAVIOUR \\ OBSERVATION AND RECORDING SCALE
}

Willem Meindert Buskermolen ${ }^{1}$, Joop Hoekman ${ }^{2}$ and Albert Pierre Aldenkamp ${ }^{3}$

1. Kentalis - Weerklank Amsterdam; the Netherlands

2. Leiden University; University of Applied Sciences Leiden; the Netherlands

3. Maastricht University; Kempenhaeghe, Heeze; the Netherlands 


\section{Abstract}

Background and objective

In people with Hearing Impairments (HI) as well as in people with an Intellectual Disability (ID behavioural problems frequently occur. Although several risk factors for these behavioural problems are reported, empirical research is needed into relations between behaviour and several external and internal factors to gain more insight into direct causes of behavioural problems. For this purpose it is necessary to use an instrument with which behaviour can be observed and recorded. Although we reviewed existing behaviour observation and recording scales on their suitability we did not succeed in finding an appropriate scale for the purpose of our study. Therefore we developed our own Individual Behaviour Observation and Recording Scale (IBORS). In this contribution we describe our exploratory research into the inter assessor agreement of IBORS.

Method and Results

We used two methods to measure agreement. Judgements were made by two staff independently, after having worked a whole shift together. The second method consisted of observing and recording videotaped behaviour of one person with both $\mathrm{HI}$ and ID by three groups observers: familiar professionals, professional outsiders and laymen. In both methods coefficients indicate a fair degree of agreement.

\section{Conclusions}

The results to date have given no reason to conclude that IBORS is unreliable and therefore not applicable to our study. The remarks we have made concern both methods we used to measure agreement, certain terms of reference and the size of our sample. Before we can be certain that the measure can be of value, it is necessary that agreement between assessors is more widely tested. 


\section{Introduction}

This article forms part of a study into the causes of the emergence or aggravation of problem behaviour. In our first article (Buskermolen, W.M., Hoekman, J. \& Aldenkamp A.P., 2012) we reported a review in risk factors leading to behavioural problems in people with both Hearing Impairments (HI) and Intellectual Disabilities (ID). We concluded that little research on this subject in people with a combination of both disabilities has been reported so far, with an exception of Timehin and Timehin (2004). The fact that individuals with both $\mathrm{HI}$ and ID are seldom studied as a separate group would indicate that these individuals are a negligible group. A possible explanation could be that many individuals are misdiagnosed. Stryker (1999) concluded that although we know that ID exists in people who are deaf or hard of hearing, it is difficult to identify them. Schum (2005) confirmed these findings and concluded that assessment of people with $\mathrm{HI}$ and such co-morbidities as epilepsy, visual impairment, ADHD or ID is very difficult because of communication problems. Conversely the same problem is recognized in people with ID for whom it is difficult to detect the hearing status. HI is often suppressed by other - more urgent - problems (MeuweseJongejeugd et al., 2006).

Much research has been done in people with ID and in people with HI. In both groups seperately behavioural problems frequently occur. Several risk factors for these behavioural problems are reported. We concluded that an increase of behavioural problems is found in people with ID as well as in people with HI when additional handicaps occur. Furthermore it is plausible that communication difficulties form an important risk factor leading to behavioural problems in individuals with ID or $\mathrm{HI}$.

There are however two major objections to be made against these results.

In the first place prevalence rates vary widely and depend on the definition and terminology used to indicate behavioural problems, background and age of the population, methods of data collection used and psychiatric instruments employed.

Secondly, we did not find any study on causal relations between risk factors and behavioural problems. Although recognising risk factors can contribute to the understanding of behavioural problems, empirical research is needed into relations between behaviour and several external and internal factors to gain more insight into direct causes of behavioural problems. When challenging behaviour occurs following specific external events, this could be an indication that this behaviour might be caused by these factors. In order to gain more insight in the relations between behaviour and external factors, it is necessary to use an instrument with which behaviour can be observed and recorded.

Although we reviewed existing behaviour observation and recording scales on their suitability of using them for this purpose, we did not succeed in finding an 
appropriate scale for the purpose of our study (Buskermolen, W.M., Hoekman, J. \& Aldenkamp A.P., Submitted).

We described the development of our Individual Behaviour Observation and Recording Scale (IBORS) which is based on the intervention method of behaviour description plans (Van der Werf, Goedhart, \& Huiberts, 1998). We do realise that it is most uncertain whether IBORS meets the most basic psychometric properties.

In this contribution we describe our exploratory research into the inter assessor agreement of IBORS.

Our research questions are:

1. To what extent do different staff agree in their judgement of observed behaviour of people with both $\mathrm{HI}$ and ID by making use of Individual Behaviour Observation Recording Scale (IBORS)?

2. Is the inter-assessment encouraging enough to use IBORS for a study on relationships between behaviour and several internal and external factors?

\section{Individual Behaviour Observation Recording Scale (IBORS)}

The Individual Behaviour Observation Recording Scale (IBORS) we developed is a five point scale (varying from relaxation (level 1) to loss of control (level 5) on which exclusively individually determined behaviour is described for eight dimensions of behaviour (making sounds, locomotion, facial expression, object manipulation, body manipulation, concentration, expressive communication and receptive communication). As a result, forty unique behaviour descriptions are defined. We proposed to define such behaviour as behaviour problems when it is necessary or challenging enough to intervene actively in order to prevent further escalation of behaviour. Therefore we concluded that the term "challenging behaviour" is the most appropriate one to describe behaviour problems. Following the method of IBORS, this is the case when behaviour is observed, representing level 3 or higher as challenging behaviour.

Behaviour in level 1 is described in terms of relaxation. Some examples are: "makes adequate contact, communicates in sign language, plays with his toys". In the second level restless behaviour is described. Some examples are: "wants to arrange all his toys, communicates only in sentences of two signs, claims attention, stands up from his chair while having dinner but returns of his own accord, laughs extra loudly, walks restlessly in circles, rubs toys softly against his face, shows some stereotypical movements". In level 3 behaviour is described as tense. This behaviour becomes problematic because it requires active intervention of the staff in order to prevent further escalation. Examples are: "hits himself, spits and smears, steals food, is continuously making screaming sounds, is frequently and compulsively going to the 
bathroom, is tearing up magazines, is insistent upon making eye contact, pinches himself, hits himself on the chest and head, smears with faeces". In level 4 behaviour represents a threatening escalation. Examples are: "hits himself in the belly and face, occasionally beats his head against the wall, pokes his finger hard into his nose, throws himself deliberately onto the ground, threatens to hit, kick or bite others, hits windows and doors with force, ignores all communication". Level five behaviour reflects a highly escalated situation. Examples are: "tears his fingernails until they bleed, throws objects at others, bites himself hard in the arms, beats his head constantly against the wall, is unapproachable, bites, hits and kicks wildly, is incessantly destructive".

\section{Inter - assessor agreement}

The main question is in to what extent different staff agree in their judgement of observed behaviour by making use of IBORS. In other words: to what extent can behaviour be described so that different observers are able to make the same judgement while observing the behaviour of a person with $\mathrm{HI}$ and ID. We used two different methods to measure the agreement between observers.

\section{Method}

The first method consisted of observing and recording the behaviour of three individuals with both $\mathrm{HI}$ and ID (aged 14, 16, 28). Subject nr. 1 (aged 14) has an Intellectual Disability. His developmental age is 2;6 years. He also has a hearing impairment (Fletcher index is 70). Challenging behaviour such as destructive behaviour aimed at objects or other people is observed several times per week. Subject nr. 2 (aged 16) has an Intellectual disability. His developmental age is 1;10 years. He also has a hearing impairment (Fletcher index is 100). Furthermore he is diagnosed with an Autism Spectrum Disorder. Challenging behaviour such as self-harming behaviour and destructive behaviour aimed at objects or other people is observed almost every day. Subject nr. 3 (aged 28) has an Intellectual Disability. His developmental age is 4;2 years. He also has a hearing impairment (Fletcher index is 110). Challenging behaviour such as destructive behaviour aimed at objects or other people is observed several times per week. These people all live in the same home in a residential institute for people with $\mathrm{HI}$ and ID. For each of these three people an individual behaviour repertoire was defined according to IBORS. Behaviour was recorded over a period of 17 days by a team of staff. These staff were all familiar with the clients, although one of them (staff number 6) was a relatively new member who had only recently worked with the clients. All staff were familiar with IBORS. Every day two of them worked together on early or late shifts. In this chapter we describe the agreement in IBORS-scores between staff members. External factors are not described. This agreement between staff 
members is measured to assess the interrater agreement of IBORS. In measuring this (interrater) agreement the aim is to observe and record behaviour and to evaluate whether the staff members have the same judgement of the observed behaviour. The recording of behaviour took place at the end of a shift and was done independently of each other.

The number of results (560) is the total amount of the parallel recordings over a period of 17 days, twice per day, for eight behavioural aspects. The maximum possible number of records is $816(17 \times 3 \times 2 \times 8)$. Because the subjects sometimes visited their parents, or because sometimes it had been too busy during a shift, so that not both staff members recorded the observed behaviour, there are less recordings. For subject nr. 1 there were 23 parallel recordings instead of $34(17 \times 2)$. For subject $n r .2$ there were 23 recordings and for subject nr. 3 there were 24 recordings. The total amount of the recordings is 70 . Because recordings have been made for eight behavioural aspects, the total amount of the parallel recordings is 560 . After consulting Dr. G. van den Witteboer, statistician at Amsterdam University, we decided that this is a representative sample because the recordings are divided over all days of the week. The difference of one point concerns the difference in judgements for each recording of each observational criterium, e.g. each behavioural aspect. IBORS is an ordinal scale, which means that it is possible that steps between the five points might differ in size. We used Cohen's Weighted Kappa (Cohen, (1968); Field, (2009); Lowry, (2013) to measure agreement between staff who worked together during the same shift. One major advantage of Cohen's Weighted Kappa over the regular Kappa is that not all disagreements are treated in the same way, because the proportions on the diagonal of the agreement matrix are not the only factors taken into consideration. Minor disagreements have less impact than major disagreements.

The second method of measuring agreement between observers consisted of observing and recording videotaped behaviour of a female client with $\mathrm{HI}$ and ID (aged 40). The videotape included a 22-minute selection of a two-hour videotape of this client. Her behaviour is diverse and consists of a compilation of four different situations (work, lunch, interaction with staff, free moment) in the client's working day. The videotape was viewed and assessed by 27 participants who were divided into three groups. The first group, called "familiars", consisted of nine staff, seven of whom were familiar with the client because they worked in the same group and took care of the client. The other two were a student who only recently got to know the client and the clinical psychologist. They were all familiar with the observation and recording method as described above. The second group of observers consisted of nine "outsiders": professional staff who were familiar with people with both $\mathrm{HI}$ and ID and were also familiar with IBORS. None of them however was familiar with this particular client. The third group consisted of nine "laymen", none of whom was familiar with IBORS. None of these had worked with people with both HI and ID or people with either HI nor ID. None of these participants was familiar with this client. 
First we used weighted Kappa to measure agreement between the observers. Secondly, Kendall's W-Test, or Concordance Coefficient 'Kendall, (1948); Field, (2009) was used to measure the agreement between the observers. Finally, Cronbach's alpha (Cronbach, (1951); Field, (2009) was measured. For this particular calculation we reorganised the file by using FLIP so observers are in columns and observations are in rows. All three measures were used to calculate agreement for the group as a whole as well as for all the three groups separately.

\section{Results}

\section{Parallel shift recording}

Examining the descriptive data (see table 4.1), we can state that in $52.5 \%$ of all results (294 out of 560) there was no difference between the records of the two observers working on the same shift. In another $39.5 \%$ of all records, a difference was noted between the two observers of one point on the five-point scale. This meant that in $92 \%$ the judgement of the several behavioural aspects was exactly the same or only one point off. In $6.8 \%$ there was a difference of 2 points between two observers and in $1.2 \%$ of all cases ( 7 out of 560 ) there was a difference of three points.

Table 4.1 Differences (D) between rough data per behavioural aspect

\begin{tabular}{lccccccccc}
\hline Difference: & Conc & E.C. & Sound & Loc. & Mim & B.M. & M.M. & R.C. & Total \\
\hline 0 & $50 \%$ & $64 \%$ & $54 \%$ & $54 \%$ & $47 \%$ & $51 \%$ & $50 \%$ & $49 \%$ & $52.5 \%$ \\
1 & $43 \%$ & $26 \%$ & $41 \%$ & $41 \%$ & $46 \%$ & $40 \%$ & $39 \%$ & $40 \%$ & $39.5 \%$ \\
2 & $4 \%$ & $9 \%$ & $4 \%$ & $3 \%$ & $6 \%$ & $7 \%$ & $11 \%$ & $10 \%$ & $6.8 \%$ \\
3 & $3 \%$ & $1 \%$ & 0 & $1 \%$ & $1 \%$ & $1 \%$ & 0 & $1 \%$ & $1.2 \%$ \\
4 & 0 & 0 & 0 & 0 & 0 & 0 & 0 & 0 & 0 \\
\hline
\end{tabular}

Data are presented as percentages.

In table 4.2 the results are represented of seven parallel observations in which the difference in judgement varied by three points. It was noted that staff number 6 was involved in five of the seven cases. She scored consistently higher than her colleagues. With reference to the remaining two observations we noted that staff number 9 reported higher scores than her colleague (staff number 1 ). Judgements were made on all three clients and are divided over various behavioural aspects. 
Table 4.2 Shifts and staff-members where the difference was 3 points.

\begin{tabular}{llccc}
\hline Client & Aspect & Staff \# (Judgement) & \multicolumn{2}{c}{ Staff \# (Judgement) } \\
\hline 1 & Conc. & $6(5)$ & 2 & $(2)$ \\
2 & Mim. & $6(4)$ & 8 & $(1)$ \\
2 & Rec.c. & $6(4)$ & 8 & $(1)$ \\
2 & B.M. & $6(5)$ & 2 & $(2)$ \\
3 & Loc. & $6(5)$ & 5 & $(2)$ \\
3 & Conc. & $9(4)$ & 1 & $(1)$ \\
3 & Exp.c. & $9(4)$ & 1 & $(1)$ \\
\hline
\end{tabular}

In order to establish agreement between observers, a weighted Kappa was determined

(Lowry, 2013). The results of Cohen's weighted Kappa are shown in table 4.3. In this table the results are given in separate columns for each client observed. The results of all judgements of all three clients are shown in a fourth column. It is clear that the results vary to a great extent. Some values do not come above .20. Agreement in the observed behaviour of client number 3 in particular is not very high. Agreement on the behaviour of the other two clients is greater. Judgements on all three clients together result in Kappa values of .44 to .66 .

Table 4.3 Cohen's weighted Kappa three clients in total:

\begin{tabular}{lcccc}
\hline Behaviour aspect & Participant 1 & Participant 2 & Participant 3 & All three \\
\hline Making Sounds & .80 & .84 & -- & .62 \\
Locomotion & .49 & .43 & .33 & .53 \\
Facial expression & .43 & .19 & -- & .47 \\
Object-Manipulation & .74 & .66 & -- & .62 \\
Body Manipulation & .43 & .29 & .52 & .44 \\
Concentration & 1.0 & .63 & .39 & .59 \\
Expressive Communication & .64 & .67 & .34 & .66 \\
Receptive Communication & .20 & .51 & .52 \\
\hline
\end{tabular}

Video-taped observations:

An initial inspection of the raw data (see table 4.4) appears to indicate that observers 22 and 27 vary. The other observers appear to agree more in their judgement of behaviour. 


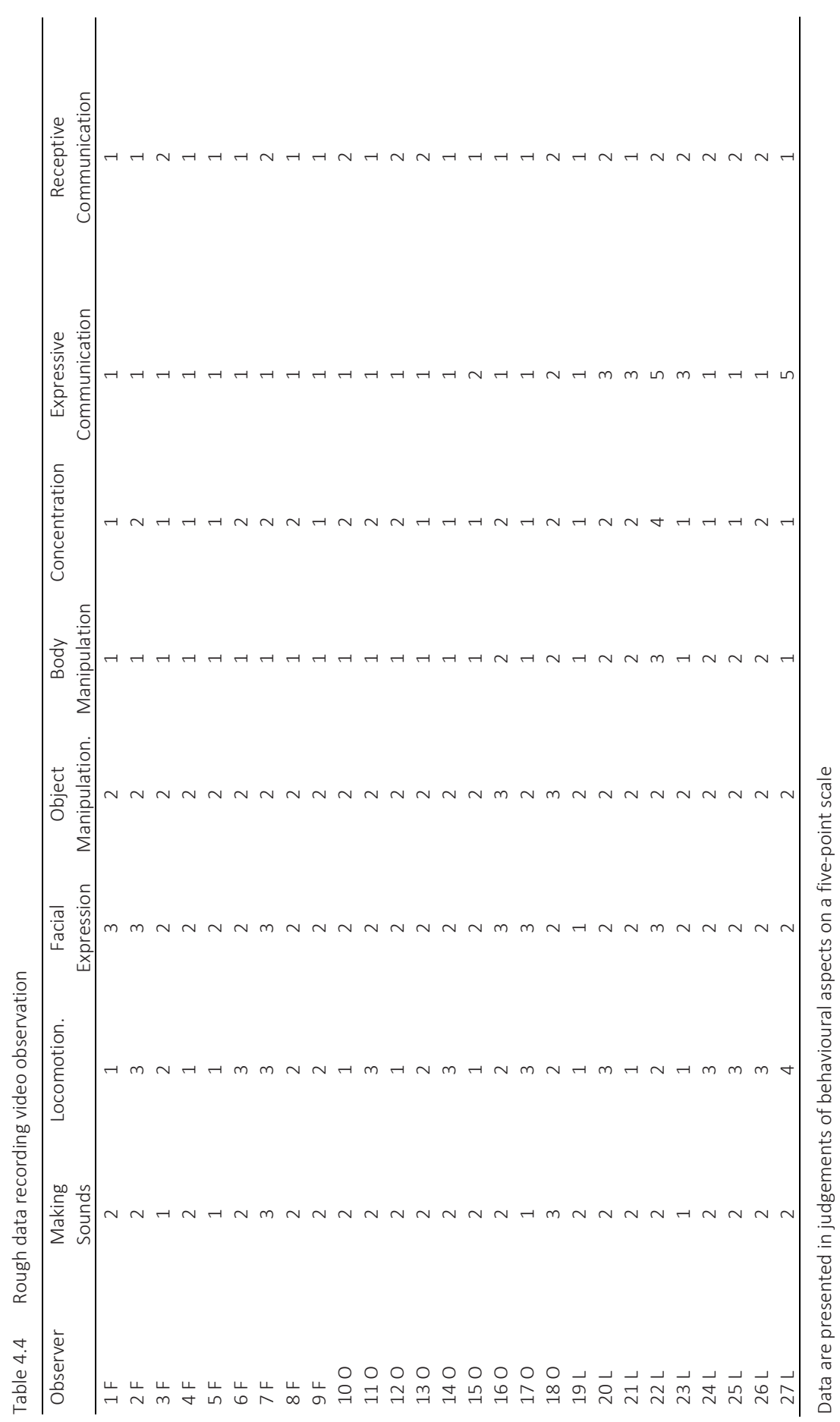


Cohen's weighted Kappa was carried out to measure agreement between the observers from all three groups. An average agreement of .20 was found (see table 4.5). The Familiar staff showed an average agreement of .45, the Outsiders . 25 and the Laymen .14.

Kendall's W-Test, or Coefficient of Concordance, was used to measure the mean agreement between the observers. For the total group an agreement of 30 was measured (see_table 4.5). For the two groups of professionals a higher agreement (familiar staff .65 and outsiders .46) was measured than for the group of laymen (.11).

Table 4.5 Statistical measures

\begin{tabular}{llll}
\hline Group: & K & W & $\alpha$ \\
\hline Total group & .20 & .30 & .86 \\
Familiar staff & .45 & .65 & .92 \\
Outsiders & .25 & .46 & .83 \\
Laymen & .14 & .11 & .54 \\
\hline
\end{tabular}

Because we wanted to know whether the results were negatively influenced by "outliers" we applied Cronbach's Alpha. For the total group an Alpha of .86 was found (see table 4.5). From the results of the three separate groups, the outcome of Cronbach's Alpha was as expected with the highest agreement measured within the group of familiar staff (.92), as where the results for the group of was .83. Agreement between laymen (.54) was lower. When some observers were eliminated (nrs. 21, 22, 23 and 27), Cronbach's alpha showed some improvement (see table 4.6). Reliability then increased up to .93. These outliers were all from the group of Laymen. 
Table 4.6 Cronbach's Alpha Item-Total Statistics

\begin{tabular}{|c|c|c|c|c|}
\hline & $\begin{array}{c}\text { Scale Mean if Item } \\
\text { Deleted }\end{array}$ & $\begin{array}{c}\text { Scale Variance if Item } \\
\text { Deleted }\end{array}$ & $\begin{array}{c}\text { Corrected Item-Total } \\
\text { Correlation }\end{array}$ & $\begin{array}{c}\text { Cronbach's Alpha if Item } \\
\text { Deleted }\end{array}$ \\
\hline VAR00001 & 46,75 & 69,93 & ,66 & 85 \\
\hline VAR00002 & 46,38 & 66,84 & ,82 & ,84 \\
\hline VAR00003 & 46,75 & 73,93 &, 50 & ,85 \\
\hline VAR00004 & 46,88 & 72,70 & ,66 & ,85 \\
\hline VAR00005 & 47,00 & 73,71 & 61 & ,85 \\
\hline VAR00006 & 46,50 & 69,71 & ,73 & ,85 \\
\hline VAR00007 & 46,13 & 68,41 & ,70 & ,85 \\
\hline VAR00008 & 46,63 & 72,00 & ,74 & ,85 \\
\hline VAR00009 & 46,75 & 70,21 & 93 & ,84 \\
\hline VAR00010 & 46,63 & 77,13 & 15 & 86 \\
\hline VAR00011 & 46,50 & 69,71 & ,73 & ,85 \\
\hline VAR00012 & 46,63 & 77,13 & ,15 & ,86 \\
\hline VAR00013 & 46,63 & 72,84 & ,64 & 81 \\
\hline VAR00014 & 46,63 & 67,98 & ,84 & ,84 \\
\hline VAR00015 & 46,75 & 73,64 & ,53 & ,85 \\
\hline VAR00016 & 46,25 & 70,50 & ,61 & ,85 \\
\hline VAR00017 & 46,63 & 66,27 & ,78 & ,84 \\
\hline VAR00018 & 46,00 & 75,71 & ,36 & ,86 \\
\hline VAR00019 & 47,00 & 75,71 & ,36 & ,86 \\
\hline VAR00020 & 46,00 & 77,43 & 14 & ,86 \\
\hline VAR00021 & 46,38 & 79,98 &,- 14 & 87 \\
\hline VAR00022 & 45,38 & 86,84 &,- 44 & ,89 \\
\hline VAR00023 & 46,63 & 78,55 &,- 02 &, 87 \\
\hline VAR00024 & 46,13 & 75,84 & ,23 & ,86 \\
\hline VAR00025 & 46,39 & 73,98 & ,40 & ,86 \\
\hline VAR00026 & 46,25 & 75,64 & 31 & ,86 \\
\hline VAR00027 & 46,00 & 70,86 &, 23 & 87 \\
\hline
\end{tabular}

\section{Discussion}

The objective of this article was a study in agreement of behaviour observation by making use of IBORS. Our research question was to what extent different staff would agree in their judgement of observed behaviour and, subsequently, if the results would be encouraging enough to use it for our study. Our first method for examining agreement consisted of parallel recording by staff while they were at work. Exploring the rough data we concluded that the judgements of both staff in the parallel shift method was exactly the same or only one point off in $92 \%$. In only seven cases (1.2\%) there was a disagreement of three points. From the statistical analyses of the data, recorded during the parallel shift, Cohen's weighted Kappa shows a fair to moderate agreement. With the statistical tests from the second method, observing and scoring videotaped behaviour of one female individual with both $\mathrm{HI}$ and ID the results were encouraging. Although a weighted Kappa of .20 for the whole group was measured, a 
Kappa of .45 for the group Familiars is reasonable. The same conclusions can be drawn from the $W$ coefficients and the a coefficients. These results also show that professional staff (Familiars and Outsiders alike) agree more highly than Laymen, but Familiars show greater agreement than professional Outsiders. We might thus conclude that IBORS is a professional scale. Secondly, familiarity with the observed client is important in making reliable behavioural judgements as well.

Some critical remarks can be made. The first method, by which two staff both judge the client after having shared a shift, does not involve them being in the same space at the same time. It is therefore not guaranteed that they have observed exactly the same behaviour. It is even possible that one of the observers has had a conflict with the client concerned whereas the other observer has not seen it. This objection does not apply to the method involving video images. All observers have seen the same images. A comment might however also be made about this method. The tape has a length of 22 minutes in which we think this persons behaviour in its diversity is being showed. We could draw more reliable conclusions about the inter-assessor reliability of the method if behaviour of several clients over a larger span of time was observed and scored.

An objection to both methods is that differences of interpretation can occur for certain terms of reference. The language used in describing behaviour needs critical evaluation. Some expressions can be interpreted in different ways, depending on personal experience and background. One example is a word like "adequate", in manipulation of objects or material, which to some people could mean "perfect" whereas it implies "sufficient" to others. Some terms, like "now and then", "functional" and "as 4, but to a greater extent" can also be interpreted varyingly. It is thus essential that different forms of behaviour are described as objectively as possible.

Furthermore, a critical comment may be made concerning the relative reliability of this method: we did not use another method as a control recording to test if the method of IBORS was more reliable than another method.

The main aim of our study is to detect factors which influence challenging behaviour of people with both $\mathrm{HI}$ and ID. For this purpose it is necessary to use a scale with which behaviour can be observed and recorded on a daily base. Because we did not find a suitable scale, we developed IBORS. In this article we tried to gain an impression of agreement between assessors of IBORS. The intention of our study into assessors' agreement was one of an orientating nature. We wonder whether the measured agreement is high enough to judge behaviour in a reliable way. Although all coefficients indicate a fair degree of agreement the sample size used is too small to draw confident conclusions. The results to date have given no reason to conclude that IBORS is unreliable and therefore not applicable to our study. Before the measure can be of value, it is necessary that agreement between assessors is more widely tested. In order to do this, several clients should be assessed over longer periods of time. The use of video images must also become more widespread. Furthermore it is important to 
assess whether terminology describing behaviour can be interpreted in various ways as it is essential to describe behaviour as far as possible in objective, unequivocal, measurable terms. 


\section{References}

Buskermolen, W.M., Hoekman, J. Aldenkamp A.P. (2012). Risk factors leading to behavioural problems in individuals with profound intellectual and hearing impairments disabilities. International Journal on Mental Health and Deafness. 1(2): 33-45.

Buskermolen, W.M., Hoekman, J. Aldenkamp A.P. Assessing Challenging Behaviour in People with Profound Intellectual Disabilities and Hearing Impairments: The Development of an Individual Behaviour Observation and Recording Scale. International Journal on Mental Health and Deafness, 3(1): 30-40.

Cohen, J. (1968). Weighted kappa: Nominal scale agreement provision for scaled disagreement or partial credit. Psychological Bulletin, 70(4): 213-220.

Cronbach, L. J. (1951). Coefficient alpha and the internal structure of tests. Psychometrika, 16(3): 297-334.

Field, A. (2009). Discovering statistics using SPSS. Third edition. London: Sage.

Kendall, M.G. (1948). Rank correlation methods. London: Griffin.

Lowry, R. (2013). Concepts and Applications of Inferential Statistics. Vassarstats: Web Site for Statistical Computation.

Meuwese-Jongejeugd, A.; Vink, M.; van Zanten, B.; Verschuure, H.; Eichhorn, E.; Koopman, D.; Bernsen, R.; Evenhuis, H. (2006). Prevalence of hearing loss in 1598 adults with an intellectual disability: Crosssectional population based study. International Journal of Audiology. 45(11): 660-669.

Schum, R. (2005). Psychological Assessment of Children with Multiple Handicaps Who Have Hearing Loss. Volta Review. 104(4): 237-255.

Stryker, D.S. (1999). Identification of learning disabilities in students who are deaf or hard of hearing: A Bayesian approach. Dissertation Abstracts International Section A: Humanities and Social Sciences. 59(9-A): 3405.

Timehin, C.; Timehin, E. (2004). Prevalence of hearing impairment in a community population of adults with learning disability: access to audiology and impact on behaviour. British Journal of learning disabilities. 32(3): 128-132

Van der Werf, L.J., Goedhart, A.W. \& Huiberts, S. (1998). Signaleringsplannen, naar minder agressie en dwang in de psychiatrie. Lisse: Swets \& Zeitlinger. 


\title{
Chapter 5
}

\section{MEASURING POSSIBLE ENVIRONMENTAL FACTORS}

\author{
INFLUENCING CHALLENGING BEHAVIOUR IN PEOPLE
}

\author{
WITH BOTH AN INTELLECTUAL DISABILITY AND
}

HEARING IMPAIRMENT / DEAFNESS (ID - HI/D)

\section{THE DEVELOPMENT OF A DIGITAL PROGRAM}

Willem Meindert Buskermolen ${ }^{1}$, Corina Maria Holsnijders ${ }^{2}$, Joop Hoekman ${ }^{3}$ and Albert Pierre Aldenkamp ${ }^{4}$

1. Kentalis - Weerklank Amsterdam; the Netherlands

2. "Bijzonder Goed Bezig" - Dieticians Practice Aalsmeer, the Netherlands

3. Leiden University; University of Applied Sciences Leiden; the Netherlands

4. Dept of Neurology, Maastricht University Medical Centre, Maastricht, The Netherlands

- Epilepsy centre Kempenhaeghe, Heeze, The Netherlands

- Faculty of Electrical Engineering, University of Technology, Eindhoven, The Netherlands 


\section{Abstract}

Background and objective

In people with both Hearing Impairments or Deafness (HI/D) and an Intellectual Disability (ID) challenging behaviour frequently occurs. Although several risk factors for these behavioural problems are reported, empirical research is needed into relations between challenging behaviour and several environmental and internal factors. In this article we focus on defining relevant environmental factors and on developing a digital recording program.

Method and results

Environmental factors were chosen after carrying out the Delphi method by several professionals who are involved in the daily care of people with both ID and HI/D. Secondly, these factors were defined in measurable terms. Finally a computer-program was developed. This computerprogram was used to do reliable recording of such factors by varying care professionals with different backgrounds.

\section{Conclusions}

Several environmental factors are defined. Professionals who have knowledge and expertise of people with both ID and HI/D consider the influence of individual staff-members on challenging behaviour as the most important environmental factor to be included in the program. 


\section{Introduction}

Care professionals working with people with both an intellectual disability (ID) and hearing impairment/deafness (HI/D) have frequently reported occurrences of behavioural problems (Nijhof \& Van Overveld, 2005). Aggressive incidents such as destructive behaviour aimed at objects or other people and self-harming behaviour are mentioned in particular.

Minimal research on behavioural problems in people with a combination of both disabilities has been found so far (Buskermolen, Hoekman \& Aldenkamp, 2012). An exception was found in the study of Timehin and Timehin (2004). In their study, 62\% of 543 people showed behavioural problems.

Studies of people with ID (Deb, Thomas \& Bright, 2001; Molteno, Finchilescu \& Dawes, 2001; Emerson et al., 2001; Tyrer et al., 2006; Crocker et al., 2006; Holden \& Gitlesen, 2006) indicate that behavioural problems frequently occur. The same conclusion can be drawn from studies of people with HI/D (Hindley, Hill, McGuigan \& Kitson, 1994; Mitchell \& Quittner, 1996; Vostanis, Hayes, Du Feu \& Warren, 1997; Van Eldik, Treffers, Veerman \& Verhulst, 2004; Van Gent, Goedhart, Hindley, \& Treffers, 2007). In both groups. however, prevalence rates vary widely. This depends mainly on the definition and terminology used to define behavioural problems, the background and age of the population, the methods of data collection used, and the psychiatric instruments utilized (Buskermolen, Hoekman \& Aldenkamp, 2012).

Recognizing risk factors can contribute to the understanding of behavioral problems, but it does not provide causal-effect relations. Therefore, empirical research is needed to gain more insight in this topic. In order to perform such research, it is necessary to define behaviour as a dependent variable in measurable terms. For this purpose, Buskermolen, Hoekman \& Aldenkamp developed an Individual Behaviour Observation and Recording Scale (IBORS; Buskermolen, Hoekman \& Aldenkamp, 2013), which consists of behaviour descriptions in five different levels, from relaxation to loss of control. In each of these levels, behaviour, which is characteristic for an individual, is described in eight behavioural dimensions ("making sounds", "locomotion", "facial expression", "object manipulation", "body manipulation", "concentration", "expressive communication" and "receptive communication"). In IBORS, behaviour that is described in stage three or higher, is defined as challenging behaviour, because behaviour in these stages is challenging enough, and it needs active intervention to prevent further escalation. When challenging behaviour occurs following specific environmental events, this could be an indication of a relationship between the observed behaviour and such events. These events could be important environmental factors for developing challenging behaviour. 
The aim of this research is to describe the development of a digital program that can be used to record both individual behaviour and different environmental factors. In this program, IBORS will be used as a measure of behaviour.

Our research questions are the following:

1. Which environmental factors should be included in our study?

2. How do we operationalize these factors?

3. Can we develop a digital program in which these environmental factors as well as behaviour can be recorded?

\section{Method}

The main hypothesis of this study concerns possible relations between (challenging) behaviour and environmental factors. In order to set up this study, it is necessary to establish which environmental factors are relevant. We explored several studies regarding the subject of how human behaviour is influenced (e.g. Hewstone \& Stroebe, 2001). We concluded that including all possible influences in our study would result in an unlimited amount and diversity of factors, whether people have ID and/or HI/D or not. We agree with Janssen, Schuengel and Stolk (2002), who proposed that a complexity of stress factors forms the basis of the development of behavioural problems in people with ID. We might expect that the same principle goes for people with both ID and HI/D. For this purpose, we have chosen the pragmatic approach of using the Delphi method (Dalkey \& Helmer, 1963). A group of five psychologists and staff, who were all professionally involved with people with both ID and HI/D, constructed a list of possible factors, based on their experience and presumptions. This list was distributed to professionals $(\mathrm{N}=36)$ from different areas: group workers, school teachers, staff members, and managers. The response was $92 \%(N=33)$. Three questions were to be answered: 1 . Select 5 factors from this list which you think are the most responsible for developing behavioural problems. 2. Which factors on this list do you think are totally irrelevant in developing behavioural problems? 3. What possible factors would you add to this list?

\section{Results}

Table 5.1 shows the results of the list as responded by 33 of the 36 addressed care professionals. 
Table 5.1 Environmental factors influencing the behaviour of people with ID and HI /D

\begin{tabular}{lcc}
\hline Factors: & $\%+$ & $\%-$ \\
\hline The presence of individual staff-workers & 91 & 0 \\
Changes in daily routine & 88 & 0 \\
Medication & 61 & 0 \\
Conflict with others & 55 & 3 \\
Number of staff & 55 & 0 \\
Conflicts between others & 48 & 0 \\
Visits & 45 & 6 \\
Day of the week & 24 & 0 \\
Nutrition & 15 & 0 \\
Early or late shift & 15 & 9 \\
Temperature & 6 & 9 \\
Air pressure & 6 & 30 \\
Phase of the moon & 3 & 30 \\
\hline
\end{tabular}

Data are presented as percentages. The first column represents the percentage of the respondents $(N=33)$ who choose a particular factor. The second column represents the percentage of the respondents who think the particular factor is irrelevant.

From the response of our first question we conclude that the presence of individual staff-members is considered to be the most influential environmental factor. Ninety-one \% of the respondents chose this factor. Changes in daily routine was mentioned by $88 \%$ of the respondents.

From the responses to our second question, ("Which factors on this list do you think are totally irrelevant?"), "Phase of the moon" and "Air pressure" were mentioned by $31 \%$ of the respondents. We may, on the other hand, conclude that $69 \%$ of the respondents (23 out of 33 ) did not want to reject the possible factors "Phase of the moon" and "Air pressure" as totally irrelevant. "Temperature", "Day of the week" and "Early or Late shift" were also mentioned by few respondents.

We decided to include those factors which were chosen by at least $10 \%$ of all respondents. Weather conditions such as air pressure and temperature as well as the lunar cycle were chosen by less than $10 \%$ of all respondents and therefore these factors were not included.

The third question to be answered was: "Which possible factors would you add to this list?" Firstly, various unexpected events were mentioned, such as alarm signals or rubbish on the footpath. Secondly, physical health was suggested as a factor. Finally, special days such as birthdays or Christmas were put forth as possible factors. We decided to include these extra possible environmental factors in our study as well. All other factors were included. In appendix 5.1 we describe the operationalization of the above mentioned factors. 


\section{Data input}

The staff that was on duty did the recording of the behaviour of the participants at the end of their shift as well as all environmental factors as described in appendix one. Data was recorded four times per day: 07.30 a.m., 09.00 a.m., 15.00 p.m. and 22.30 p.m. This data is entered digitally in a specially designed access program. This program has been tested over a number of months in order to give staff the experience of working with it and to give feedback. This feedback was then incorporated into the definitive version.

\section{The staff are given the following instructions:}

1. The staff are to record the data as soon as possible at the end of their shift. The program does not offer the possibility to do such the following day.

2. If more than one staff-member was working during this shift, they are to agree as to who will record the data.

3. Per shift, all pages are to be completed unless the participant was not present.

4. If the participant was present for only a part of the shift, staff will record the data that are available. It is obvious that second-hand observations/information are less reliable, but it can provide valuable information.

5. If the participant has been at the residential home for some time and also involved in an activity or at work during the period studied, a record is made by the staff who was present at the time the meal (usually lunch) was taken.

6. During the weekend, it is possible that the periods "to 9.00 a.m." and "from 09.00 to 3.00 p.m." are recorded together as one session. This is the case when breakfast and lunch become brunch. If both breakfast and lunch are taken, these are recorded separately.

7. When the page has been completed, click on the "Finished?" button. A green checkmark will appear instead of the red exclamation mark and the red dot. If you have missed any of the questions, the green checkmark will not appear.

8. New names of staff-members can be added. This is done by clicking on the button marked "Participants, support staff and (specific) night shift staff. The page you then see explains what to do next. Names of staff-members can not be deleted.

9. Data is then exported to a file, preferably by a permanent member of staff for each group. This happens using the button at the left on the bottom. In the box to the right you can see when the last file was exported. This file is then automatically mailed to the mail-address of W.M. Buskermolen.

\section{How to record behaviour}

Extra instructions are provided for recording behaviour. Behaviour is defined according to the IBORS classification. Each participant's specific behaviour is categorised in five 
mood levels from relaxed via confusion, tension, threatening to completely unrestrained behaviour. In each of these stages, behaviour, which is characteristic for an individual, is described in eight behavioural dimensions ("making sounds", "locomotion", "facial expression", "object manipulation", "body manipulation", "concentration", "expressive communication" and "receptive communication"). Options from 1 to 5.

Maximum time of observed behaviour: $<15$ minutes, $<60$ minutes, $>60$ minutes. In the case of Level one or two, the maximum time is automatically $>60$ minutes.

\section{The following norms apply:}

1. If there is any doubt, the highest score is chosen; even if it was only exhibited for a short period, the behaviour recorded is the least relaxed behaviour observed.

2. If the score was a 1 or a 2, an extra box will appear on the form indicating that the behaviour was observed for longer than an hour.

3. If a score of 3, 4 or 5 is noted, an extra box will appear with a number of choices: shorter than 15 minutes, shorter than 60 minutes, or longer than 60 minutes.

Above the recording of behaviour by IBORS, staff were asked to give school-rating marks from one to ten. (Behaviour 2.) Ten means: All went perfectly right as where "one" means that the participant had a very bad day. A third judgement of behaviour was asked by a "feel-good" scale. This was also a five-point behaviour observation and recording scale. When staff had the impression that the participant felt very well during a particular shift, this was to be recorded as a "five".

\section{Processing of data}

Data is transferred into Excel files which are then processed through the SPSS, version 14.

\section{Discussion}

We carried out the Delphi-method to detect which environmental factors should be included in our study. These factors were defined and operationalized. In appendix 1 , we have illustrated the computerprogram. There are some shortcomings in this study. Firstly, we originally designed three behaviour recording scales. After IBORS was developed, we proposed two other scales. To complete the second scale, staff had to give a mark from one to ten. In the third scale, staff was asked to give an impression of how the participant must have felt. We explained that, for scientific purpose, it would be important to investigate if IBORS and the two other scales all three were reliable observation and recording scales. Unfortunately, despite of this extra argument, the 
response on these scales was disappointing and too low. Therefore we did not include these results in our study. We asked several staff-members why this response was so low. Many staff-members reported that they found these two scales too subjective. Since they were familiar with IBORS it was too difficult for them to give judgements using an alternative approach. A second problem was the response of the staff who worked during the night-shift. It turned out to be too much time-consuming for these staff-members to record factors for all participants. Therefore we did not include the few data in the programme.

A possible restriction of our study is the selection of environmental factors by using the Delphi-method. Although this is a recognized method (Dalkey \& Helmer, 1963) we have no full guarantee that this results in a complete list of the most relevant factors. Several factors were excluded using our criteria that nonetheless may be meaningful.

The method will consequently be applied in our clinical study and re-evaluated analyzing the resulting data. 


\section{References}

Buskermolen, W.M., Hoekman, J. \& Aldenkamp, A.P. (2012). Risk factors leading to behavioural problems in individuals with hearing impairments and intellectual disabilities. International Journal on Mental Health and Deafness, 2(1): 33-45.

Buskermolen, W.M., Hoekman, J. \& Aldenkamp, A.P. (2013) Assessing Challenging Behaviour in People with Hearing Impairments and Profound Intellectual Disabilities: The Development of an Individual Behaviour Observation and Recording Scale. International Journal on Mental Health and Deafness, 3(1): 30-40.

Crocker, A.G.; Mercier, C.; Lachapelle, Y.; Brunet, A.; Morin, D.; Roy, M.E. (2006). Prevalence and types of aggressive behaviour among adults with intellectual disabilities. Journal of Intellectual Disability Research, 50(9): 652-661.

Dalkey, N.; Helmer, O (1963), An experimental application of Delphi method to the use of experts, Management Science, 9, 458

Deb, S.; Thomas, M.; Bright, C. (2001). Mental disorder in adults with intellectual disability. 2: The rate of behaviour disorders among a community-based population aged between 16 and 64 years. Journal of Intellectual Disability Research, 45(6): 506-514.

Emerson, E.; Kiernan, C.; Alborz, A.; Reeves, D.; Mason, H.; Swarbrick, R.; Mason, L.; Hatton, C. (2001). The prevalence of challenging behaviors: A total population study. Research in developmental disabilities, 22(1): 77-93.

Hewstone, M. \& Stroebe, W. (2001). Introduction to Social Psychology: A European Perspective, Third Edition. Blackwell, Oxford, UK.

Hindley, P.A.; Hill, P.D.; McGuigan, S.; Kitson, N. (1994). Psychiatric disorder in deaf and hearing impaired children and young people: prevalence study. Journal of Child Psychology and Psychiatry, 35(5): 917935.

Holden, B. \& Gitlesen, J.P. (2006). A total population study of challenging behaviour in the county of Hedmark, Norway: Prevalence, and risk markers. Research in developmental disabilities, 27(4): 456465.

Janssen, C.G.C., Schuengel, C. \& Stolk, J. (2002). Understanding challenging behaviour in people with severe and profound intellectual disability:a stress-attachment model. Journal of Intellectual Disability Research, 46(6): 445-453.

Mitchell, T.V. \& Quittner, A.L. (1996). Multimethod study of attention and behavior problems in hearingimpaired children. Journal of clinical child psychology, 25(1): 83-96.

Molteno, G.; Molteno, C.D.; Finchilescu, G.; Dawes, A.R.L. (2001). Behavioural and emotional problems in children with intellectual disability attending special schools in Cape Town, South Africa. Journal of Intellectual Disability Research, 45(6): 515-520.

Nijhof, R. \& Van Overveld, S. (2005). FOBO Jaarverslag 2005. Amsterdam: Effatha Guyot Zorg.

Timehin, C.; Timehin, E. (2004). Prevalence of hearing impairment in a community population of adults with learning disability: access to audiology and impact on behaviour. British Journal of learning disabilities. 32(3): 128-132.

Tyrer, F.; McGrother, C.W.; Thorp, C.F.; Donaldson, M.; Bhaumik, S.; Watson, J.M.; Hollin, C. (2006). Physical aggression towards others in adults with learning disabilities: prevalence amd associated factors. Journal of intellectual disability research, 50(4): 295-304.

Van Eldik, T., Treffers, P.D.A., Veerman, J.W., Verhulst, F.C. (2004). Mental health problems of deaf children as indicated by parents responses to the Child Behavior Checklist. American annals of the deaf, 148(5): 390-394.

Van Gent, T.; Goedhart, A.W.; Hindley, P.A.; \& Treffers, P.D.A. (2007). Prevalence and correlates of psychopathology in a sample of deaf adolescents. Journal of Child Psychology and Psychiatry. 48(9): 950-958.

Vostanis, P.; Hayes, M.; Du Feu, M.; Warren, J. (1997). Detection of behavioural and emotional problems in deaf children and adolescents: Comparison of two rating scales. Child care, Health and Development, 23(3): 233-246. 


\section{Appendix 5.1}

\section{Operationalisation}

In this section we describe how we operationalised the several environmental factors we included in our research. These factors were the result of the Delphi-method we carried out.

Start-screen: Staff has to choose the participant and from which time-period this recording is about. There are four possibilities: Night-shift (0), Morning-shift (1), Dayshift (2) and Evening-shift (3).

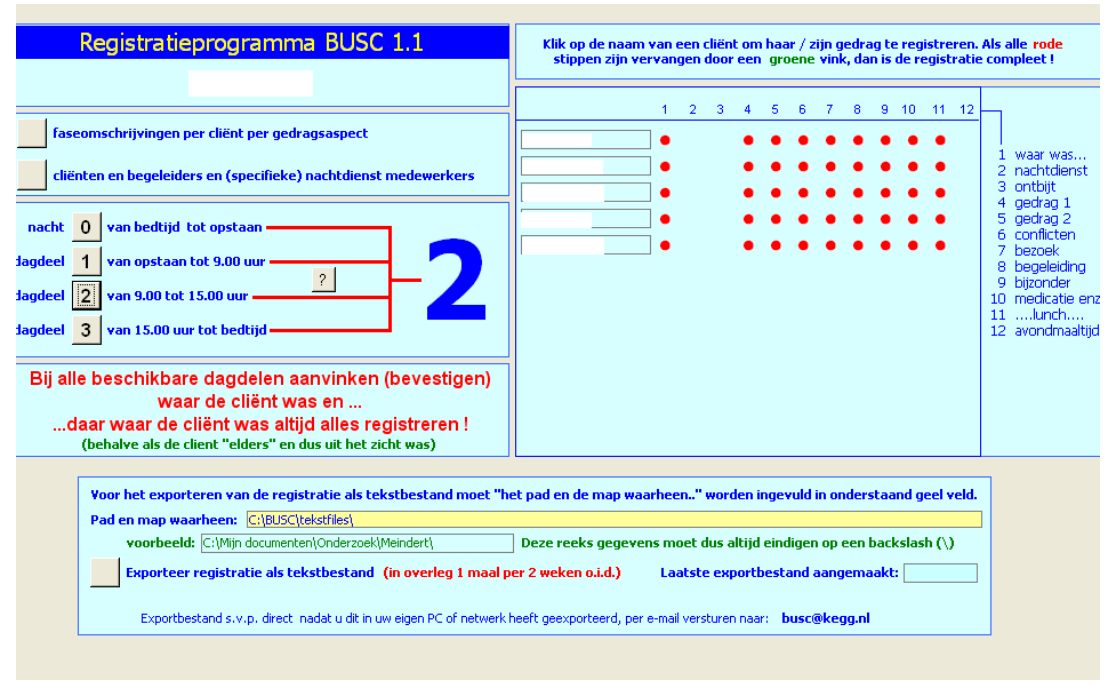

Figure 5.1 Start screen

Day of the week / Night-shift, Morning-shift, Day-shift or Evening-shift (Chapers 0, 1, 2 and 3) 
The program automatically points out the date as well as the day of the week. In this program Four different "chapters" are designed.

0: Night-shift

1: Morning-shift, from getting up until 9.00 a.m.

2: Day-shift, from 9.00 a.m. until 3.00 p.m., or in any case until the end of a daily shift activity programme or school.

3: Evening-shift, from approximately 3.00 p.m. until bedtime.

In each chapter the first page includes:

Presence: Where was the participant: was he or she present during the recording period? If not, where was he or she?

Options: With parents or other relatives, visiting another residential home, in hospital, with family doctor, dentist, other medical specialist, on holiday.

This screen was meant to be recorded by staff-members who worked during the night.

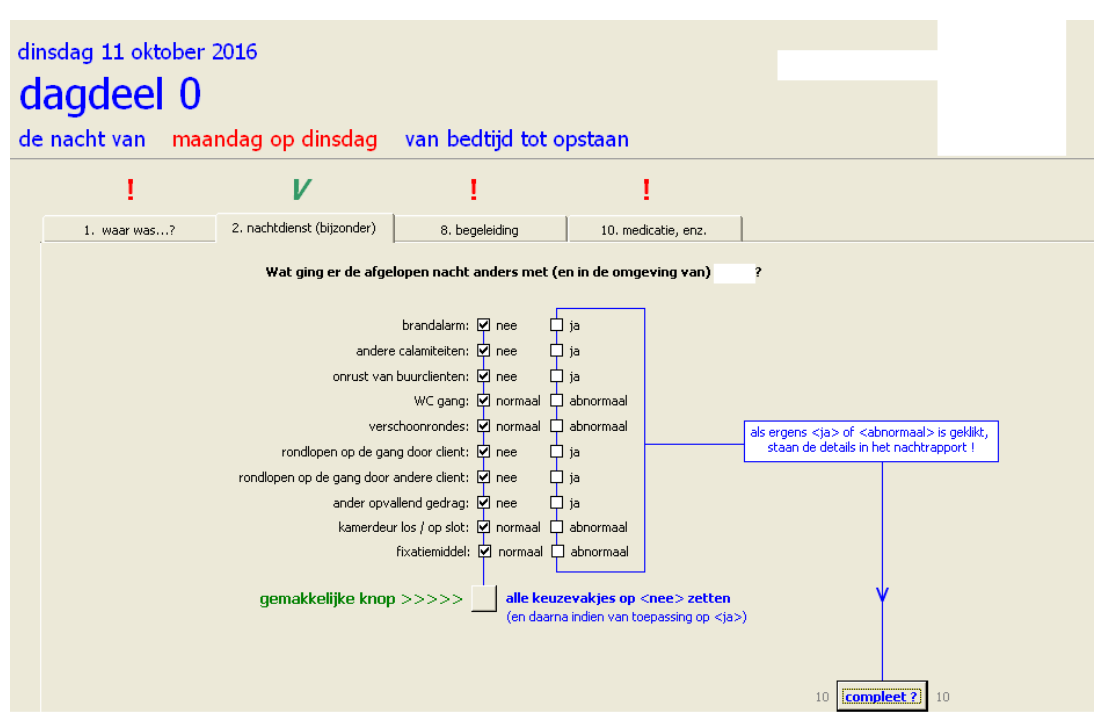

Figure 5.2 Screen for night-shift 


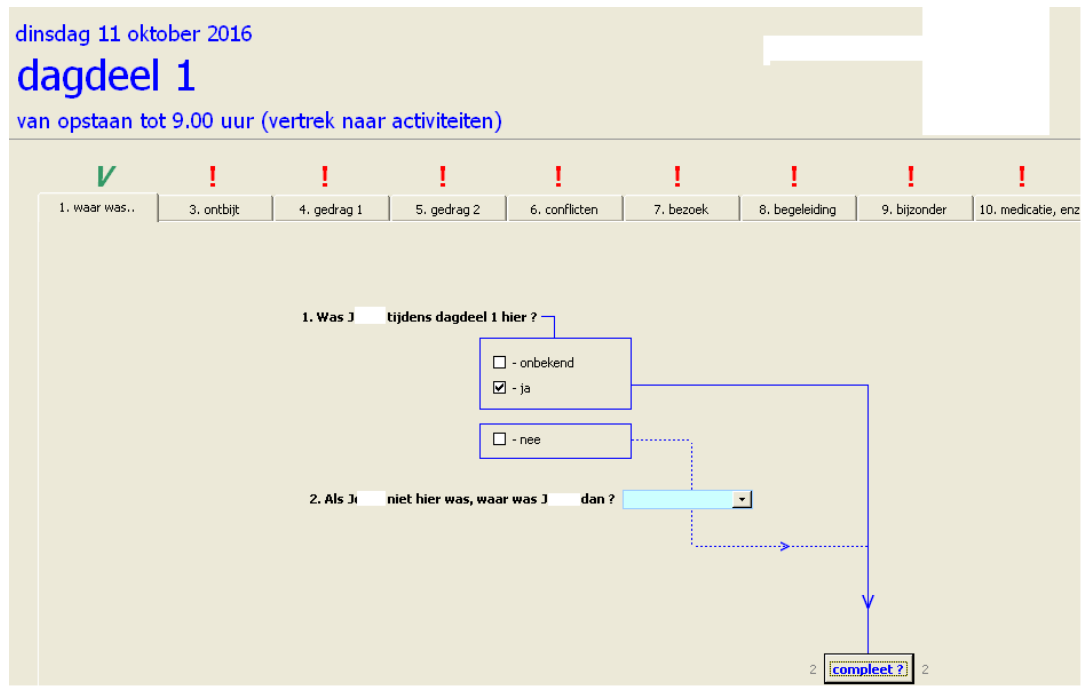

Figure 5.3 Presence of the participant

\section{The presence of staff-members (Chapers 0, 1, 2 and 3)}

The most frequently mentioned possible environmental factor, as a result from the Delphi-method is the presence of individual staff-members. Personality and pedagogic style of certain staff-members can prove to be a factor, as well as such characteristics as hair, skin colour, gender, clothing, make-up, jewelry, or fragrance of the staff. However, these factors are not included as this would introduce an unlimited number of variables. We decided to make records of the presence of staff-members. Above this we distinguished if a certain staff-member did the recording.

\section{Staff}

Staff: Choose your own code; Did you do the recording: Yes/No.

Was there a second staff member? Yes/No. Choose staff code 2. Did staff the recording? Yes/No.

Was there a third staff member? Yes/No. Staff code 3.

Was there a fourth staff member? Yes/No. Staff code 4.

Was there a fifth staff member? Yes/No. Staff code 5.

Was there a sixth staff member? Yes/No. Staff code 6. 


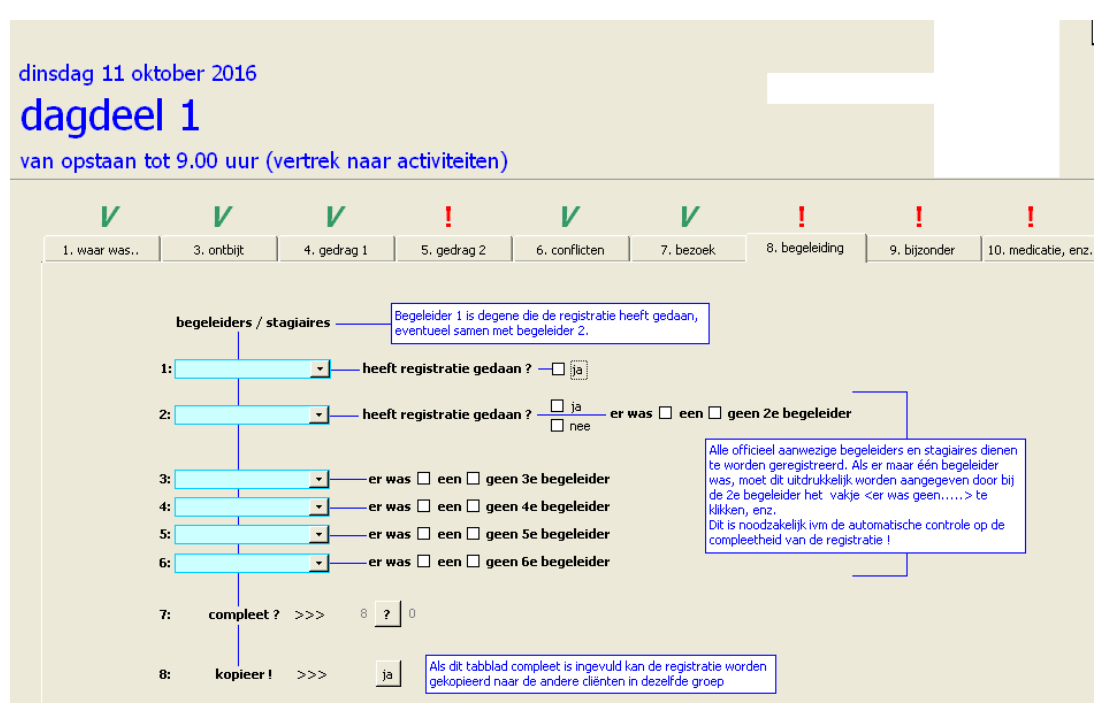

Figure 5.4 Presence of staff 


\section{Medication (Chapers 0, 1, 2 and 3)}

Has standard medication been given? Options: There has been an error; Standard medication; First time according a new standard; No medication (If standard).

Was medication being given occasionally? No/Yes, see report.

Were there unusual physical problems that you think might have had an effect on the participant? No/Yes: See report.

Menstruation. Yes/No. For male participants choose "Not Applicable".

In this screen medication, physical condition and the "feel-good" scale are recorded.

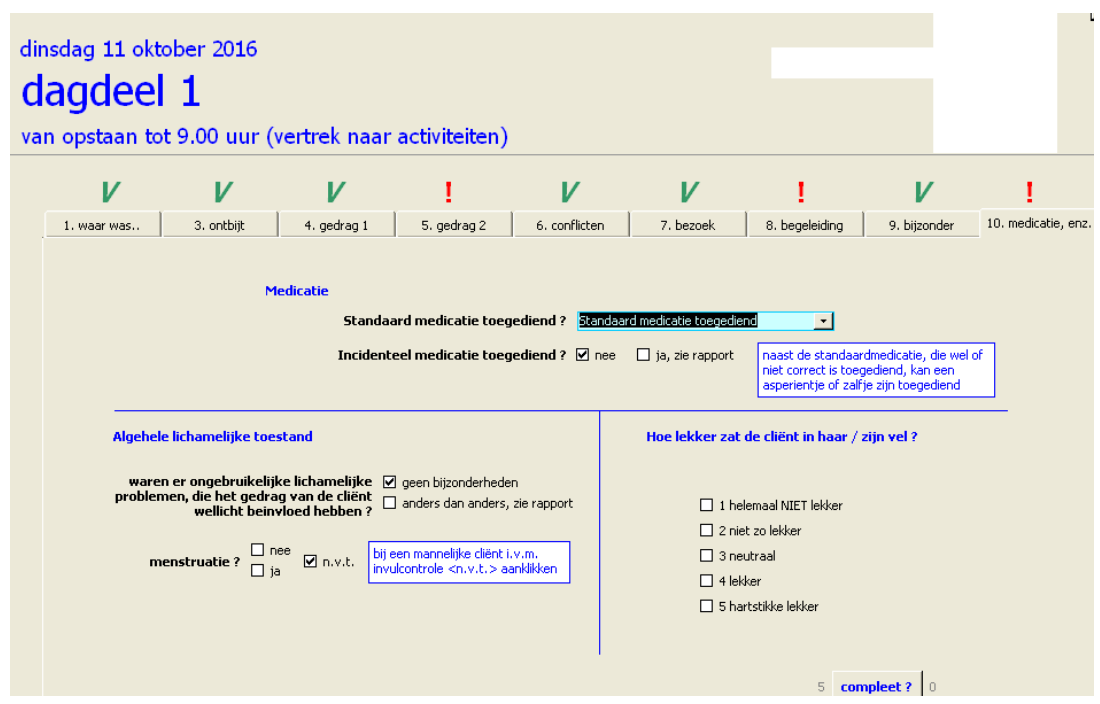

Figure 5.5 Screen medication and physical health 
Conflict with others and Conflicts between others (Chapers 1, 2 and 3)

Participant with another participant. If yes, whom with? Duration ( $<10$ minutes, 10-60 minutes, $>60$ minutes.)

Participant with staff. If yes, whom with? Duration ( $<10$ minutes, 10-60 minutes, $>60$ minutes.)

Between other participants. If yes, between which two? Duration $(<10$ minutes, $10-$ 60 minutes, $>60$ minutes.)

Between another participant and staff. If yes, between whom? Duration $(<10$ minutes, $10-60$ minutes, $>60$ minutes.)

Between staff: If yes, between whom? Duration ( $<10$ minutes, $10-60$ minutes, $>60$ minutes.)

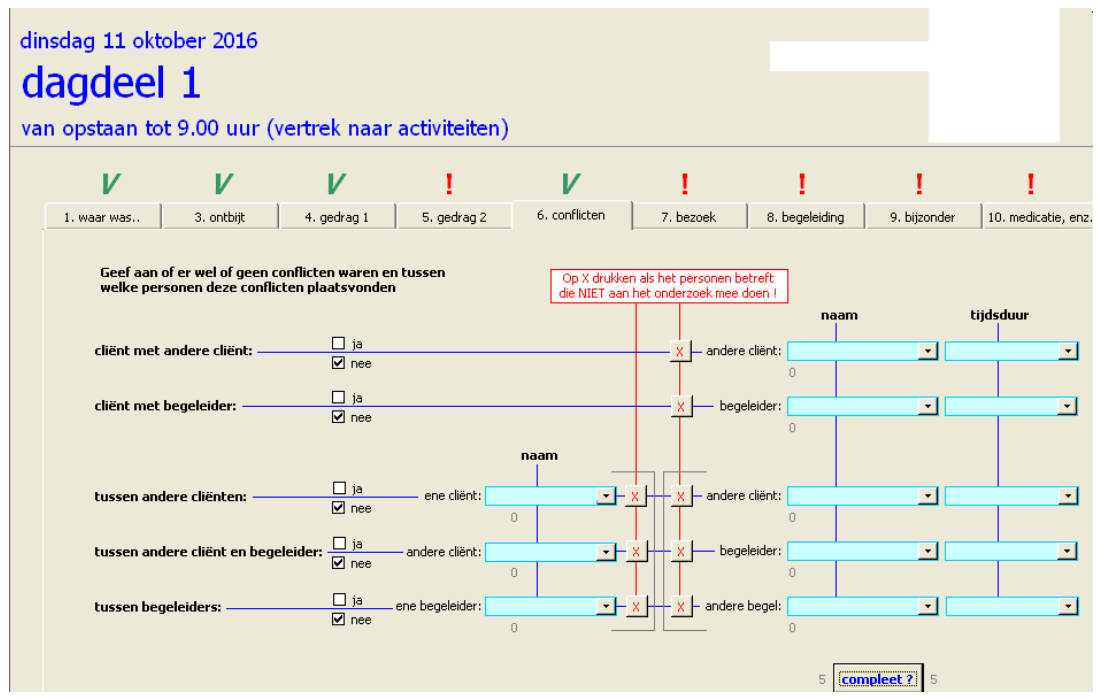

Figure 5.6 Screen for conflicts 


\section{Visit (Chapers 1, 2 and 3)}

Were there any visitors? If yes, who?

Options: Parents, father, mother, sister, brother, family group, another relative, group of relatives, volunteer, friend (male), friend (female).

Was this visit announced? Yes/No.

Was there a visit from an outsider? If yes, whom?

Options: Family doctor, workmen, fire brigade, police, staff colleague, others.

Was this visit announced? Yes/No.

Did other participants have visitors?

Was this told to the participant?

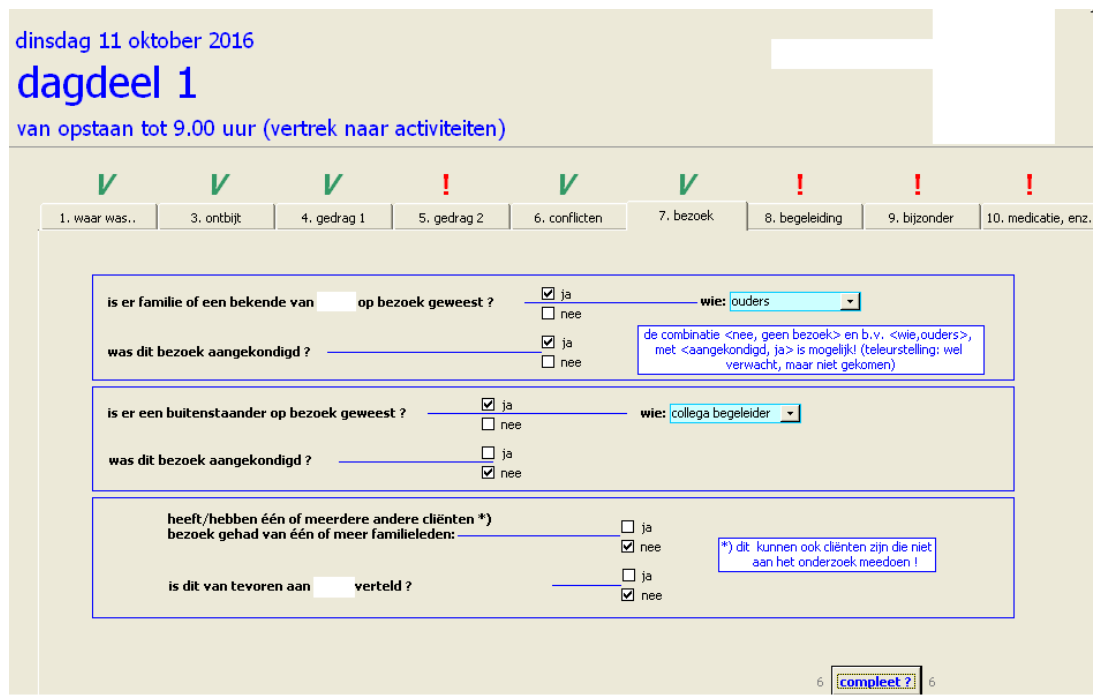

Figure 5.7 Screen for visits 


\section{Nutrition}

To establish which items of nutrition we could include in our research, we took the year-menu of Weerklank, the residential home where most of the participants live, as a starting point. A dietician specialised in nutrition for people with ID (C.M. Holsnijders) was asked to complete the list with possible items. Not just the nutrition, but especially in dinner, the method of preparation was included as a possible factor as well.

\section{Breakfast (Chapter 1)}

$1^{\text {st }}, 2^{\text {nd }}, 3^{\text {rd }}$ and $4^{\text {th }}$ Primary bread or bread substitutes

$1^{\text {st }}, 2^{\text {nd }}, 3^{\text {rd }}$ and $4^{\text {th }}$ Topping

$1^{\text {st }}, 2^{\text {nd }}$ and $3^{\text {rd }}$ Drinks

Options Primary bread or bread substitutes: none, biscuit or rusk, brown bread, wholewheat bread, white bread, cracker, muesli, gingerbread, oatmeal, yoghurt.

Options Topping: none, chocolate spread, fried egg, boiled egg, cheese, muesli, peanut butter, sandwich spread, salad, meat products, jam/marmalade.

Options Drinks: none, beer, chocolate milk, cola, buttermilk, coffee, tea, lemonade or other soft drink, milk, fruit juice, water, yoghurt drink.

Amount: Not applicable, small, normal, large portion

Speed: Not applicable, slow, normal, fast

(In relation to what is common for the participant)

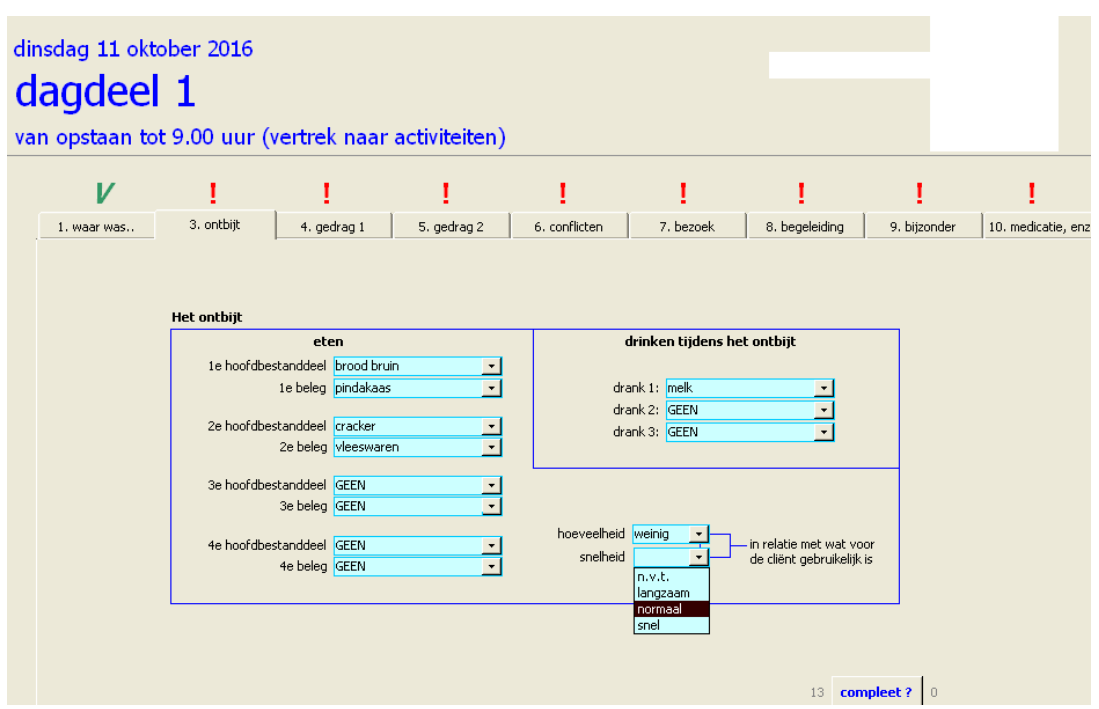

Figure 5.8 Screen for breakfast 


\section{Break before lunch (Chapter 2)}

1st and $2^{\text {nd }}$ Snack

Options: none, plain crisps, spicy crisps, chocolate, fruit, biscuit, nuts, sweets, soup, pie, savoury biscuits, peanuts, other.

$1^{\text {st }}, 2^{\text {nd }}$ and $3^{\text {rd }}$ Drinks

Options: none, beer, chocolate milk, cola, buttermilk, coffee, tea, lemonade or other soft drink, milk, fruit juice, water, yoghurt drink.

\section{Lunch (Chapter 2)}

$1^{\text {st }}, 2^{\text {nd }}, 3^{\text {rd }}$ and $4^{\text {th }}$ Primary bread or bread substitutes

$1^{\text {st }}, 2^{\text {nd }}, 3^{\text {rd }}$ and $4^{\text {th }}$ Topping

$1^{\text {st }}, 2^{\text {nd }}$ and $3^{\text {rd }}$ Drinks

Options Primary bread or bread substitutes: none, biscuit or rusk, brown bread, wholewheat bread, white bread, cracker, muesli, gingerbread, oatmeal, yoghurt.

Options Topping: none, chocolate spread, fried egg, boiled egg, cheese, muesli, peanut butter, sandwich spread, salad, meat products, jam/marmalade.

Options Drinks: None, beer, chocolate milk, cola, buttermilk, coffee, tea, lemonade or other soft drink, milk, fruit juice, water, yoghurt drink.

Amount: Not applicable, small, normal, large portion

Speed: Not applicable, slow, normal, fast

(In relation to what is common for the participant)

\section{Break after lunch (Chapter 2)}

1st and $2^{\text {nd }}$ Snack

Options: none, plain crisps, spicy crisps, chocolate, fruit, biscuit, nuts, sweets, soup, pie, savoury biscuits, peanuts, other.

$1^{\text {st }}, 2^{\text {nd }}$ and $3^{\text {rd }}$ Drinks

Options: none, beer, chocolate milk, cola, buttermilk, coffee, tea, lemonade or other soft drink, milk, fruit juice, water, yoghurt drink. 


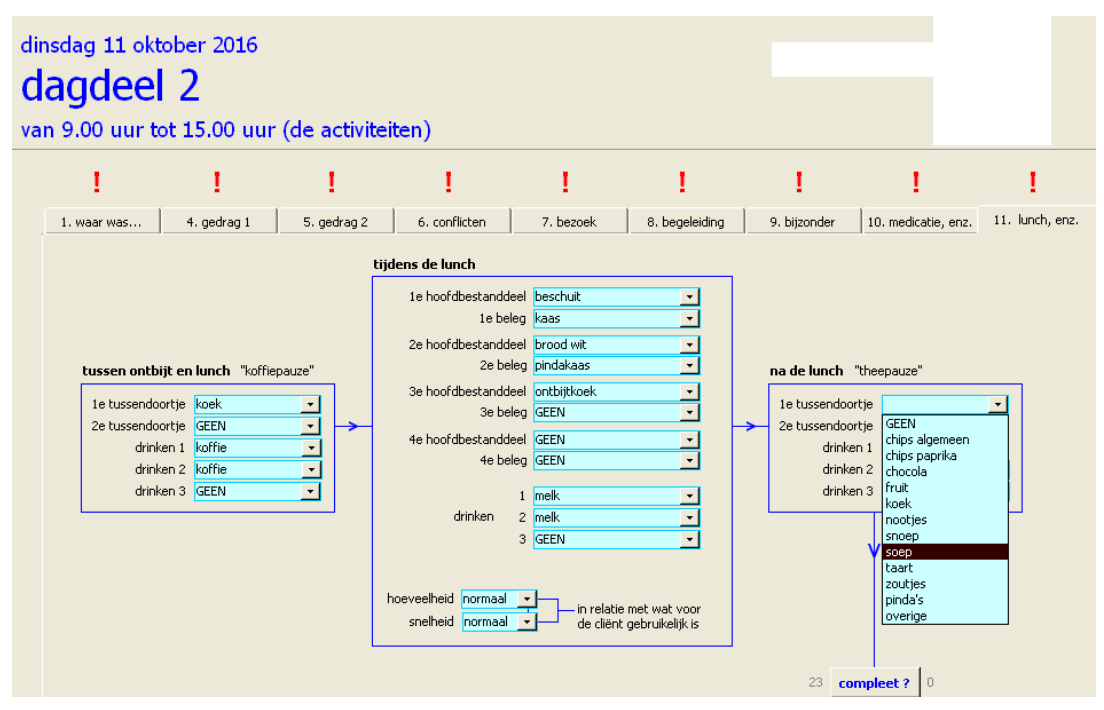

Figure 5.9 Screen for break before lunch, lunch and break after lunch

\section{Dinner (Chapter 3)}

\section{$1^{\text {st }}$ and $2^{\text {nd }}$ Meat/fish/vegetarian}

Options: none, egg, cod, turkey, chicken, prawn crackers, lamb, horse, mushrooms, beef, crustaceans, soya product, tofu, tuna, pork, stew.

Method of preparation

Options: none, Fried, roasted, deep fried, grilled, boiled, battered/crumbed, smoked, stewed.

Sauce

Options: none, gravy, curry, herbal, mustard, pepper, spicy peanut, cream, sherry, soya, tomato, fruit.

$1^{\text {st }}$ and $2^{\text {nd }}$ Starch products

Options: none, potato, white beans, brown beans, bread, pancakes, pasta, pastry crust, ravioli, white rice, wholemeal rice, rye bread.

Method of preparation

Options: none, fried, deep fried, boiled, mashed.

Sauce

Options: none, bechamel, egg, mayonaise, milk/butter, tomato.

$1^{\text {st }}, 2^{\text {nd }}, 3^{\text {rd }}$ and $4^{\text {th }}$ Vegetables

Options: none, endive, apple sauce, asparagus, Indonesian pickle, aubergine, beetroot, celery, cauliflower, kale, broccoli, Chinese vegetables, courgette, peas, Indonesian style 
vegetables, mixed vegetables, garlic, sweetcorn, red pepper, leek, cole slaw, red cabbage, salsify, lettuce, sliced beans, green beans, spinach, Chinese cabbage, mushy peas, Brussel sprouts, bamboo sprouts, tomato, broad beans, onions, chicory, white cabbage, carrots, sauerkraut.

\section{Method of preparation}

Options: none, deep-fried, grilled, boiled, battered/crumbed, stir-fried, soup, stewed.

Sauce

Options: Bechamel, butter, salad dressing, peanut, sambal, sherry.

$1^{\text {st }}, 2^{\text {nd }}$ and $3^{\text {rd }}$ Drinks

Options: none, beer, chocolate milk, cola, buttermilk, coffee, tea, lemonade or other softdrinks, milk, fruit juice, water, yoghurt drink.

$1^{\text {st }}$ and $2^{\text {nd }}$ Dessert

1. Options sweet: None, yoghurt, vanilla pudding, chocolate pudding, sweet oatmeal, ice cream.

2. Options fruit: none, apple, banana, grapes, cherries, kiwi, mandarin, orange, pear, peach.

Amount: Not applicable, small/normal/large portion.

Speed: Not applicable, slow/normal/fast

(in relation to what is common for the participant)

\section{Evening break (Chapter 3)}

$1^{\text {st }}, 2^{\text {nd }}$ and $3^{\text {rd }}$ Drinks

Options: none, beer, chocolate milk, cola, buttermilk, coffee, tea, lemonade or other soft drink, milk, fruit juice, water, yoghurt drink.

$1^{\text {st }}$ and $2^{\text {nd }}$ Evening snacks

Options: none, plain crisps, spicy crisps, chocolate, fruit, biscuit, nuts, sweets, soup, pie, savoury biscuits, other.

Speed: Not applicable, slow/normal/fast 


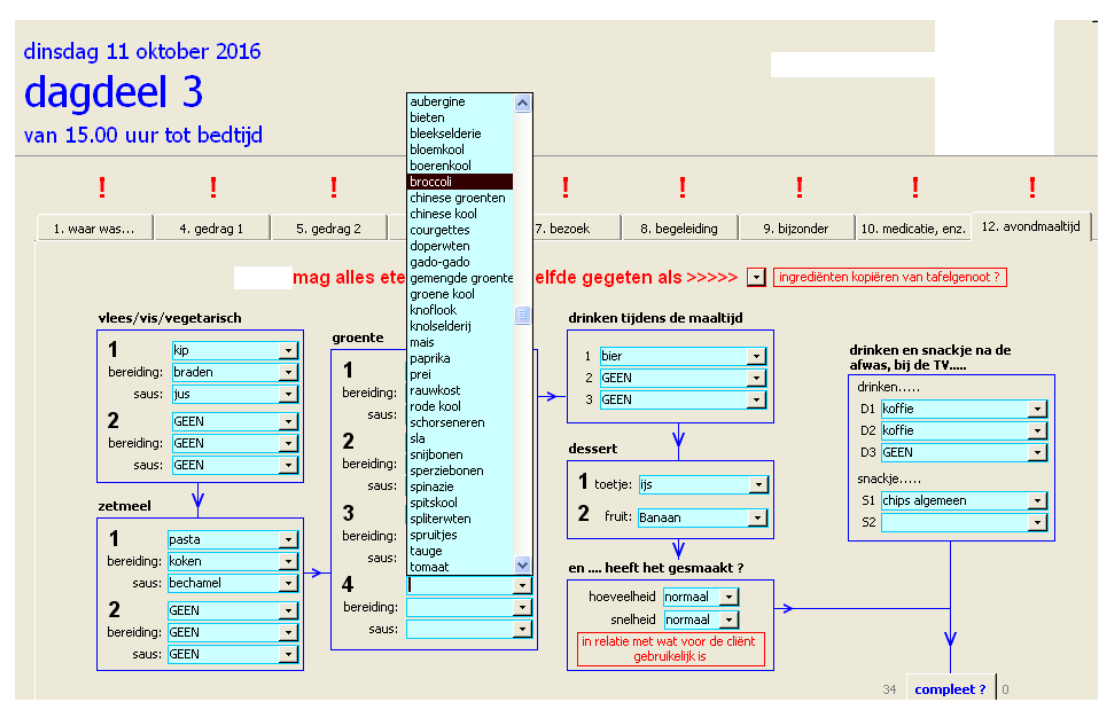

Figure 5.10 Screen for dinner and evening-break

Changes in daily routine (Chapters 1, 2 and 3)

Choice between Yes/No for:

Accident indoors

Accident outdoors

Noise

Alarm went off in another group

Alarm went off in own group

Birthday

Other unexpected occurrences 


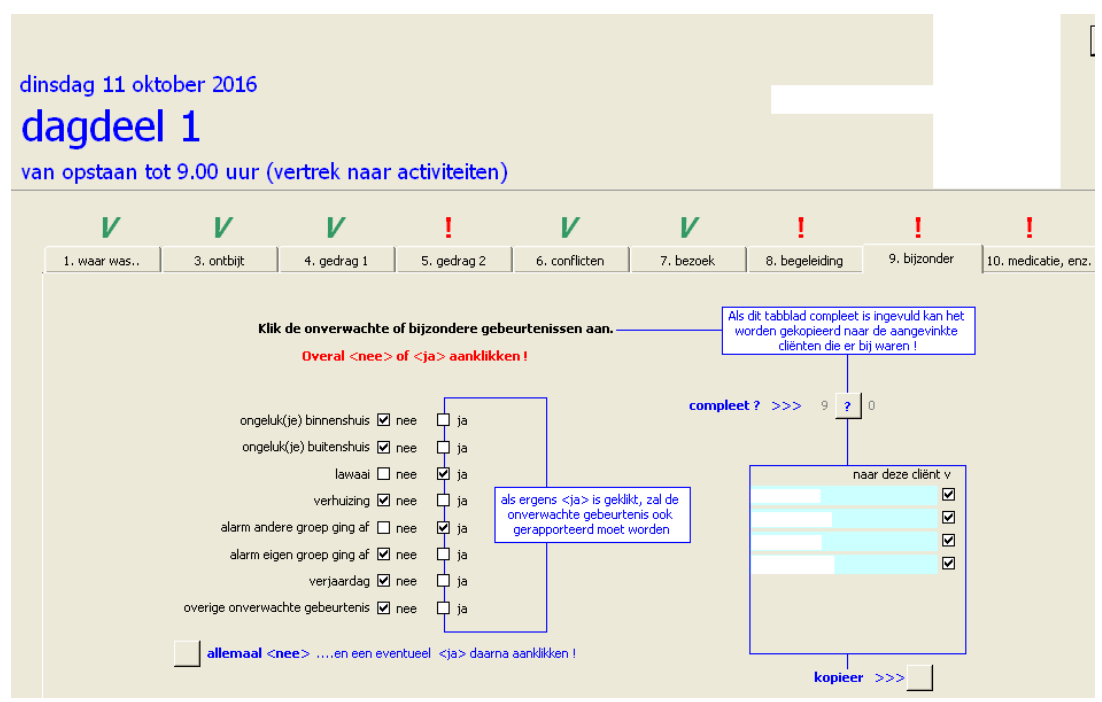

Figure 5.11 Screen for changes in daily routine or "unexpected" events

\section{Operationalisation behaviour (Chapters 1, 2 and 3)}

Two scales were presented. The first scale is according tot he IBORS-method. In the second scale behaviour is defined as "school-results".

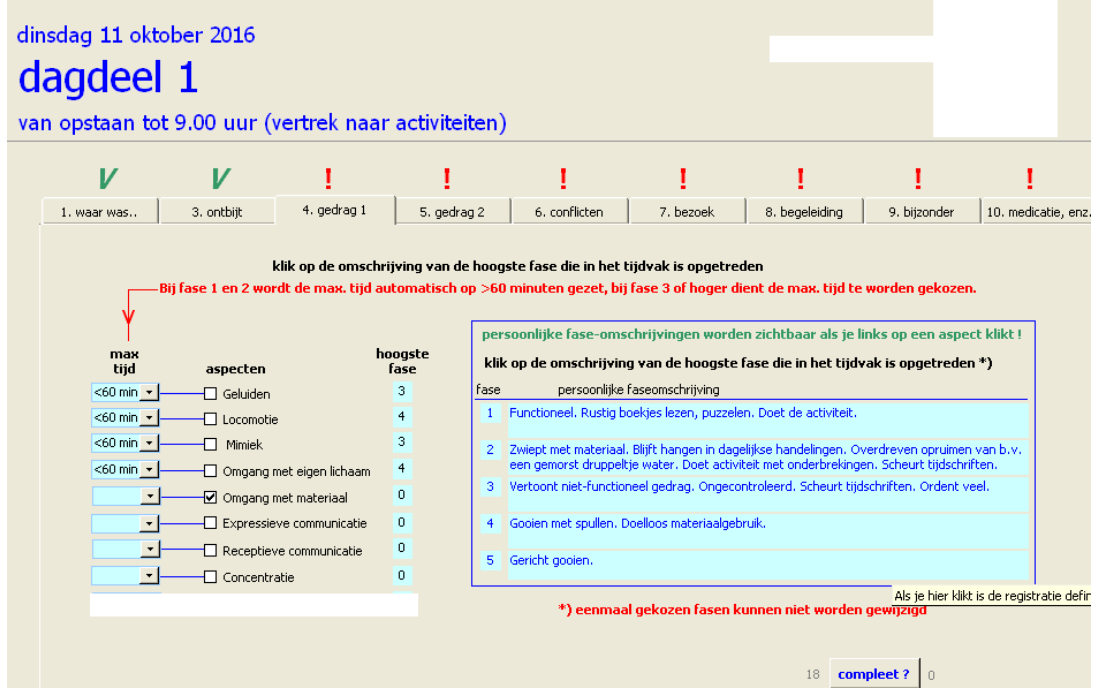

Figure 5.12 Screen for IBORS 
A second scale, for "school-results" was introduced:

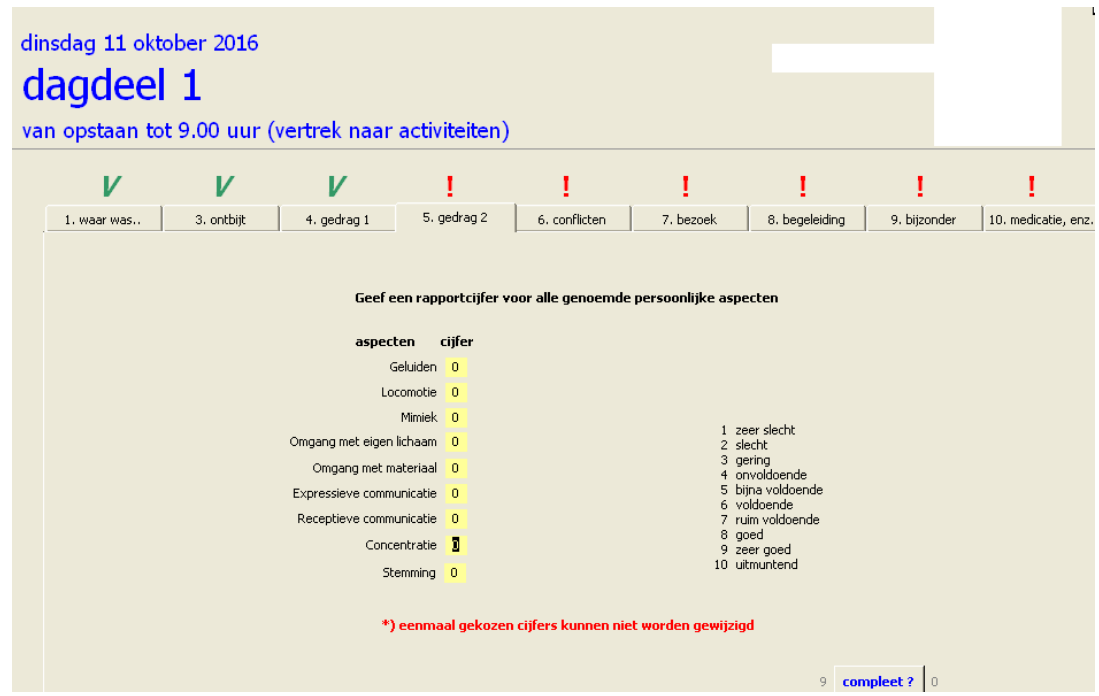

Figure 5.13

Screen for "school-results" 


\section{Chapter 6}

THE NATURE AND RATE OF BEHAVIOUR THAT

CHALLENGES IN INDIVIDUALS WITH INTELLECTUAL

DISABILITIES WHO HAVE HEARING

IMPAIRMENTS/DEAFNESS

$(I D-H I / D)$

\section{(A LONGITUDINAL PROSPECTIVE COHORT SURVEY)}

Willem Meindert Buskermolen ${ }^{1}$, Joop Hoekman ${ }^{2}$ and Albert Pierre Aldenkamp ${ }^{3}$

1. Kentalis - Weerklank Amsterdam; the Netherlands

2. Leiden University; University of Applied Sciences Leiden; the Netherlands

3. Maastricht University; Kempenhaeghe, Heeze; the Netherlands

Accepted for publication in British Journal of Learning Disabilities 


\section{Accessible summary}

1. Behaviour that Challenges amongst people with both an intellectual disability (ID) and hearing impairment or deafness (HI/D) is common. The aim of our study was to identify factors influencing behaviour (that challenges).

2. We used the Individual Behaviour and Observation Recording Scale (IBORS) to observe and rate behaviour during a period of one year. In this article we focus on possible relationships between internal factors and behaviour that challenges.

3. We found that social independence, delay of communication, and comorbidity of an autism spectrum disorder (ASD) are possible important risk factors in developing behaviour that challenges.

4. This is important because in clinical practice, we should focus on daily care. Training should be aimed at stimulating social independence and communication skills. Individual training programs aimed at these skills are therefore essential.

\section{Abstract}

Background and objective

In this article, we describe our study of the prevalence of behaviour that challenges and which internal factors are related to behaviour that challenges in 21 people (fourteen are male, seven are female, varying in age from 12.4 to 42 years; mean 26.6, SD 7.27) with intellectual disabilities who have hearing impairments.

Method and results

Data were obtained by recording behaviour on a daily basis during one year using the 'Individual Behaviour Observation and Recording Scale' that was developed especially for this study. It was found that $100 \%$ of the participants in this study showed behaviour that challenges, although this was not observed every day in each participant. Prevalence rates during a year varied from $1.8 \%$ to $77.3 \%$. On average, the prevalence rate was $28.9 \%$. We found a significantly negative correlation between behaviour that challenges and delay of communication as well as the level of social independence. We also found that in people with autism spectrum disorder, the prevalence of behaviour that challenges was significantly higher than in people without autism spectrum disorder. The level of intellectual disability as well as the level of hearing impairments was not related to the prevalence of behaviour that challenges.

\section{Conclusion}

Because there are several patterns of increasing and decreasing behaviour that challenges throughout the day, it is not possible to draw one conclusion on this issue for the whole group. However, where certain individual patterns can be recognised, it is possible to make individual plans for the participants. This could mean an improvement in daily care and as a result an improvement in the quality of life for people with intellectual disability who have hearing impairments. Implications for clinical practice are discussed. 


\section{Introduction}

In clinical practice, professionals working with people with both an intellectual disability (ID) and hearing impairments or deafness (HI/D) are frequently confronted with aggressive incidents such as destructive behaviour aimed at objects or other people and self-harming behaviour (Nijhof \& Van Overveld, 2005). Buskermolen, Hoekman \& Aldenkamp (2012) reported that much research has been done in different aspects in the care of people with ID and in those with HI/D. However, little research has been found to date on the prevalence of behavioural problems in people with a combination of both disabilities. One exception is the study of Timehin and Timehin (2004). They reported that of 543 people with both ID and HI/D, 62\% showed problem behaviour and $34 \%$ exhibited self-harming behaviour.

Behavioural problems frequently occur in people with an intellectual disability (ID) (Deb, Thomas \& Bright, 2001; Molteno, Molteno, Finchilescu \& Dawes, 2001; Emerson et al., 2001; Tyrer et al., 2006; Crocker et al., 2006; Holden \& Gitlesen, 2006). In these studies, prevalence rates varied widely, from less than $10 \%$ to over $40 \%$, depending on the definition and terminology indicating behavioural problems, the type and age of the participants, the data collection methodology, and the psychiatric measures. Several risk factors for behavioural problems were mentioned. In some studies, a gender effect was found. In general, males showed more behavioural problems (McClintock, Hall \& Oliver, 2003; Tyrer et al., 2006). Deb, Thomas \& Bright (2001), on the contrary, found that the rate of self-harming behaviour was significantly associated with the female gender. Emerson et al. (2001) and Tyrer et al. (2006) reported an age effect: young adults and adolescents showed more behavioural problems. The severity of the ID was also mentioned as a risk factor (e.g. Molteno, Molteno, Finchilescu \& Dawes, 2001; Tyrer et al., 2006). Additional problems such as sensory impairments (Besag, 2003; Dekker \& Koot, 2003) and autism (e.g. Matson, Boisjoli \& Mahan, 2009), were also established as risk factors, although Tyrer et al. (2006) question the relationship between aggression and autism. Chadwick et al. (2000), and Emerson et al. (2001) found a higher prevalence of behavioural problems when people were more limited in their daily skills, such as eating and dressing. Crockett \& Hagopian (2006) found an increase in behavioural problems when people were challenged by demanding situations. Communication was often mentioned as a risk factor. This was concluded in several meta analyses (e.g. Sigafoos, 2000; Emerson et al., 2001; Besag, 2003) and in several case studies (e.g. Frea, Arnold \& Vittimberga, 2001; Durand \& Merges, 2001).

For people with $\mathrm{HI} / \mathrm{D}$, similar findings for the prevalence and range of behavioural problems were reported (e.g. Van Eldik, Treffers, Veerman \& Verhulst, 2004; Van Gent, Goedhart, Hindley, \& Treffers, 2007). As in studies of people with ID, differences in the terminology indicating behavioural problems, type and age of the population, the 
methods of data collection used, and the psychiatric measuring instrument varied. In studies of people with $\mathrm{HI} / \mathrm{D}$, behavioural problems were defined in a more general way than in studies of people with ID. The most important reason for this seems to be the use of only two diagnostic instruments.

Several risk factors for developing behavioural problems in people with HI/D were mentioned as well. Sinkkonen (1994) found that children with HI/D with additional handicaps showed more behaviour that challenges. Van Eldik et al. (2004) found an increase of behavioural problems in people with HI/D who also had intellectual disabilities. Sarimski (2007) concluded that it is very difficult to differentiate between several risk factors for mental health disorders among children and youth with hearing disorders, blindness, physical handicaps or intellectual disabilities. Additional possible risk factors included issues in the development of social competence and social participation as well as problems in parent-child relations. Vernon \& Greenberg (1999) and Miller \& Vernon (2003) studied the relationship between hearing loss and violence; they discovered that people with HI/D were overrepresented in the prison population. They hypothesized that ID, communication disorders, and un- and underemployment in people with HI/D creates frustration, which tends to manifest itself in disproportionate aggression. Cappelli et al. (1995) found that children with HI/D who were integrated into regular classrooms were more likely to be rejected by their peers than were children with normal hearing. This was caused by a reduced amount of competence in social skills in children with HI/D. Vostanis, Hayes, Du Feu \& Warren (1997) found that the use of speech additional to sign language had a positive effect on social skills for adolescents with HI/D. However, Brubaker \& Szakowski (2000) concluded in their study on the relation between parenting practice and behavioural problems that there was no evidence that the greater prevalence of behavioural problems among deaf children was a result of inadequate parenting.

Clearly, risk factors contribute to, and can give comprehension and understanding of the development of behavioural problems. Although recognizing risk factors can contribute to the understanding of behavioural problems, empirical research is needed into the relationships between behaviour and several external factors. When behavioural problems occur following specific external events, this could be an indication that this behaviour might be caused by these factors. Unfortunately, there are no known studies in which the relationship between specific internal and/or external risk factors and behaviour in people with both ID and HI/D can be clearly demonstrated. This article will consider the possible internal factors. External factors will be discussed in a later publication. 
Our research questions were:

1. What is the prevalence of behaviour that challenges in people with ID who have $\mathrm{HI} / \mathrm{D}$ ?

2. Which internal factors are related to behaviour that challenges in people with ID who have HI/D?

\section{Materials and methods}

\section{Participants}

The study comprised 21 individuals with ID who have HI/D. They were residents of three different homes for people with ID who have HI/D, situated in the province of North Holland in The Netherlands. A data and safety monitoring board supervised study progress and outcomes. Written and informed consent was obtained from the legal guardians of all participants enrolled in the study, in accordance with the 1975 Declaration of Helsinki, as revised in 2013. The daily routine of the participants was not influenced in any way as a result of their participation in the study, since only observation and recording by staff members of daily behaviour was done. All participants were involved in a daily work or activity program. Fourteen were male, seven were female, varying in age from 12.4 to 42 years (mean 26.6, sd 7.27). The level of ID was measured by the Vineland Adaptive Behaviour Scale (De Bildt \& Krayer, 2003), the Snijders Oomen Non-Verbal Intelligence Test 2 1/2 - 7 (Tellegen, Winkel, Wijnberg-Williams, \& Laros, 1998), or the Snijders Oomen Non-Verbal Intelligence Test $51 / 2-16$ (Snijders, Tellegen \& Laros, 1988). Using the first tests, it was not possible to calculate an IQ; therefore, it was decided to indicate the cognitive level in developmental age. This was possible with all three of the above-mentioned tests. The cognitive level varied from one year and three months $(1 ; 3)$ to eight years and one month $(8 ; 1)$ (mean 4.11, sd 2.4). The severity of HI/D was measured through "free field audiometry" or "pure tone-audiometry", which was done by an audiological centre that specializes in assessments of people with ID and HI/D. In our study, we used the Fletcher Index (Fletcher, 1929), the standard method of measuring hearing loss since 1929. The Fletcher Index measurements for our participants varied from 40 to 110 decibels. The origin of the deafness and intellectual disabilities was unknown for most of the participants, so we decided not to consider this as an internal factor. Ten participants were diagnosed with Autism Spectrum Disorder (ASD) after extensive diagnostic testing using DSM IV, by clinical psychiatrists specialized in patients with both ID and HI/D. The level of social independence was determined using the Sociale Redzaamheidsschaal voor Zwakzinnigen (Social Developmental Level Scale for People with ID) (Krayer \& Kema, 1994). The scale consisted of nine levels. The total score for this scale is based upon scales of Independence, Ability to Focus on Tasks, Social 
Abilities, and Communication. The scale was completed by the clinician together with the patient's personal counselor. The delay of communicative development was determined using the Communicatie Profiel voor Zwakzinnigen (Communication Profile for People with ID) (Willems \& Verpoorten, 1994). This is a 10-point scale based on receptive non-vocal, receptive vocal, expressive non-vocal, and expressive vocal scores. This scale was also completed by the clinician and the personal counselor.

\section{Method}

Staff members were asked to record the participants' behaviour at the end of their shift. In order to gain insight into the relationship between behaviour and external factors, it was necessary to use an instrument that can measure specific individuallydefined behaviour, as well as an instrument that can measure descriptions of circumstances in which this behaviour occurred. Buskermolen, Hoekman \& Aldenkamp (2013) studied several scales with which behaviour can be measured. They concluded that none of these were suitable for their study. Their main objection was that there was no questionnaire in which there is the opportunity for descriptions of individual behaviours. Therefore, they developed an Individual Behaviour Observation and Recording Scale (IBORS), in which they defined behavioural problems as behaviour that needs active intervention to prevent further escalation. They therefore agreed with Emerson et al. (2001) and Holden \& Gitlesen (2006) in the use of the term "challenging behaviour" for describing behavioural problems. We used instead the term behaviour that challenges, because this term focuses on staff and reflects the need to intervene if necessary. We used IBORS in this article to measure the frequency of behaviour that challenges in individuals with both ID and HI/D. IBORS contains forty unique behavioural descriptions. For each individual participating in the study, eight generally accepted dimensions of behaviour (making sounds, facial expression, locomotion, body manipulation, object manipulation, concentration, receptive communication, and expressive communication) were combined with five levels of severity (relaxation, restlessness, tension, threat, and loss of control). Behaviour at level three or higher requires active intervention by staff. Therefore, behaviour representing level three (tension) or higher was defined as behaviour that challenges. A study of inter-rater reliability of the IBORS was carried out (Buskermolen, Hoekman \& Aldenkamp, 2014, submitted). The results to date have been promising.

\section{Recording procedure}

Prior to the study recording period, staff were trained to observe and record behaviour of all participants by discussing and refining all behavioural descriptions to try to maximise agreement. They were instructed to score the highest behavioural level they observed during their shift. It was impossible to see previous records for purposes of reliability. Recording of IBORS-scores was done digitally using a Microsoft Access 
software program, developed for this study (Buskermolen, Holsnijders, Hoekman \& Aldenkamp, 2015, submitted).

Each record consisted of behavioural scores in accordance with the IBORS method as described above. Staff recorded behaviour three times per day (at 09.00, 15.00, and $22.00 \mathrm{hrs}$ ) at the end of their shift. The first and third records were made by staff in the homes, while the second record was made by either staff at the work or daily activity centre or staff in the homes. During weekends, only two recording sessions per day were carried out (at 14.00 and 22.00 hrs), both because shifts began later in the morning and since there was no work or activity program. When the participant was not present due to holidays or during a stay with parents or family, no records were made. The recording period was for one year, which resulted in a maximum of 988 records per person.

\section{Results}

The total amount of records of the behaviour (and the percentage) per participant is presented in Table 6.1. For the 21 participants in our study, a total of 11,961 recordings were made. This indicates a response of $59 \%$. The response for shift 1 was $48 \%$, for shift 2 it was $46 \%$, and for shift 3 it was $62 \%$.

\begin{tabular}{|c|c|c|c|c|c|c|c|c|c|}
\hline Participant & Gender & Age (years) & Data & $\%$ & ID (years) & $\mathrm{HI}$ & ASD & SRZ & $\mathrm{CPZ}$ \\
\hline 1 & $\mathrm{M}$ & $28 ; 9$ & 752 & 76 & $2 ; 4$ & 100 & + & 3 & 3 \\
\hline 2 & $\mathrm{M}$ & $19 ; 11$ & 542 & 53 & $2 ; 6$ & 70 & - & 5 & 5 \\
\hline 3 & $M$ & $23 ; 8$ & 764 & 77 & $2 ; 3$ & 100 & + & 4 & 2 \\
\hline 4 & $\mathrm{M}$ & $21 ; 7$ & 808 & 82 & $1 ; 10$ & 100 & + & 3 & 2 \\
\hline 5 & $\mathrm{M}$ & $20 ; 9$ & 839 & 85 & $2 ; 4$ & 100 & + & 3 & 3 \\
\hline 6 & $\mathrm{M}$ & $17 ; 8$ & 513 & 52 & $5 ; 4$ & 40 & - & 4 & 5 \\
\hline 7 & $M$ & $26 ; 3$ & 212 & 21 & $2 ; 7$ & 60 & - & 6 & 6 \\
\hline 8 & $M$ & $22 ; 8$ & 537 & 59 & $4 ; 3$ & 100 & - & 8 & 7 \\
\hline 9 & $\mathrm{~F}$ & $23 ; 9$ & 718 & 74 & $4 ; 0$ & 90 & + & 2 & 4 \\
\hline 10 & $\mathrm{M}$ & $22 ; 7$ & 647 & 65 & $1 ; 10$ & 110 & + & 4 & 2 \\
\hline 11 & $\mathrm{M}$ & $28 ; 5$ & 586 & 59 & $1 ; 3$ & 100 & - & 2 & 2 \\
\hline 12 & $\mathrm{M}$ & $29 ; 2$ & 236 & 24 & $7 ; 8$ & 80 & + & 6 & 8 \\
\hline 13 & $\mathrm{M}$ & $34 ; 5$ & 688 & 76 & $7 ; 4$ & 100 & - & 9 & 8 \\
\hline 14 & $\mathrm{~F}$ & $34 ; 4$ & 458 & 46 & $8 ; 1$ & 90 & + & 9 & 9 \\
\hline 15 & $\mathrm{~F}$ & $39 ; 8$ & 642 & 71 & $3 ; 4$ & 110 & - & 8 & 6 \\
\hline 16 & $M$ & $31 ; 8$ & 363 & 37 & $7 ; 2$ & 90 & + & 9 & 9 \\
\hline 17 & $\mathrm{~F}$ & $32 ; 1$ & 418 & 42 & $7 ; 0$ & 70 & - & 9 & 9 \\
\hline 18 & $\mathrm{~F}$ & $42 ; 6$ & 660 & 73 & $7 ; 4$ & 70 & - & 7 & 8 \\
\hline 19 & $\mathrm{~F}$ & $12 ; 11$ & 664 & 67 & $4 ; 0$ & 40 & + & 3 & 3 \\
\hline 20 & $M$ & $18 ; 8$ & 602 & 61 & $1 ; 3$ & 60 & - & 1 & 2 \\
\hline 21 & $\mathrm{~F}$ & $24 ; 9$ & 312 & 31 & $3 ; 3$ & 90 & - & 4 & 4 \\
\hline Av: & & $26 ; 6$ & 570 & 59 & $4 ; 11$ & 84 & & & \\
\hline
\end{tabular}

Data represent: \%: Recording respons; ID: Level of cognitive development; HI: Fletcher-index; ASD: Comorbidity of ASD; SRZ: Level of social independence; CPZ: Level of communication. 
Table 6.2 represents percentages of behaviour that challenges (levels 3, 4, and 5 together). The results in this table show that all participants exhibited behaviour that challenges, varying from $1.8 \%$ of the time (subject 8 ) to $75.4 \%$ of the time (subject 19 ). The average percentage was $28.9 \%$.

Table 6.2 Challenging behaviour (Level 3-4-5) Percentage

\begin{tabular}{|c|c|c|c|c|}
\hline Partic & Shift 1 & Shift 2 & Shift 3 & Overall \\
\hline 1 & 16.7 & 37.3 & 30.7 & 29.8 \\
\hline 2 & 1.8 & 11.1 & 1.0 & 3.9 \\
\hline 3 & 12,7 & 25.0 & 29.5 & 23.4 \\
\hline 4 & 36.9 & 59.5 & 74.9 & 60.7 \\
\hline 5 & 28.2 & 38.9 & 56.4 & 43.0 \\
\hline 6 & 17.5 & 22.2 & 44 & 30.3 \\
\hline 7 & 7.0 & 16.2 & 16.9 & 14.6 \\
\hline 8 & 1.9 & 1.8 & 1.8 & 1.8 \\
\hline 9 & 59.2 & 69.1 & 69.1 & 66.4 \\
\hline 10 & 36.8 & 45.7 & 49.0 & 43.4 \\
\hline 11 & 4.8 & 8.7 & 3.6 & 5.5 \\
\hline 12 & 25.0 & 86.5 & 44.6 & 68.6 \\
\hline 13 & 2.2 & 13.8 & 4.9 & 6.4 \\
\hline 14 & 8.2 & 3.7 & 8.8 & 7.4 \\
\hline 15 & 3.5 & 8.6 & 8.3 & 6.9 \\
\hline 16 & 0 & 1.1 & 6.5 & 3.0 \\
\hline 17 & 3.0 & 1.1 & 11.9 & 6.9 \\
\hline 18 & 11.7 & 39.4 & 29.4 & 26.1 \\
\hline 19 & 71.8 & 78.1 & 77.6 & 75.4 \\
\hline 20 & 6.6 & 30.6 & 26.5 & 21.4 \\
\hline \multirow[t]{2}{*}{21} & 4.2 & 11.7 & 22.4 & 12.8 \\
\hline & & & & 28.9 \\
\hline
\end{tabular}

Data are presented in percentages

No significant difference in the prevalence of behaviour that challenges was found between the three shifts (see Table 6.3).

Table 6.3 Difference between shifts (Independent Samples Test)

\begin{tabular}{lrrr}
\hline & $\mathrm{t}$ & $\mathrm{df}$ & $\mathrm{p}$ \\
\hline Shift 1-2 & -1.889 & 40 & .066 \\
Shift 1-3 & -1.711 & 40 & .095 \\
Shift 2-3 & .194 & 40 & .847 \\
\hline
\end{tabular}

Using Pearson's $r$ (Field, 2009), a significant negative correlation between behaviour that challenges and age, level of social independence (SRZ), and delay of communicative development (CPZ) was found (see Table 6.4). In other words, a higher age, a higher degree of social independence, and a higher level of communicative 
development appear to correspond to a lower prevalence of behaviour that challenges. Using the Independent Samples Test (Field, 2009), the occurrence of ASD showed a significant difference: people with ASD showed more behaviour that challenges. The level of ID as well as the level of HI/D was not related to the prevalence of behaviour that challenges (see Table 6.4). Gender differences were not found (See Table 6.5).

Table 6.4 Correlations between challenging behaviour and internal variables

\begin{tabular}{lcc}
\hline & Pearsons $r$ & $p$ \\
\hline Age & $-.44^{*}$ & .04 \\
ID & .30 & .18 \\
HI & .20 & .38 \\
SRZ & $-.44^{*}$ & .04 \\
CPZ & $-.59^{*}$ & .01 \\
\hline
\end{tabular}

Table 6.5 Correlations between challenging behaviour and Gender and ASD (Independent Samples Test)

\begin{tabular}{lllc}
\hline & $\mathrm{t}$ & $\mathrm{df}$ & $\mathrm{p}$ \\
\hline Gender & -.255 & 19 & .801 \\
ASD & 3.424 & 19 & $.003^{*}$ \\
\hline
\end{tabular}

\section{Discussion}

In this paper we described a study of the nature and rate of behaviour that challenges in people with ID who have HI/D. The behaviour of 21 people with ID who have HI/D was monitored and recorded over a period of one year using IBORS.

Our first research question was: "What is the prevalence of behaviour that challenges in people with ID who have HI/D?" Although behaviour that challenges was not observed every day in each subject, it was found that $100 \%$ of the participants in this study showed behaviour that challenges. The lowest prevalence during the year of the study (1.8\%) was found in a male subject (22.10 years), which meant that active intervention was only needed occasionally. The highest prevalence of behaviour that challenges during the year (75.4\%) was found in a female subject (12.11 years). On average, the prevalence rate was $28.9 \%$.

Two participants showed no difference in the frequency of behaviour that challenges throughout the day. These participants were the two extremes in frequency. Subject 8 seldom showed any behaviour that challenges at all (overall 1.8\%), and subject 19 showed the highest prevalence of behaviour that challenges (overall 75.4\%). If we consider prevalence scores further, it appears that behaviour that challenges shown in some participants varied between shifts. With our data it is impossible to draw conclusions on this issue, and therefore further research is needed. 
Our second research question was: "Which internal factors are related to behaviour that challenges in people with ID who have HI/D?" We found a significant correlation between the level of social independence (SRZ) and behaviour that challenges. In those participants with ID who have HI/D who showed more socially independent behaviour, fewer instances of behaviour that challenges were observed. This agrees with the findings of Chadwick et al. (2000) and Emerson et al. (2001), who found a higher prevalence of behavioural problems when people with ID were more limited in their daily skills, and Crockett \& Hagopian (2006), who found an increase in behavioural problems when people with ID were challenged by demanding situations. The possibility of being less dependent upon other people (staff) can be an important factor in reducing behaviour that challenges. We also found a significant correlation between delay of communication (CPZ scores) and behaviour that challenges. The likelihood of behaviour that challenges appears to increase proportionally with a decrease in communicative skills. It is plausible that adequate communication skills are an important factor in social independency.

The participants with ASD showed more behaviour that challenges than those without ASD. This was also demonstrated in previous studies (McClintock, Hall \& Oliver, 2001; Kamio, 2002; Matson, Boisjoli \& Mahan, 2009). There was also a negative and significant correlation (-0.44) between age and behaviour that challenges. It is possible that behaviour that challenges decreases as a result of aging. This result confirms research by Emerson et al. (2001) and Tyrer et al. (2006).

This study did contain a number of limitations. In the first place, only 21 participants were included. This is a small sample and probably not representative. Whilst we would have liked to have had more participants, it is very difficult to find people with ID who also have HI/D. The two institutes where our participants live are the only ones specialised in this target population in The Netherlands. A second limitation concerns the use of IBORS: although inter-rater reliability showed that the instrument was suitable for the purposes of observing and recording behaviour, further research is necessary. Thirdly, results obtained from this study do not indicate the cause of behaviour that challenges or the varying prevalence scores in the same participants during different shifts. It is therefore necessary to consider external factors that may have played a role at any given time. As mentioned in the introduction, the results of the study regarding these external factors will follow in another article.

Based on the results of our study, we will discuss possible implications for clinical practice. Firstly, in several studies on behaviour that challenges in people with either ID or $\mathrm{HI} / \mathrm{D}$, communication problems are cited as a major risk factor. The results of our study seem to confirm this. It is very likely that this risk factor plays an important role in people with ID who have HI/D and that it may increase the likelihood that behaviour that challenges occurs. Our study also indicated that there was a higher prevalence of behaviour that challenges in individuals with a lower level of social independence. Thirdly, co-morbidity with ASD is an important risk factor. It is plausible that people 
with ASD frequently exhibit communication problems. Therefore, we recommend the implementation of individual training programs aimed at stimulating and developing communication skills in people ID who have HI/D, especially when ASD is diagnosed. Daily care and training should be aimed at stimulating these skills as well.

This article is a part of a study into the reasons for an increase in behaviour that challenges in people with ID who have HI/D and the underlying causes. Although communication problems, poor social independence, and ASD seem to be major risk factors, this does not mean that the reasons for and causes of behaviour that challenges in people with ID who have HI/D are clear. We will focus on this issue in our next article. Behaviour that challenges will be studied and compared with several external factors and circumstances. 


\section{References}

Besag, F.M.C. (2003). Psychopathology in people with epilepsy and intellectual disability. Journal of Neurology, Neurosurgery and Psychiatry, 74, 1464.

Brubaker, R.G. \& Szakowski, A. (2000). Parenting practices and behaviour problems among deaf children. Child and family behaviour therapy, 22(4): 13-28.

Buskermolen, W.M., Hoekman, J. \& Aldenkamp, A.P. (2012). Risk factors leading to behavioural problems in individuals with hearing impairments and intellectual disabilities. International Journal on Mental Health and Deafness, 2(1): 33-45.

Buskermolen, W.M., Hoekman, J. \& Aldenkamp, A.P. (2013) Assessing Challenging Behaviour in People with Hearing Impairments and Profound Intellectual Disabilities: The Development of an Individual Behaviour Observation and Recording Scale. International Journal on Mental Health and Deafness, 3(1): 30-40.

Buskermolen, W.M., Hoekman, J. \& Aldenkamp, A.P. (2014) Assessing Challenging Behaviour in People with Hearing Impairments and Profound Intellectual Disabilities: The Inter-Assessor Reliability of the Individual Behaviour Observation and Recording Scale. (Submitted in International Journalon Mental Health and Deafness).

Buskermolen, W.M., Holsnijders, C.M., Hoekman, J. \& Aldenkamp, A.P. (2015) The Operationalisation of Possible External Factors influencing Challenging Behaviour in People with Hearing Impairments and Profound Intellectual Disabilities. (Submitted).

Cappelli, M., Daniels, T., Durieux-Smith, A., McGrath, P.J. \& Neuss, D. (1995). Social development of children with hearing impairments who are integrated into general education classrooms. Volta Review, 97(3): 197-208

Chadwick, O., Piroth, N., Walker, J., Bernard, S. \& Taylor, E. (2000). Factors affecting the risk of behaviour problems in children with severe intellectual disability. Journal of Intellectual Disability Research, 44(2): 108-123.

Crocker, A.G., Mercier, C., Lachapelle, Y., Brunet, A., Morin, D. \& Roy, M.E. (2006). Prevalence and types of aggressive behaviour among adults with intellectual disabilities. Journal of Intellectual Disability Research, 50(9): 652-661.

Crockett, J.L. \& Hagopian, L.P. (2006). Prompting procedures as establishing operations for escapemaintained behavior. Behavioral Intervention, 21(1): 65-71.

De Bildt, A.A. \& Kraijer, D.W. (2003). Vineland-Z: sociale redzaamheidsschaal voor kinderen en jeugdigen met een verstandelijke beperking. Handleiding. [Vineland Adaptive Behaviour Scales-Manual]. Leiden: Pits.

Deb, S., Thomas, M. \& Bright, C. (2001). Mental disorder in adults with intellectual disability. 2: The rate of behaviour disorders among a community-based population aged between 16 and 64 years. Journal of Intellectual Disability Research, 45: 506-514.

Dekker, M.C. \& Koot, H.M. (2003). DSM-IV Disorders in children with borderline to moderate intellectual disability. 1: Prevalence and Impact. Journal of the American academy of child and adolescent psychiatry, 42(8): 915-922.

Durand, V.M. \& Merges, E. (2001). Functional communication training : a contemporary behavior analytic intervention for problem behaviors. Focus on autism and other developmental disabilities, 16(2): 110119.

Emerson, E., Kiernan, C., Alborz, A., Reeves, D., Mason, H., Swarbrick, R., Mason, L. \& Hatton, C. (2001). The prevalence of challenging behaviors: A total population study. Research in developmental disabilities, 22: 77-93.

Field, A. (2009). Discovering statistics using SPSS (and sex and drugs and rock ' $n$ ' roll). London: SAGE.

Fletcher H. (1929). Speech and hearing. New York: Van Nostrand.

Frea, W.D., Arnold, C.L. \& Vittimberga, G.L. (2001). A demonstration of effects of augmentative communication on the extreme aggressive behavior of a child with autism within an integrated preschool setting. Journal of positive behavior interventions, 3(4): 194-198.

Holden, B. \& Gitlesen, J.P. (2006). A total population study of challenging behaviour in the county of Hedmark, Norway: Prevalence, and risk markers. Research in developmental disabilities, 27: 456-465. 
Kamio, Y. (2002). Self-injurious and aggressive behavior in adolescents with intellectual disabilities: A comparison of adolescents with and without autism. Japanese Journal of Special Education, 39(6): 143154.

Kraijer, D.W. \& Kema, G.N. (1994). Sociale redzaamheidsschaal voor zwakzinnigen SRZ. Handleiding [Social Self Care for People with ID-Manual.] Lisse: Swets \& Zeitlinger.

Matson, J.L., Boisjoli, J. \& Mahan, S. (2009). The Relation of Communication and Challenging Behaviors in Infants and Toddlers with Autism Spectrum Disorders. Journal of Developmental and Physical Disabilitie, 21(4): 253-261.

McClintock, K., Hall, S. \& Oliver, C. (2003). Risk markers associated with challenging behaviours in people with intellectual disabilities: A meta-analytic study. Journal of Intellectual Disability Research, 47: 405-416.

Miller, K. \& Vernon, M. (2003). Deaf Sex Offenders in a Prison Population. Journal of Deaf Studies and Deaf Education, 8: 357-362.

Molteno, G., Molteno, C.D., Finchilescu, G. \& Dawes, A.R.L. (2001). Behavioural and emotional problems in children with intellectual disability attending special schools in Cape Town, South Africa. Journal of Intellectual Disability Research, 45: 515-520.

Nijhof, R. \& Van Overveld, S. (2005). FOBO Jaarverslag 2005. Amsterdam: Effatha Guyot Zorg.

Sarimski, K. (2007). Psychische Störungen bei Behinderten Kindern und Jugendlichen- Ubersicht und Schlussfolgerungen für die Psychodiagnostik. Zeitschrift fur Kinder- und Jugendpsychiatrie und Psychotherapie, 35(1): 19-29.

Sigafoos, J. (2000). Communication development and aberrant behavior in children with developmental disabilities. Education and Training in Mental Retardation and Developmental Disabilities, 35: 168-176.

Sinkkonen, J. (1994). Evaluation of mental health problems among Finnish hearing impaired children. Psychiatrica Fennica. 25: 52-65.

Snijders, J. Th., Tellegen, P. J. \& Laros, J. A. (1988). Snijders-Oomen niet-verbale intelligentietest SON-R 5.5-17. Verantwoording en handleiding. [Snijders-Oomen Non-verbal Intelligence Scale-Manual 5.5-17.] Groningen: Wolters-Noordhoff.

Tellegen, P.J., Winkel, M., Wijnberg-Williams, B.J. \& Laros, J.A. (1998). Snijders-Oomen Niet-verbale intelligentietest SON-R 2.5-7. Verantwoording en handleiding [Snijders-Oomen Non-verbal Intelligence Scale-Manual 2.5-7.] Amsterdam: Hogreve.

Timehin, C. \& Timehin, E. (2004). Prevalence of hearing impairments in a community population of adults with learning disability: access to audiology and impact on behaviour. British Journal of learning disabilities, 32: 128-132.

Tyrer, F., McGrother, C.W., Thorp, C.F., Donaldson, M., Bhaumik, S., Watson, J.M. \& Hollin, C. (2006). Physical aggression towards others in adults with learning disabilities: prevalence amd associated factors. Journal of Intellectual Disability Research, 50(4): 295-304.

Van Eldik, T., Treffers, P.D.A., Veerman, J.W. \& Verhulst, F.C. (2004). Mental health problems of deaf Dutch children as indicated by parents responses to the Child Behavior Checklist. American annals of the deaf, 148(5): 390-394.

Van Gent, T.; Goedhart, A.W.; Hindley, P.A.; \& Treffers, P.D.A. (2007). Prevalence and correlates of psychopathology in a sample of deaf adolescents. Journal of Child Psychology and Psychiatry. 48(9): 950-958.

Vernon, M., \& Greenberg, S. (1999). Violence in deaf and hard-of-hearing people: A review of the literature. Aggression and violent behavior, 4: 259-272.

Vostanis, P., Hayes, M., Du Feu, M. \& Warren, J. (1997). Detection of behavioural and emotional problems in deaf children and adolescents: Comparison of two rating scales. Child care, Health and Development, 23: $233-246$.

Willems J. \& Verpoorten R. (1996). Communicatie Profiel-Z. Handleiding [Communication Profile-Z. Manual]. Lisse: Swets \& Zeitlinger. 


\section{Chapter 7}

RELATIONS BETWEEN ENVIRONMENTAL FACTORS AND

CHALLENGING BEHAVIOUR IN PEOPLE WITH BOTH

INTELLECTUAL DISABILITIES AND HEARING

IMPAIRMENTS/DEAFNESS

$(\mathrm{ID}-\mathrm{HI} / \mathrm{D})$

AN EXPLORATIVE STUDY

Willem Meindert Buskermolen ${ }^{1}$, Joop Hoekman ${ }^{2}$ and Albert Pierre Aldenkamp ${ }^{3}$

1. Kentalis - Weerklank Amsterdam; the Netherlands

2. Leiden University; University of Applied Sciences Leiden; the Netherlands

3. Maastricht University; Kempenhaeghe, Heeze; the Netherlands

Accepted for publication in British Journal of Learning Disabilities 


\section{Abstract}

Background and objective

In this article, we describe our study in which environmental factors are related to challenging behaviour in 21 people (fourteen are male, seven are female, varying in age from 12.4 to 42 years; mean 26.6, SD 7.27) with intellectual disabilities who have hearing impairments.

Method and results

Data were obtained by recording behaviour on a daily basis during one year using the 'Individual Behaviour Observation and Recording Scale' that was developed especially for this study. One hundred percent of the participants in this study showed challenging behaviour, although this was not observed every day for each participant. For almost each participant several environmental factors were found to be relevant.

Conclusion

It is difficult to isolate the individual influence of each separate factor as probably the interaction between factors plays an essential role, which makes it difficult to isolate the individual influence of separate factors. Points of concern appeared to be the high number of varying staff-members involved with the participants and the uneasy situations which seem to occur after alarmsituations. Implications for clinical practice are discussed. 


\section{Introduction}

Professional carers, working in clinical practice with people with an intellectual disability (ID) as well as hearing impairments or deafness (HI/D) are frequently confronted with challenging behaviour (Nijhof \& Van Overveld, 2005). Common problems in particular are aggressive incidents. Examples are destructive behaviour aimed at objects or other persons and self-harming behaviour.

People with both ID and HI/D as a group are understudied, with an exception of the study by Timehin \& Timehin (2004), who studied a group of 543 people with both ID and HI/D. In this group 62\% showed problem behaviour and 34\% exhibited selfharming behaviour. For people with ID as well for people with HI/D much research is conducted on challenging behaviour. In several studies it is concluded that challenging behaviour occurs frequently in people with an intellectual disability (ID) (Deb, Thomas \& Bright, 2001; Molteno, Finchilescu \& Dawes, 2001; Emerson et al, 2001; Tyrer et al, 2006; Crocker et al, 2006; Holden \& Gitlesen, 2006). For people with HI/D, the same conclusion is drawn (Hindley, Hill, McGuigan \& Kitson, 1994; Mitchell \& Quittner, 1996; Vostanis, Hayes, Du Feu, Warren, 1997; Van Eldik, T., Treffers, P.D.A., Veerman, J.W. \& Verhulst, F.C., 2004; Van Gent, T.; Goedhart, A.W.; Hindley, P.A.; \& Treffers, P.D.A., 2007). In these studies, several risk factors for challenging behaviour were mentioned. In some studies, the severity of the ID was detected as a risk factor (e.g. Molteno, Molteno, Finchilescu \& Dawes, 2001; Tyrer et al. 2006). In other studies, a gender effect was found. In these studies, males showed more behavioural problems (McClintock, Hall \& Oliver 2003; Tyrer et al. 2006). In the study of Deb, Thomas \& Bright (2001), one of the results was, that the rate of self-harming behaviour was significantly associated with the female gender. Emerson et al. (2001) and Tyrer et al. (2006) found that young adults and adolescents showed more behavioural problems than adults. Autism was also established as a risk factor (e.g. Matson, Boisjoli \& Mahan 2009), although Tyrer et al. (2006) question the relationship between aggression and autism. Additional sensory impairments were also mentioned as risk factors (Besag, 2003; Dekker \& Koot, 2003). Another possible risk factor is mentioned by Chadwick et al. (2000), and Emerson et al. (2001). In their study they found a higher prevalence of behavioural problems when people were more limited in their daily skills, such as eating and dressing. Demanding situations were detected as a risk factor in the study of Crockett \& Hagopian (2006). They found an increase in behavioural problems when people were challenged by such situations. Communication was often mentioned as a risk factor. In several meta analyses (e.g. Sigafoos, 2000; Emerson et al., 2001; Besag, 2003) and in several case studies (e.g. Frea, Arnold \& Vittimberga, 2001; Durand \& Merges, 2001) it was concluded that communicational abilities were a risk factor.

Similar findings for the range and prevalence of behavioural problems were reported for people with HI/D (e.g. Van Eldik, Treffers, Veerman \& Verhulst, 2004; Van 
Gent, Goedhart, Hindley, \& Treffers, 2007). The most important findings in these studies are that in people with ID as well as in those with $\mathrm{HI} / \mathrm{D}$, communication difficulties form an important risk factor that could lead to challenging behaviour. Secondly an increase in challenging behaviour was found for both groups when additional handicaps occur. It is plausible, that communicational difficulties are even more severe in people with both ID and HI/D. Although recognizing risk factors can contribute to the understanding of challenging behaviour, empirical research is needed into relations between several internal and environmental factors and (challenging) behaviour if we want to gain more knowledge about possible causes for challenging behaviour.

Buskermolen, Hoekman \& Aldenkamp (2016) investigated internal factors as possible risk factors in 21 people with both ID and HI/D. Significant relationships were found between challenging behaviour and the level of social independence as well as the delay of communication. They hypothesized that being less dependent upon other people can be an important factor in reducing challenging behaviour. It is plausible that adequate communicational skills are an important factor in social independency. Secondly, they found a significant relation between challenging behaviour and autism.

Although several risk factors are detected, it is impossible to draw conclusions about the cause for challenging behaviour in our patients-group. The assumption that in people with both ID and HI/D there seems to be a relationship between internal factors and challenging behaviour, probably constitutes only a partial explanation for the prevalence of challenging behaviour. Another explanation can possibly been found in environmental factors. When challenging behaviour occurs following specific environmental events, this could be an indication for a possible relation between the observed behaviour and such an event. In this study we will analyze possible relationships between environmental factors and challenging behaviour. If we can detect these relations we can make predictions for future behavioural reactions. More important, it could create possibilities to make better rules for interventions. By intervening in a more specific way, it could decrease the prevalence of challenging behaviour.

The question which we set out to answer in this study is whether it is possible to determine relations between certain environmental factors and challenging behaviour of people with ID and HI/D.

\section{Materials and methods}

\section{Participants}

The study comprised 21 individuals with both ID and HI/D. They were residents of three different homes for people with this combination of disabilities, situated in the 
province of North Holland in The Netherlands. A data and safety monitoring board supervised study progress and outcomes. Written and informed consent was obtained from the legal guardians of all participants enrolled in the study, in accordance with the 1975 Declaration of Helsinki, as revised in 2013. The daily routine of the participants was not influenced in any way as a result of their participation in the study, since only observation and recording by staff-members of daily behaviour was done. All participants were involved in a daily work or activity program. Fourteen were male, seven were female, varying in age from 12.4 to 42 years (mean 26.6, sd 7.27). The level of ID was measured by the Vineland Adaptive Behaviour Scale (De Bildt \& Krayer, 2005), the Snijders Oomen Non-Verbal Intelligence Test 2 1/2 - 7 (Tellegen, Winkel, Wijnberg-Williams, \& Laros, 1998), or the Snijders Oomen Non-Verbal Intelligence Test $5 \frac{1}{2}-16$ (Snijders, Tellegen \& Laros, 1988). Using the first tests, it was not possible to calculate an IQ; therefore, it was decided to indicate the cognitive level in developmental age. This was possible with all three of the above-mentioned tests. The cognitive level varied from one year and three months $(1 ; 3)$ to eight years and one month $(8 ; 1)$ (mean 4.11 , sd 2.4). The severity of HI/D was measured through "free field audiometry" or "pure tone-audiometry", which was done by an audiological centre that specializes in assessments of people with ID and HI/D. In our study, we used the Fletcher Index (Fletcher, 1929), the standard method of measuring hearing loss since 1929. The Fletcher Index measurements for our participants varied from 40 to 110 decibels. The origin of the deafness and intellectual disabilities was unknown for most of the participants, so we decided not to consider this as an internal factor. Ten participants were diagnosed with Autism Spectrum Disorder (ASD) after extensive diagnostic testing using DSM IV, by clinical psychiatrists specialized in patients with both ID and HI/D. The level of social independence was determined using the Sociale Redzaamheidsschaal voor Zwakzinnigen (Social Developmental Level Scale for People with ID) (Krayer \& Kema, 1994). The scale consisted of nine levels. The total score for this scale is based upon scales of Independence, Ability to Focus on Tasks, Social Abilities, and Communication. The scale was completed by the clinician together with the patient's personal counselor. The delay of communicative development was determined using the Communicatie Profiel voor Zwakzinnigen (Communication Profile for People with ID) (Willems \& Verpoorten, 1994). This is a 10-point scale based on receptive non-vocal, receptive vocal, expressive non-vocal, and expressive vocal scores. This scale was also completed by the clinician and the personal counselor.

\section{Method}

In order to gain insight into the relationship between behaviour and external factors, it was necessary to use an instrument that can measure specific individually-defined behaviour, as well as an instrument that can measure descriptions of circumstances in which this behaviour occurred. Buskermolen, Hoekman \& Aldenkamp (2013) studied 
several scales with which behaviour can be measured. They concluded that none of these were suitable for their study. Their main objection was that there was no questionnaire in which there is the opportunity for descriptions of individual behaviours. Therefore, they developed an Individual Behaviour Observation and Recording Scale (IBORS), in which they defined behavioural problems as behaviour that needs active intervention to prevent further escalation. We used IBORS in this study to measure the frequency of challenging behaviour in individuals with both ID and HI/D. IBORS contains forty unique behavioural descriptions. For each individual participating in the study, eight generally accepted dimensions of behaviour (making sounds, facial expression, locomotion, body manipulation, object manipulation, concentration, receptive communication, and expressive communication) were combined with five levels of severity (relaxation, restlessness, tension, threat, and loss of control). Behaviour at level three or higher requires active intervention by staff. Therefore, behaviour representing level three (tension) or higher was defined as challenging behaviour. A study of inter-assessor reliability of the IBORS was carried out (Buskermolen, Hoekman \& Aldenkamp, submitted). The results of this study are promising.

Behaviour of the participants was recorded by the staff-members at the end of their shift by using the IBORS-method.

\section{Recording procedure}

Prior to the study recording period, staff were trained to observe and record individual behaviour by discussing and refining all behavioural descriptions to try to maximise agreement. They were instructed to score the highest behavioural level they observed during their shift. It was impossible to see previous records for purposes of reliability. Recording of IBORS-scores was done digitally using a Microsoft Access software program, developed for this study (Buskermolen, Holsnijders, Hoekman \& Aldenkamp, submitted).

Each record consisted of behavioural scores in accordance with the IBORS method as described above. Staff recorded behaviour three times per day (at 09.00, 15.00, and $22.00 \mathrm{hrs}$ ) at the end of their shift. The first and third records were made by staff in the homes, while the second record was made by either staff at the work or daily activity centre or staff in the homes. During weekends, only two recording sessions per day were carried out (at 14.00 and 22.00 hrs), both because shifts began later in the morning and since there was no work or activity program. When the participant was not present due to holidays or during a stay with parents or family, no records were made. The recording period was for one year, which resulted in a maximum of 988 records per person. 


\section{Environmental factors}

Several environmental factors were recorded. These factors were generated by the Delphi method (Dalkey \& Helmer, 1963). A group of psychologists and staff managers, who all worked in Weerklank, a residential home in Amsterdam for people with both ID and $H I / D$, constructed a list of possible factors, based on their experience and presumptions. This list was distributed to staff-members from different sections: group-workers, schoolteachers and managers. The results were analysed and we decided to include the following factors in our study:

1. Staff-member on duty.

2. Conflicts between others (staff-members or other persons with ID and HI/D).

3. Visits (expected or unexpected; familiar or unknown persons).

4. Medication.

5. Nutrition.

6. Unusual physical problems.

7. Several special occasions such as accidents, unusual or exceptional noise, birthdays, alarm-signals.

\section{Statistical method}

Spearman's rho was used to investigate relations between environmental factors and challenging behaviour because IBORS-scores and most environmental variables are recorded on an ordinal scale. Spearman was carried out for each of the three different shifts.

Special attention was given to the factor Staff. This factor represents possible differences between the prevalence of challenging behaviour in the presence of certain staff-members in relation to other staff-members. To measure this factor, we carried out: Graphs, Boxplots, Defined as Summaries of separate variables and Simple boxplots. We then defined participants as boxes and staff as cases to detect significant differences. Figure 7.1 is an example of the result of this calculation. In this figure, PP1, PP 3, PP 4 \& PP 5 are participants who were together in the same home and in the same activity-group. Their behaviour was recorded by the same staff-members. The $y$-axe represents the percentage of challenging behaviour. The personal codes of staff members who recorded significant other scores then their colleagues show up in this graph. For example: when staff-member 106 was present, irrespective whether this staff-member did the recording, a significant lower percentage of challenging behaviour was observed in PP 1. 


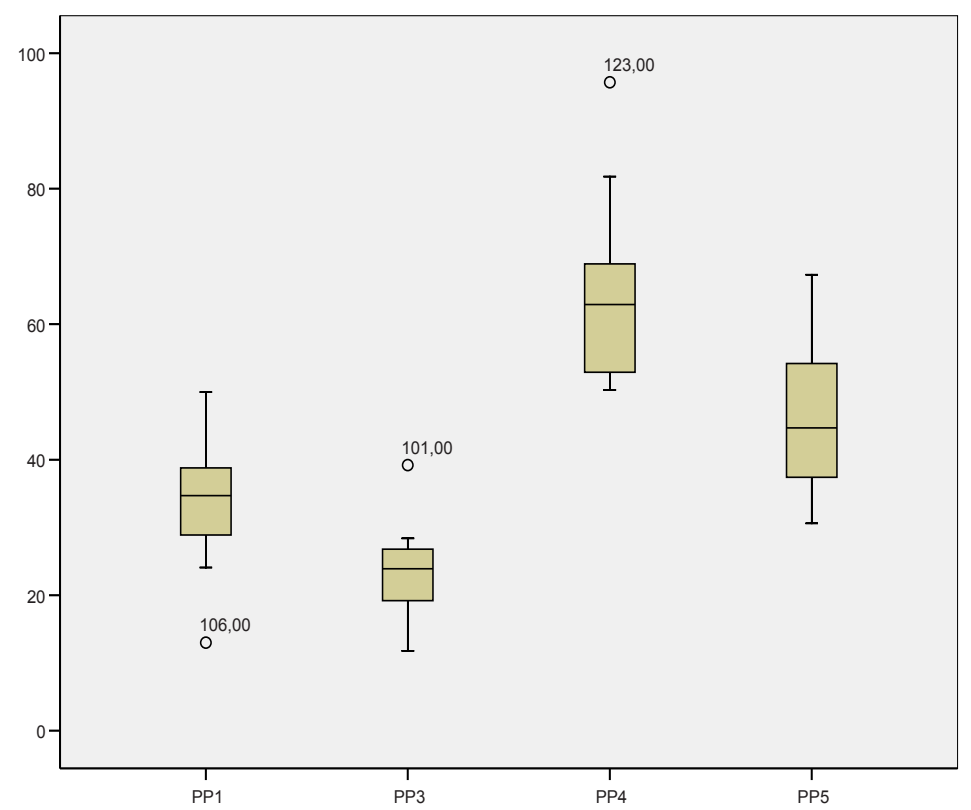

Figure 7.1 Example of boxplot

In Table 7.1, we have marked a + in these cases in which a difference of two standard deviations of prevalence of challenging behaviour between different staffworkers was found.

Another statistical calculation, cross-tabulations, was carried out for the factor nutrition. The reason for this approach is that in the total group it is impossible to measure differences between several food-products related to challenging behaviour, because the number of participants $(N=21)$ is far less than the number of foodproducts. Therefore all statistical analyses aimed at group tendencies lack sufficient power and will result in random outcomes. Only on the individual level $(N=1)$ tendencies can be explored. Because there are many variables in nutrition (e.g. 17 different kinds of meat and 41 different vegetables were recorded), we explored these factors with cross tabulations. 


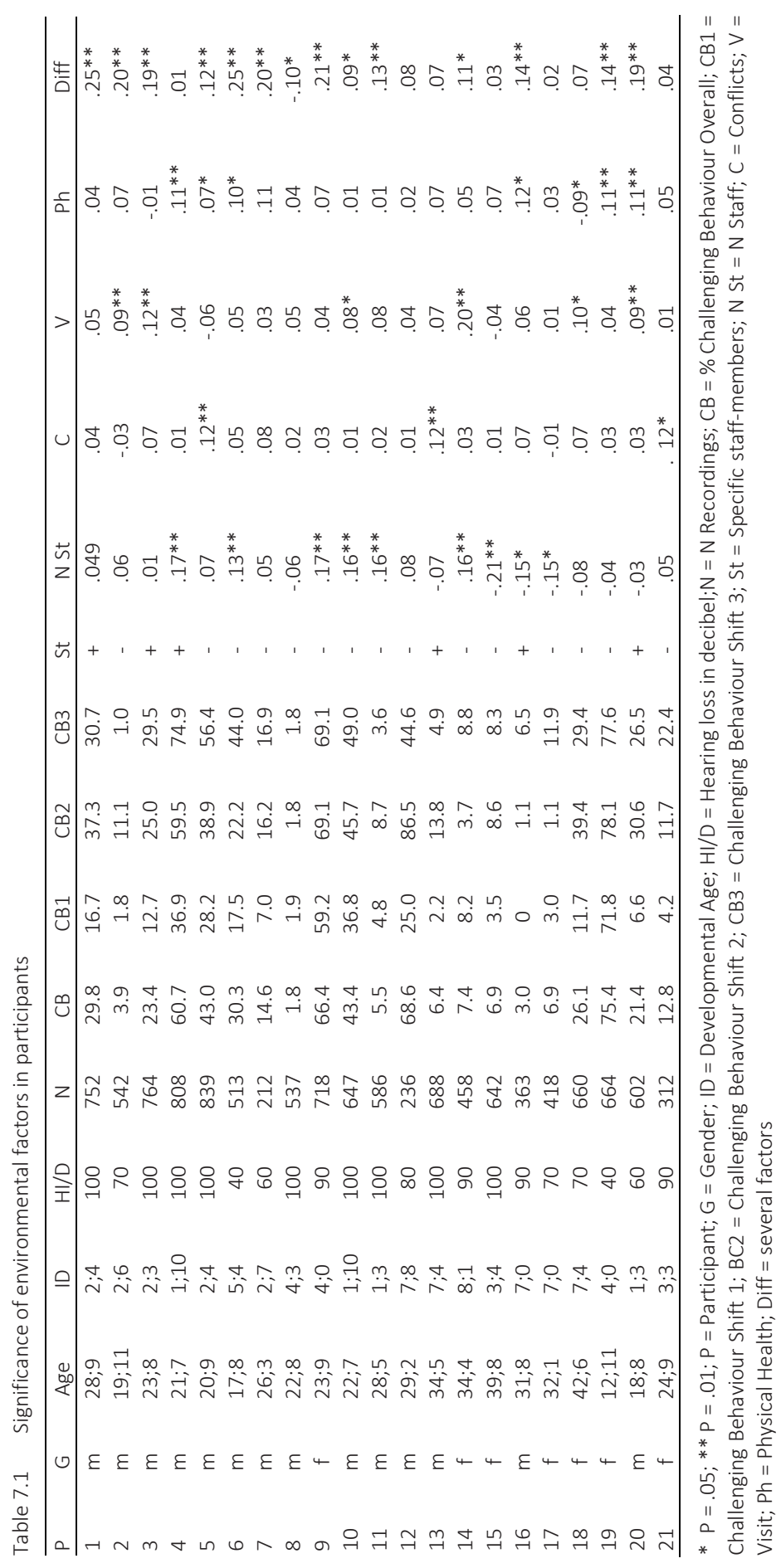




\section{Results}

The total amount of records of the behaviour is presented in Table 7.1. For these 21 participants 11,961 recordings were made. This means a response of 59\%. The response for Shift 1 was 48\%, for Shift 2 it was $46 \%$ and for Shift 3,62\%. Table 7.1 represents all participants with percentages of challenging behaviour (Level 3, 4 and 5 together). The results in this table show that all individuals exhibited challenging behaviour, varying from $1.8 \%$ of the time (participant 8 ) to $75.4 \%$ of the recordings (participant 19). For each participant, the table shows the statistically significant correlations with the environmental factors involved in our study as well.

We decided to conduct $21 \times \mathrm{N}=1$ studies. In our next section we will discuss significant results in 21 case reports. In these reports we mention percentages. These percentages are used to illustrate differences between the average prevalence challenging behaviour and the prevalence of challenging behaviour when a particular environmental factor occurs.

\section{$\mathrm{N}=1$ Studies}

In this section we will describe the results of the 21 participants separately. For each of them we discuss the prevalence of challenging behaviour, possible differences in challenging behaviour between different shifts and environmental factors. For some participants the environmental factor "alarm-situations" is mentioned. In one of the residential institutes the participants live in different homes. For each resident of this institute a protocol is written for situations that challenging behaviour occurs. In seriously threatening or escalated situations staff has to push an alarm-button which is a signal for staff of the other homes in the building to assist during such an alarmsituation.

\section{Participant 1: A.K., Male, 28;9}

The overall prevalence of challenging behaviour is $29.8 \%$. One staff-member seems to have a positive influence on A.K. because the prevalence of challenging behaviour is $13 \%$ during shifts in which this staff-member is present. Alarm situations are responsible for the significant factor resulting under "several factors": during alarm situations in other homes, the prevalence of challenging behaviour is $37.5 \%$.

\section{Nutrition}

When A., during all three meals, eats slower than usual, the prevalence of challenging behaviour increases (57\%). The prevalence of challenging behaviour is also higher when A. eats less than usual during diner (60\%). During lunch relatively high prevalence challenging behaviour goes with: whole-grain bread (61.6\%), boiled egg (63.2\%), 
buttermilk (54.5\%). During diner a high prevalence of challenging behaviour goes with: no fish nor flesh (52.1\%), currysauce (64.3\%). When A. does not drink during diner, the prevalence of challenging behaviour is $50 \%$. When there is no desert, the prevalence is $50 \%$.

\section{Participant 2: A.R., Male, 19;11}

The overall prevalence of challenging behaviour is 3.9\%. A significant factor is visits: A.R. showed challenging behaviour during $27 \%$ of the times an outsider such as a technical assistant or an unknown care professional was present. Alarm situations are responsible for the significant factor resulting under "several factors": during alarm situations in other homes, the prevalence of challenging behaviour during evening shifts is $6.3 \%$.

\section{Nutrition}

During lunch the high prevalence of challenging behaviour goes with: brown bread $(14.3 \%)$, sandwich spread or salad $(21.6 \%)$, milk (16.1\%) or water instead $(66.7 \%)$.

\section{Participant 3: J.D., Male, 23;8}

The overall prevalence of challenging behaviour is $23.4 \%$. The prevalence of challenging behaviour increases during the day (12.7\%; 25.0\%; 29.5\%). One staff-member seems to have a negative influence on J.D., because the prevalence of challenging behaviour is $39.2 \%$ during shifts this staff-member is present. There is also a higher prevalence of challenging behaviour during visits of outsiders $(33.3 \%)$ or his own family $(32.0 \%)$. Unexpected occasions not otherwise specified are responsible for the significance of the factor resulting under "several factors".

\section{Nutrition}

When J.D. eats his dinner faster than usual, challenging behaviour was recorded in $67 \%$, when he eats more than usual, challenging behaviour was also recorded in $67 \%$ of all cases. During dinner, high prevalence challenging behaviour goes with curry sauce, $(55.6 \%)$, beetroots $(100 \%)$, broccoli $(41.7 \%)$, lettuce $(50 \%)$, icecream as a desert (55.6\%)

\section{Participant 4: O.S., Male, 21;7}

The overall prevalence of challenging behaviour is $60.7 \%$. There is a tendency of increasing challenging behaviour during the day (36.9\%; 59.9\%; 74.9\%). There also was more challenging behaviour (85.7\%) in shifts that O.S. suffered from physical discomfort such as illness. 


\section{Nutrition}

When O.S. eats lunch faster than usual challenging behaviour was recorded in $71.9 \%$. Eating more than usual especially during breakfast goes more often with challenging behaviour: (83.3\%). During lunch (56.6\%) and dinner (80\%) there is no such effect. challenging behaviour is only $23.1 \%$ when O.S. eats white bread during breakfast

Some possible suspicious vegetables are tomatoe (100\%) and cauliflower (85.7\%). Other possible factors are when O.S. does not get any desert (88.9\%) or when he eats just fruit for desert like mandarine or peach (90\%).

Participant 5: Y.F., Male, 20;9

The overall prevalence of challenging behaviour is $43 \%$. There is a tendency of increasing BC during the day $(28.2 ; 38.9 ; 56.4 \%)$. During conflicts between other participants and staff the prevalence of challenging behaviour was $67.5 \%$. Alarm situations are responsible for the significant factor resulting under "several factors": during alarm situations in other homes, the prevalence of challenging behaviour is $50.9 \%$. (For the different shifts these figures are: $34.2 \%, 42.2 \%$ and $61.6 \%$.)

\section{Nutrition}

During breakfast, challenging behaviour appears in $18.8 \%$ when Y.F drinks coffee, but in 41.9\% when he gets to drink fruit juice. This percentage increases when he drinks fruit juice during lunch (55.6\%). Having chocolate on his bread during lunch goes with $60.6 \%$. When eating soup as a snack after lunchtime, the prevalence was $51.9 \%$. Suspicious ingredients during dinner are turkey $(69.2 \%)$, curry sauce $(80 \%)$, tomatoe (100\%), spinach (70\%) and porridge as a desert (76.9\%).

Participant 6: J.E., Male, 17;8

The overall prevalence of challenging behaviour is $30.3 \%$. There is a tendency of increasing BC during the day $(17.5 \% ; 22.2 \% ; 44.0 \%)$. The number of staff present is a relevant factor. With one staff-member on duty the prevalence of challenging behaviour is $18.1 \%$, with two staff-members the prevalence is $32.1 \%$ and with three staff-members the prevalence is $38.7 \%$. During alarm situations in other homes there is a significant higher prevalance of challenging behaviour (46.5\%).

\section{Nutrition}

Eating slower than usual during breakfast goes with $36.8 \%$ challenging behaviour, during dinner this is $53.3 \%$. When J. eats faster than usual prevalence of challenging behaviour is $16.6 \%$. During lunch, eating soup goes with $57.1 \%$. When codfish is on the menu the prevalence of challenging behaviour is $25 \%$. While eating carrots, this 
percentage is $71.4 \%$. Drinks during dinner: while drinking beer (12.5\%) or cola (24.2\%), the prevalence of challenging behaviour is lower but while drinking lemonade (56\%) or no drinks at all (70.4\%) the prevalence of challenging behaviour is higher.

\section{Participant 7: M.G., Male, 26;3}

The overall prevalence of challenging behaviour is $14.6 \%$. During morning shifts the prevalence of challenging behaviour is lower $(7.0 \%)$ than during the other shifts $(16.2 \%$ and $16.9 \%)$. During alarm situations in other homes there is a higher prevalance of challenging behaviour (31,3\%)

\section{Nutrition}

We could not found any significant results concerning nutrition.

Participant 8: V.A., Male, 22;8

The overall prevalence of challenging behaviour is $1.8 \%$. We did not measure any significant environmental factors who are responsible for an increase of challenging behaviour. The prevalence of challenging behaviour however disappears (0\%) when special events like birthdays or other not otherwise specified unusual occasions occur.

\section{Nutrition}

We could not found any remarkable results concerning nutrition.

\section{Participant 9: K.B., Female, 23;9}

The overall prevalence of challenging behaviour is $66.4 \%$. The number of staff present during a shift is an environmental factor: in the presence of only one staff-member the prevalence of challenging behaviour is $59 \%$. With two staff-members the prevalence is $67 \%$. challenging behaviour appears in $82.6 \%$ when three staff-members are present and during shifts where four staff-members were present, the prevalence of challenging behaviour was $100 \%$. Challenging behaviour was also recorded in $87 \%$ when several unexpected occurences were observed. Furthermore, when noticeable noise was recorded, in $85 \%$ of these occasions K.B. showed challenging behaviour.

\section{Nutrition}

Challenging behaviour is different during early shifts: when $\mathrm{K}$. drinks milk there is a lower prevalence (37.5\%) than when she drinks buttermilk (57.9\%). Other remarkable results are eating white bread (41.4\%) or having sugar products (47.4\%). 


\section{Participant 10: W.W., Male, 22;7}

The overall prevalence of challenging behaviour is $43.4 \%$. The number of staff present during a shift is an environmental factor: in the presence of only one staff-member the prevalence of challenging behaviour is $35.9 \%$. With two staff-members the prevalence is $45.9 \%$. challenging behaviour appears in $46.7 \%$ when three staff-members are present and during shifts where four staff-members were present, the prevalence of challenging behaviour was $100 \%$. Challenging behaviour also slightly increases in cases of unexpected occasions, not otherwise specified (52.5\%).

\section{Nutrition}

Having no drinks before lunch, the prevalence of challenging behaviour is $21.4 \%$ and having no drinks during lunch the prevalence of challenging behaviour is $25 \%$. Eating soup as a snack after lunch goes with $53 \%$ challenging behaviour. During dinner codfish $(66.7 \%)$, curry sauce $(100 \%)$ and endive $(80 \%)$ are suspicious.

\section{Participant 11: M.S., Male, 28;5}

The overall prevalence of challenging behaviour is $5.5 \%$. The number of staff present during a shift is an environmental factor: in the presence of only one staff-member the prevalence of challenging behaviour is $4.1 \%$. With two staff-members the prevalence is $6.1 \%$. When M. suffered from physical discomfort such as illness, in none of the shifts challenging behaviour was recorded. When unexpected events (not otherwise specified) occur, the prevalence of challenging behaviour increases (50\%). When unusual loud noises were recorded, the prevalence was even higher (66.6\%).

\section{Nutrition}

The prevalence of challenging behaviour is $18.5 \%$ when $\mathrm{M}$. does not get any snack before lunch. Having no drinks before lunch this prevalence is $18.8 \%$. Having no drinks during dinner goes with $50 \%$ challenging behaviour.

\section{Participant 12: B.E., Male, 29;2}

The overall prevalence of challenging behaviour is 68.6\%. Remarkable is the difference in prevalence of challenging behaviour between the afternoon shift (86.5\%) and the morning shift (25.0\%) and evening shift (44.6\%).

\section{Nutrition}

A notable figure appears during dinner when B.E. had endive on the menu (100\%). On the other hand eating white rice $(33.3 \%)$ or drinking coffee $(35.1 \%)$ go together with less challenging behaviour. 


\section{Participant 13: B.V., Male, 34;5}

The overall prevalence of challenging behaviour is $6.4 \%$. A difference can be seen in the prevalence of challenging behaviour between the afternoon shift (13.8\%) compared to the prevalence during the morning shift (2.2\%) and evening shift (4.9\%). Two particular staff-members may have a negative influence because challenging behaviour occurs in $10.7 \%$ (staff-member $\mathrm{X}$ ) and $\mathbf{1 3 . 6 \%}$ (staff-member $\mathrm{Y}$ ) during shifts these staff-members are present. This result is even more remarkable, because these staff-members were only present during the morning or evening shift during which the overall prevalence challenging behaviour was only $2.2 \%$. In $33.3 \%$ of the shifts in which conflicts between others occured, B.V. showed challenging behaviour.

\section{Nutrition}

During the afternoon shift drinking milk (35.5\%) or buttermilk (10.7\%) are notable figures.

\section{Participant 14: L.S., Female, 34;4}

The overall prevalence of challenging behaviour is 7.4\%. A difference can be seen in the prevalence of challenging behaviour between the afternoon shift (3.7\%) and the prevalence during the morning shift (8.2\%) and evening shift (8.8\%). There is a higher prevalence of challenging behaviour during visits of outsiders (100\%), own family (25.0\%) or family of other participants (17.2\%). When other unexpected events (not otherwise specified) occur, the prevalence of challenging behaviour increases up to $75 \%$.

\section{Nutrition}

Eating white bread during breakfast goes with 16.1\% challenging behaviour. Drinking water during diner goes with $11.8 \%$, but having no drinks during dinner goes with $2.8 \%$ challenging behaviour.

\section{Participant 15: M.B., Female, 39;8}

The overall prevalence of challenging behaviour is $6.9 \%$. The number of staff present is a factor. The prevalence of challenging behaviour increases when, in evening shifts, there are less staff-members on duty. When only one staff-member is present, challenging behaviour is recorded in $13.8 \%$ of all shifts. With two staff-members this percentage is reduced to $7.3 \%$ and with three staff-members the prevalence is $0 \%$.

\section{Nutrition}

The only notable figure is eating satay sauce during dinner (28.6\%) 
Participant 16: R.G., Male, 31;8

The overall prevalence of challenging behaviour is 3.0\%. Challenging behaviour occurs almost entirely during the evening shifts (6.5\%). One staff-member seems to have a negative influence because challenging behaviour occurs in $18.8 \%$ during shifts this staff-member is present. Remarkably, this is the same staff-member who has a possible negative influence on the challenging behaviour of participant 17 . The number of staff present is a factor. The prevalence of challenging behaviour increases from $0 \%$ with 5 staff-members to $8.6 \%$ with only one staff-member on duty. The prevalence of challenging behaviour even disappears $(0 \%)$ when special events like birthdays or other not otherwise specified unusual occasions occur.

Nutrition

Eating chicken (14.3\%) or satay sauce (36.4\%) are remarkable figures.

Participant 17: T.K., Female, 32;1

The overall prevalence of challenging behaviour is $6.9 \%$. Challenging behaviour occurs almost entirely during evening shifts: $11.9 \%$. One staff-member seems to have a negative influence because challenging behaviour occurs in $28.1 \%$ during shifts this staff-member is present. Remarkably, this is the same staff-member who has a possible negative influence on the challenging behaviour of participant 16 . The number of staff present is a factor. The prevalence of challenging behaviour increases from $0 \%$ with 5 staff-members to $18.0 \%$ with only one staff-member on duty.

Nutrition

Drinking tea during breakfast (11.5\%) or coffee (1.0\%) could be a meaningfull factor. Eating codfish $(22.7 \%)$ or drinking yoghurt drink (100\%) could also be meaningfull factors.

Participant 18: I.M., Female, 42.6

The overall prevalence of challenging behaviour is $26.1 \%$. A difference can be seen in the prevalence of challenging behaviour during the three different shifts. In the morning challenging behaviour occurs in only $11.7 \%$ of the shifts while during afternoon shifts (39.4\%) and evening shifts $(29.4 \%)$ the prevalence is higher. There is also more challenging behaviour (61.1\%) in shifts that I.M. suffered from physical discomfort such as illness. 


\section{Nutrition}

When having meats or sausages during breakfast the challenging behaviour is $46.2 \%$. Eating fried egg $(85.7 \%)$ or sugar products on bread (78.9\%) during lunch or drinking tea $(67.3 \%)$ could be factors. Drinking tea after dinner goes with $75 \%$ challenging behaviour, drinking soft drinks with $53.8 \%$.

\section{Participant 19: C.G., Female, 12;11}

The overall prevalence of challenging behaviour is $75,4 \%$. There is a higher prevalence of challenging behaviour (84.6\%) in shifts that C.G. suffered from physical discomfort such as illness.

\section{Nutrition}

During breakfast whole meat bread (44.0\%) or sugar products on bread (39.1\%) could have a positive influence.

\section{Participant 20: O.N., Male, 18;8}

The overall prevalence of challenging behaviour is $21.4 \%$. A difference can be seen in the prevalence of challenging behaviour between the morning shift $(6.6 \%)$ and the prevalence during the afternoon shift (30.6\%) and evening shift (26.5\%). One staffmember seems to have a negative influence because challenging behaviour occurs in $50.0 \%$ during shifts this staff-member is present. During alarm situations in other homes there is a higher prevalance of challenging behaviour (29.6\%).

\section{Nutrition}

Buttermilk goes with BC in $75 \%$. Sugar products on bread with $70.6 \%$. During dinner notable figures are: curry sauce $(60 \%)$, courgette (100\%); drinking milk after dinner goes with $46.2 \%$.

\section{Participant 21: M.SI. Female 24;9}

The overall prevalence of challenging behaviour is $12.8 \%$. Through the day the prevalence of $\mathrm{BC}$ increases. During morning shifts the prevalence of $\mathrm{BC}$ is $4.2 \%$. The prevalence of challenging behaviour increases in the afternoon shift to $11.7 \%$ and in the evening to $22.4 \%$. 


\section{Nutrition}

When $\mathrm{M}$. does not start with a brown slice of bread, the prevalence of challenging behaviour is $0 \%$. When $\mathrm{M}$. drinks tea in the evening, prevalence of challenging behaviour is $42.9 \%$.

\section{Discussion}

In this study our research question was whether there are relations between environmental factors and challenging behaviour of people with both ID and HI/D. In $21 \mathrm{~N}=1$ studies we explored these relations. Data were obtained by observing and recording these variables during a period of one year We summarized these results in Table 7.1. In the descriptions of possible environmental factors for each participant we made some remarks about possible relations between these environmental factors and challenging behaviour.

The overall average prevalence of challenging behaviour for this group is $28.9 \%$. From the results of the 21 studies we conclude that only for participant 12 no relations between challenging behaviour and environmental factors were found, although a remarkable pattern of challenging behaviour during the day can be seen for this participant.

From the Delphi-method the factor "staff-member" was mentioned by professionals as the most probably environmental factor. Firstly, the number of staffmembers on duty during a shift is a factor for nine participants. The more staffmembers were present, the higher the prevalence of challenging behaviour was for six of them $(4,6,9,10,11,14)$. Three participants $(15,16,17)$ on the contrary showed a higher prevalence of challenging behaviour when there were less staff-members on duty. Secondly, for six participants the staff-member itself is a factor. When a certain staff-member is present, irrespective whether this staff-member did the recording, there has been reported either more or less challenging behaviour. For three participants $(5,13,21)$, conflicts between others is a factor. For six other participants $(2,3,10,14,18,20)$ visits from people who do not work in their particular home is a factor. Physical health is a factor for seven participants. When staff observed an aberrant physical condition six of them $(4,5,6,16,19,20)$ showed more challenging behaviour, while one participant (11), on the contrary, showed a decrease of challenging behaviour. In our study medication turns out to be no factor at all. We suspect that this is mainly due to our operationalization of this factor. Staff-members had to choose between the alternatives: "There has been an error; Standard medication was given; First time according to a new standard; No medication (If standard)." Data show that this was too confusing for some staff-members. In some occasions option 3 (a new standard) was recorded. Recordings the days before this 
occasion as well as after this occasion show that option 4 (no medication) was recorded. Regrettably, this makes these data unreliable. For fourteen participants different factors were found. Alarm signals in situations of extreme challenging behaviour of a participant in other homes is a significant factor for seven $(1,2,3,5,6,7$ and 20) participants. Not otherwise specified, unexpected environmental factors were found for four participants $(3,10,11$, and 14).

For almost each participant several environmental factors were found. This does not mean that it is possible to answer our research question. Probably, the interaction between factors plays an important role, which makes it difficult to isolate the individual influence of separate factors. This makes it too complicated to draw unambiguous conclusions about certain factors.

A serious point of concern is the fact that during the observation period a total of 263 alarm situations were recorded. These alarm-situations were only recorded for one of the three locations in which 15 participants lived. In these particular situations, staff of all other homes are obliged to assist. In our study, seven of these 15 participants (46.7\%) show an increase of challenging behaviour when alarm-situations in another home of this location occur. It is plausible that such situations are stressful for the staff as well as for the residents whether they are directly involved or not. This may cause a cascade of events and may have to be organized differently. We suspect the risk of a vicious circle. According to individual plans, challenging behaviour can be a reason for staff to push the alarm-button. Although we realize that it is much to ask for professional staff-members, this should be an important issue. In daily practice, staffmembers who are giving assistance in these situations immediately have to run towards the place where they are expected for assistance. After having assisted they return to their own participants. They should be very much aware that such alarmsituations can be a risk-factor for challenging behaviour.

Another issue for debate concerns the amount of staff-members who were involved with the participants. During the observation and recording period of one year the number of switches of staff per participant varies from 14 to 30 (mean 22.4), which, in our opinion is a worrisome sign. People with both ID and HI/D have to rely on staff and it is essential that staff are predictable, understandable and secure. It is very important to create conditions in which people with ID en HI/D can be supported in a safe, clear and therefore predictable environment. With so many changing staffmembers it seems very difficult to guarantee such a climate. The management should give serious attention to the fact that during one year so many staff-members were involved in the daily care of these participants. It is very doubtful if it is advantageous for people with ID and HI/D when they are confronted with over 20 staff-members. Further research about the reasons staff-members resign is important.

This study did have some limitations. In the first place, only 21 participants were included. The two institutes where our participants live are the only ones specialised in this target population in The Netherlands. Therefore we could not find a larger sample 
of people with ID who also have HI/D. 21 Participants is a small sample and probably not representative. On the other hand we collected a large database for each of our participants because behaviour of these 21 participants and environmental factors were observed and recorded over a period of one year. The average collected amount data of all 21 participants was 570 records.

Another possible limitation concerns the use of IBORS: further research is necessary, although inter-assessor reliability showed that the instrument was suitable for the purposes of observing and recording behaviour.

Thirdly, with the results of our study we cannot draw conclusions about causal relations. However, we can detect mediating connections between internal or environmental factors and challenging behaviour.

A fourth limitation is, that in our study, medication was not detected as a possible factor. Medication was only to be recorded when a change in medication was prescribed, but this turned out to be confusing. It would demand another approach to measure a possible effect.

Finally, we are not certain that we included all relevant environmental factors by making use of the Delphi-method. We have no full guarantee that this results in a complete list of the most relevant factors, although this is a recognized method (Dalkey, \& Helmer, 1963). Several factors were excluded using our criteria that nonetheless may be meaningful.

With our study, we made it plausible that for 20 out of 21 participants different environmental factors play a role in increasing or decreasing of challenging behaviour. For each participant unique combinations of environmental factors were found. In addition, internal risk-factors play an important role as well (Buskermolen, Hoekman \& Aldenkamp, 2016). For clinical practice, this means that we cannot give generic advice about environmental factors which are influencing challenging behaviour in people with ID and HI/D in general. The results of our study have however given clues for possible environmental factors on an individual level. The staff could try to avoid these clues in order to prevent challenging behaviour. Above this, staff could consider possible factors by offering the participants explicit choices in, for instance, nutrition when staff suspects that certain nutrition is possibly related to challenging behaviour.

To achieve knowledge about suspicious factors, professionals could benefit from the IBORS-method. By describing behaviour of participants in detail, following this method (descriptions of eight behavioural aspects over five mood-levels of severity) more insight can be gained in behavioural patterns of the participant. Above this, specific and differentiated interventions can be described, based on the level of severity in which a participant is observed. If professionals can be facilitated to intervene in an early stadium, the chance will increase that aggression-incidents or other mood-escalations can be prevented. Another advantage of IBORS is that behaviour can be recorded in measurable terms. When staff is able to observe and 
record behaviour by making use of IBORS, it is possible that certain trends can be discovered. 


\section{References}

Besag, F.M.C. (2003). Psychopathology in people with epilepsy and intellectual disability. Journal of Neurology, Neurosurgery and Psychiatry, 74: 1464

Buskermolen, W.M., Hoekman, J. \& Aldenkamp, A.P. (2013) Assessing Challenging Behaviour in People with Hearing Impairments and Profound Intellectual Disabilities: The Development of an Individual Behaviour Observation and Recording Scale. International Journal on Mental Health and Deafness, 3(1): 30-40.

Buskermolen, W.M., Hoekman, J. \& Aldenkamp, A.P. (2014) Assessing Challenging Behaviour in People with Hearing Impairments and Profound Intellectual Disabilities: The Inter-Assessor Reliability of the Individual Behaviour Observation and Recording Scale. (Submitted in International Journal on Mental Health and Deafness).

Buskermolen, W.M., Holsnijders, C.M., Hoekman, J. \& Aldenkamp, A.P. (2015) The Operationalisation of Possible External Factors influencing Challenging Behaviour in People with Hearing Impairments and Profound Intellectual Disabilities. (Submitted).

Buskermolen, W.M., Hoekman, J. \& Aldenkamp, A.P. (2016). The Nature and Rate of Behaviour that Challenges in Individuals with Intellectual Disabilities who have Hearing Impairments / Deafness (ID $\mathrm{HI} / \mathrm{D}$ ) (a longitudinal prospective cohort survey). Accepted for publication in British Journal of Learning Disabilities

Chadwick, O., Piroth, N., Walker, J., Bernard, S. \& Taylor, E. (2000). Factors affecting the risk of behaviour problems in children with severe intellectual disability. Journal of Intellectual Disability Research, 44(2): 108-123.

Crocker, A.G., Mercier, C., Lachapelle, Y., Brunet, A., Morin, D. \& Roy, M.E. (2006). Prevalence and types of aggressive behaviour among adults with intellectual disabilities. Journal of Intellectual Disability Research, 50(9): 652-661.

Crockett, J.L. \& Hagopian, L.P. (2006). Prompting procedures as establishing operations for escapemaintained behavior. Behavioral Intervention, 21(1): 65-71.

Dalkey, N., O. Helmer, (1963), An experimental application of Delphi method to the use of experts, Management Science, 9: 458

De Bildt, A.A. \& Kraijer, D.W. (2003). Vineland-Z: sociale redzaamheidsschaal voor kinderen en jeugdigen met een verstandelijke beperking. Handleiding. [Vineland Adaptive Behaviour Scales-Manual]. Leiden: Pits.

Deb, S., Thomas, M. \& Bright, C. (2001). Mental disorder in adults with intellectual disability. 2: The rate of behaviour disorders among a community-based population aged between 16 and 64 years. Journal of Intellectual Disability Research, 45: 506-514.

Dekker, M.C. \& Koot, H.M. (2003). DSM-IV Disorders in children with borderline to moderate intellectual disability. 1: Prevalence and Impact. Journal of the American academy of child and adolescent psychiatry, 42(8): 915-922.

Durand, V.M. \& Merges, E. (2001). Functional communication training : a contemporary behavior analytic intervention for problem behaviors. Focus on autism and other developmental disabilities, 16(2): 110119.

Emerson, E., Kiernan, C., Alborz, A., Reeves, D., Mason, H., Swarbrick, R., Mason, L. \& Hatton, C. (2001). The prevalence of challenging behaviors: A total population study. Research in developmental disabilities, 22: 77-93.

Fletcher H. (1929). Speech and hearing. New York: Van Nostrand.

Frea, W.D., Arnold, C.L. \& Vittimberga, G.L. (2001). A demonstration of effects of augmentative communication on the extreme aggressive behavior of a child with autism within an integrated preschool setting. Journal of positive behavior interventions, 3(4): 194-198.

Hindley, P.A., Hill, P.D., McGuigan, S. \& Kitson, N. (1994). Psychiatric disorder in deaf and hearing impaired children and young people: prevalence study. Journal of Child Psychology and Psychiatry, 35(5): 917935.

Holden, B. \& Gitlesen, J.P. (2006). A total population study of challenging behaviour in the county of Hedmark, Norway: Prevalence, and risk markers. Research in developmental disabilities, 27: 456-465. 
Kraijer, D.W. \& Kema, G.N. (1994). Sociale redzaamheidsschaal voor zwakzinnigen SRZ. Handleiding [Social Self Care for People with ID-Manual.] Lisse: Swets \& Zeitlinger.

Matson, J.L., Boisjoli, J. \& Mahan, S. (2009). The Relation of Communication and Challenging Behaviors in Infants and Toddlers with Autism Spectrum Disorders. Journal of Developmental and Physical Disabilitie,. 21(4): 253-261.

McClintock, K., Hall, S. \& Oliver, C. (2003). Risk markers associated with challenging behaviours in people with intellectual disabilities: A meta-analytic study. Journal of Intellectual Disability Research, 47: 405-416.

Mitchell, T.V. \& Quittner, A.L. (1996). Multimethod study of attention and behavior problems in hearingimpaired children. Journal of Clinical Child Psychology, 25(1): 83-96.

Molteno, G., Molteno, C.D., Finchilescu, G. \& Dawes, A.R.L. (2001). Behavioural and emotional problems in children with intellectual disability attending special schools in Cape Town, South Africa. Journal of Intellectual Disability Research, 45: 515-520.

Nijhof, R. \& Van Overveld, S. (2005). FOBO Jaarverslag 2005. Amsterdam: Effatha Guyot Zorg.

Sigafoos, J. (2000). Communication development and aberrant behavior in children with developmental disabilities. Education and Training in Mental Retardation and Developmental Disabilities, 35: 168-176.

Snijders, J. Th., Tellegen, P. J. \& Laros, J. A. (1988). Snijders-Oomen niet-verbale intelligentietest SON-R 5.5-17. Verantwoording en handleiding. [Snijders-Oomen Non-verbal Intelligence Scale-Manual 5.5-17.] Groningen: Wolters-Noordhoff.

Tellegen, P.J., Winkel, M., Wijnberg-Williams, B.J. \& Laros, J.A. (1998). Snijders-Oomen Niet-verbale intelligentietest SON-R 2.5-7. Verantwoording en handleiding [Snijders-Oomen Non-verbal Intelligence Scale-Manual 2.5-7.] Amsterdam: Hogreve.

Timehin, C. \& Timehin, E. (2004). Prevalence of hearing impairments in a community population of adults with learning disability: access to audiology and impact on behaviour. British Journal of learning disabilities, 32: 128-132.

Tyrer, F., McGrother, C.W., Thorp, C.F., Donaldson, M., Bhaumik, S., Watson, J.M. \& Hollin, C. (2006). Physical aggression towards others in adults with learning disabilities: prevalence amd associated factors. Journal of Intellectual Disability Research, 50(4): 295-304.

Van Eldik, T., Treffers, P.D.A., Veerman, J.W. \& Verhulst, F.C. (2004). Mental health problems of deaf Dutch children as indicated by parents responses to the Child Behavior Checklist. American annals of the deaf, 148(5): 390-394.

Van Gent, T.; Goedhart, A.W.; Hindley, P.A.; \& Treffers, P.D.A. (2007). Prevalence and correlates of psychopathology in a sample of deaf adolescents. Journal of Child Psychology and Psychiatry. 48(9): 950-958.

Vostanis, P., Hayes, M., Du Feu, M. \& Warren, J. (1997). Detection of behavioural and emotional problems in deaf children and adolescents : Comparison of two rating scales. Child care, Health and Development, 23: $233-246$.

Willems J. \& Verpoorten R. (1996). Communicatie Profiel-Z. Handleiding [Communication Profile-Z. Manual]. Lisse: Swets \& Zeitlinger. 


\section{Chapter 8}

GENERAL DISCUSSION 


\section{General discussion}

The aim of this study was to gain more insight into the relations between internal and environmental factors and challenging behaviour in people with both an intellectual disability (ID) and hearing impairment/deafness (HI/D). For this purpose, an Individual Behaviour Observation and Recording Scale (IBORS) was developed. We used IBORS to collect data from 21 participants with both ID and HI/D over a period of one year. During this period, several environmental factors were recorded as well. This resulted in 21 databases with over 150 factors. From these data, we identified internal riskfactors as well as several environmental factors which, together, are connected with the behaviour of these participants. In addition to these connections, the data gave us extra insight into some other issues, which will be discussed in this section.

\section{Study population}

Twenty-one people with ID and HI/D participated in our study. Fifteen of them are residents of Weerklank, a home for people with ID and HI/D in Amsterdam, the Netherlands. The other six participants are residents of two different homes for people with ID and HI/D from Odion, in Purmerend and Middenbeemster. In daily life, they are supported by different professional caregivers in their homes, as well as in their work or activity program. In addition, these professionals are supported by staffworkers such as physiotherapists, communication specialists, physicians, psychologists, and psychiatrists. In Chapter 6, the diagnostic data of all participants is described, and in Chapter 7, we summarize in 21 mini-case- descriptions which environmental factors are possibly related to challenging behaviour.

In this chapter the most important results of this study are summarized. These results will be discussed and after this we will make some suggestions for further research. Implications for clinical practice will be discussed later in a separate valorisation chapter.

\section{Main Findings}

In this section we summarize the main findings from our study. These findings will be explained in more detail in our discussion.

- With the exception of the study of Timehin \& Timehin, there has been no research into the prevalence of challenging behaviour for people with both ID and HI/D (Chapter 2).

- In studies of people with ID and in people with HI/D prevalence rates of behavioural problems varied from less than $10 \%$ to over $40 \%$. In both groups, these results depend on the definition and terminology used to indicate 
behavioural problems, the background and age of the population, the methods of data collection used, and the psychiatric scales employed (Chapter 2).

- The Individual Behaviour Observation and Recording System (IBORS) that we developed could be an adequate way to describe behaviour in concrete, measurable terms (Chapters 3 and 4).

- $\quad$ IBORS also gives the possibility of defining challenging behaviour more precisely as behaviour that is challenging enough to require intervention in order to prevent further escalating situations (Chapters 3 and 4 ).

- The level of social (in)dependence, the level of communication abilities, and comorbidity of an autism spectrum disorder (ASD) appear to be risk-factors for challenging behaviour (Chapter 6).

- Age correlates negatively with challenging behaviour (Chapter 6).

- The participants in our study are cared for by many different staff-workers (Chapter 7).

- For each participant different environmental factors are related to challenging behaviour. (Chapter 7).

The aim of this study was to explore possible environmental factors, as well as internal risk factors, which are possibly related to challenging behaviour such as aggression, either self-directed or aimed at other people or materials. The reason for this study was that in Weerklank, a residential home for people with both ID and HI/D, a high prevalence of aggression- incidents are reported. Our first goal was to explore other research regarding challenging behaviour in this special group of people. With the exception of the study by Timehin \& Timehin (2004), no research has been done regarding people with this particular combination. It seems that people with both ID and $H I / D$ are not recognised as a special group in scientific research. In several studies it is concluded that a variety of intelligence exists in people with HI/D. Stryker (1999) concluded that, although we know that ID exists in people who are deaf or hard of hearing, it is difficult to identify them. Schum (2005) confirmed these findings. Assessment of people with HI/D and such co-morbidities as epilepsy, visual impairment, ADHD or ID is very difficult because of communication problems. Vice versa, it is recognized that hearing problems exist in people with ID. Yeates (1995), Timehin \& Timehin (2004), and Meuwese-Jongejeugd et al. (2007) explored the frequency of hearing problems in people with ID. Findings in these studies illustrated that the hearing status of people with ID is commonly disregarded. People with ID who also have HI/D and people with HI/D who have a low IQ prove to be an "understudied" group. The prevalence of incidents as a result of aggression is unacceptable (approximately 700 per year for 25 people). The urgency for a study into possible riskfactors for challenging behaviour is obvious when we consider that the employee absence- rate due to illness at Weerklank is 7.7\% (Beek, 2016). We agree with Timehin \& Timehin that "deafness in learning disability has been described as a 'double 
jeopardy' because the difficulties are compounded to be more than the sum of their parts" (Timehin \& Timehin, 2004, p.g. 128).

To explore the nature and prevalence of challenging behaviour in people with both ID and HI/D, we carried out a literature study. We also looked for several possible risk- factors in these studies. We concluded that for people with ID, prevalence rates of challenging behaviour varied from less than $10 \%$ to over $40 \%$. Similar results were found for people with HI/D. These results depend on the definition and terminology used to indicate behavioural problems, the background and age of the population, the methods of data collection used, and the psychiatric scales employed. The aim of our study was to detect possible relationships between challenging behaviour and environmental and internal risk-factors. We included gender, hearing loss, cognitive level, level of social independence, level of communicative development, and autism spectrum disorder. The environmental factors were nutrition, staff- members, visits, medication, conflicts between others, and several unusual or unexpected factors.

Because it proved to be very difficult to define challenging behaviour unambiguously, it was necessary to find a proper behaviour observation and recording scale. We defined conditions for such a scale: a variety of non-verbal behavioural aspects must be measurable; there must be room for individual behavioural descriptions; there should be room for several records per day; it should be filled in by professional caregivers; and it must be efficient and easy to use for every caregiver. Such a scale did not exist, although the non-scientific method of description-plans (Van der Werf, 1998) fulfilled these conditions. We developed this method, which resulted in the Individual Behaviour Observation and Recording Scale (IBORS). IBORS contains 40 unique behavioural descriptions. For each individual participating in the study, eight generally accepted dimensions of behaviour (making sounds, facial expression, locomotion, body manipulation, object manipulation, concentration, receptive communication, and expressive communication) were combined with five levels of severity (relaxation, restlessness, tension, threat, and loss of control). An important contribution of IBORS was that it made it possible to describe behaviour more precisely in measurable terms. Challenging behaviour was defined as "behaviour that needs active intervention by caregivers in order to prevent further escalation of behaviour". With this definition we agreed with Emerson et al (2001) who used the term "challenging behaviour" and with the more recent British tradition to use the definition "behaviour that challenges".

With the scale we developed, we executed an inter-assessor reliability study. This study was carried out with two methods. Firstly, the behaviour of three people with ID and $\mathrm{HI} / \mathrm{D}$ was recorded independently for a period of three weeks by two professional staff- workers who were on duty during a certain shift. Secondly, a 20-minute video of one participant was observed by three different groups: familiar professionals, nonfamiliar professionals, and laypeople. The results of this study were reasonable and convinced us to use IBORS in our study. 
Prior to the study recording period, staff were trained to observe and record individual behaviour by discussing and refining all behavioural descriptions to try to maximise agreement. Sometimes this resulted in a more subjective description. An example is the word "fiedelen", which describes a sound that a certain participant makes when he is in a pleasant mood. This description is clearly defined for all staffmembers who were involved in the daily care of this participant. An outsider would have more difficulty in recognizing this sound and in making the right interpretation of the participant's mood. The staff- workers were instructed to score the highest behavioural level they observed during their shift. It was impossible to see previous records for purposes of reliability. Recording of IBORS-scores was done digitally using a Microsoft Access software program, which was developed for this study. It is almost impossible to avoid all subjective descriptions, but professionals who are familiar with the participant and his behaviour proved to have a higher agreement in judging behaviour than non-familiar professionals and laypeople. We think that the use of IBORS offers possibilities in observing and judging individual behaviour because behaviour is described in many aspects and details. A second advantage of IBORS is that, based on the behaviour descriptions, differentiated interventions can be carried out. An example is that a participant can easily be corrected by directive non-verbal communication when behaviour is observed that is described in stage three, but that the same participant has to be separated for a short while if behaviour is observed that is described in stage five. We also recommend IBORS in measuring certain effects as a result of intended changes in pedagogic treatment, medication, or physical environment. If behaviour as observed and recorded by the IBORS method before a certain change or intervention can be compared with recorded behaviour in a period after this intervention, it is then possible to evaluate whether the intervention has led to a change in behaviour.

Furthermore, we wanted to investigate which environmental factors presumably could be related with the behaviour of people with ID and HI/D. At first we conducted literature research into a wide variety of factors that could possibly influence human behaviour in general. The literature research resulted in an extensive number of factors. Therefore, we decided to make a selection and carried out the Delphi method. A group of psychologists and staff, who all were professionally involved with people with both ID and HI/D, constructed a list of possible factors, based on their experience and presumptions. This list was distributed to professionals from different sections: group- workers, school teachers, staff members, and managers. The factors that derived from this method were defined in objective and measurable terms.

For data- collection, we had to depend on the cooperation of many professional staff- workers. Extensive education about the aim of our study was provided to these staff. We are convinced that this education was beneficial, since these staff-workers have observed and recorded behaviour and environmental factors three times per day for a period of one year. These staff- workers were very aware that the results from 
this study can contribute to a more favourable pedagogic climate for their participants and a better experience of competence and work- satisfaction for themselves.

From these data, we concluded that some internal factors could be marked as risk- factors. Firstly, a relation between challenging behaviour and age was found. In our participants, aging correlates with a decreasing challenging behaviour. This result confirms research by Emerson et al. (2001) and Tyrer et al. (2006). Co-morbidity with ASD proved to be a second risk- factor. In participants who are diagnosed with ASD, a higher prevalence of challenging behaviour was found. This was also demonstrated in previous studies (McClintock, Hall \& Oliver, 2001; Kamio, 2002; Matson, Boisjoli \& Mahan, 2009). Thirdly, the level of social independence was marked as a risk-factor. There seems to be a relation between a low level in this domain and a high prevalence of challenging behaviour. This agrees with the findings of Chadwick et al. (2000) and Emerson et al. (2001), who found a higher prevalence of behavioural problems when people with ID were more limited in their daily skills, and Crockett \& Hagopian (2006), who found an increase in behavioural problems when people with ID were challenged by demanding situations. Finally, we found a relation between the level of communication and challenging behaviour. Poor communication abilities are related to a higher prevalence of challenging behaviour. This was also concluded in several meta analyses (e.g., Sigafoos, 2000; Emerson et al., 2001; Besag, 2003) and in several case studies (e.g., Frea, Arnold \& Vittimberga, 2001; Durand \& Merges, 2001). Poor social and communication abilities mean that a person has to depend more on others; because it is difficult to make wishes or unease clear, it is plausible that this can lead to challenging behaviour. Thus, challenging behaviour might be the result of inadequacy. Support for people with ID and HI/D should be aimed primarily at stimulating the ability to cope independently. Therefore, we agree completely with Huber (2011) who advocates for defining health as "the ability to adapt and self-manage". The participants in our study all live in residential settings, and therefore they have to depend on professional caregivers. This causes a difficult dilemma. The education of professionals should therefore be aimed at "Positive Psychology" (Wehmeijer et al, 2014). In this vision, stimulating abilities is far more important than focusing on disabilities.

We also investigated possible relationships between challenging behaviour and environmental factors. For this purpose, we carried out 21 individual case- studies. From the results of these studies, we concluded that for only one participant was there no relationship between challenging behaviour and environmental factors. The results were discussed in Chapter 7. For each participant, several environmental factors were found, which makes it difficult to draw conclusions for people with ID and HI/D in general. For clinical practice, this means that we cannot give concrete advice about environmental factors that are influence challenging behaviour in people with ID and $\mathrm{HI} / \mathrm{D}$ in general. However, with IBORS, it is possible to gain a better understanding of certain environmental factors that are related to challenging behaviour in individuals. If 
possible, these factors could be avoided, which could decrease the prevalence of challenging behaviour.

\section{Limitations of our study}

This study did have some limitations. In the first place, only 21 participants were included. The two institutes where our participants live are the only ones specialised in this target population in The Netherlands. We were aiming for more participants and tried to include another group of people with ID and HI/D who live in another residential home. Unfortunately, this organisation decided not to participate. Therefore we could not find a larger sample of people with both ID and HI/D. 21 Participants is a small sample and probably not representative. On the other hand we collected a large database for each of our participants because behaviour of these 21 participants and environmental factors were observed and recorded over a period of one year. The average collected amount data of all 21 participants was 570 records.

A second possible limitation concerns the use of IBORS: further research is necessary, although inter-assessor reliability showed that the instrument was suitable for the purposes of observing and recording behaviour.

Thirdly, with the results of our study we can not draw conclusions about causal relations. However, we can detect mediating connections between internal or environmental factors and challenging behaviour.

Fourthly, we are not certain that we included all relevant environmental factors by making use of the Delphi-method. Although this is a recognized method (Dalkey \& Helmer, 1963) we have no full guarantee that this results in a complete list of the most relevant factors. Several factors such as the moon-phase or weather-conditions were excluded using our criteria that nonetheless may be meaningful.

Finally, we also wanted to include visual disabilities and certain syndromes and aetiology for ID and HI/D such as rubella or fragile x-syndrome. For several participants these data were not available. Therefore it was impossible to include these data in our study. 


\section{References}

Beek, M. (2016). Ziekteverzuim 2012 - 2015. Interne notitie database Kentalis Zorg. Weerklank, Amsterdam.

Besag, F.M.C. (2003). Psychopathology in people with epilepsy and intellectual disability. Journal of Neurology, Neurosurgery and Psychiatry, 74, 1464.

Chadwick, O., Piroth, N., Walker, J., Bernard, S. \& Taylor, E. (2000). Factors affecting the risk of behaviour problems in children with severe intellectual disability. Journal of Intellectual Disability Research, 44(2), 108-123.

Crockett, J.L. \& Hagopian, L.P. (2006). Prompting procedures as establishing operations for escapemaintained behavior. Behavioral Intervention, 21(1), 65-71.

Dalkey, N.; Helmer, O (1963), An experimental application of Delphi method to the use of experts, Management Science, 9, 458

Durand, V.M. \& Merges, E. (2001). Functional communication training : a contemporary behavior analytic intervention for problem behaviors. Focus on autism and other developmental disabilities, 16(2), 110119.

Frea, W.D., Arnold, C.L. \& Vittimberga, G.L. (2001). A demonstration of effects of augmentative communication on the extreme aggressive behavior of a child with autism within an integrated preschool setting. Journal of positive behavior interventions, 3(4), 194-198.

Huber M, Knottnerus JA, Green L, Horst H van der, Jadad AJ, Kromhout D, Leonard B, Lorig K, Loureiro MI, Meer JWM van der, Schnabel P, Smith R, Weel C van, Smid H. (2011). How should we define health? BMJ, 343(4163):235-237.

Kamio, Y. (2002). Self-injurious and aggressive behavior in adolescents with intellectual disabilities: A comparison of adolescents with and without autism. Japanese Journal of Special Education. 39(6). 143154.

Matson, J. L., Boisjoli, J., Mahan, S. (2009). The Relation of Communication and Challenging Behaviors in Infants and Toddlers with Autism Spectrum Disorders. Journal of Developmental and Physical Disabilities. 21(4): 253-261.

McClintock, K., Hall, S. \& Oliver, C. (2003). Risk markers associated with challenging behaviours in people with intellectual disabilities: A meta-analytic study. Journal of Intellectual Disability Research, 47, 405-416.

Meuwese-Jongejeugd, A.; Vink, M.; van Zanten, B.; Verschuure, H.; Eichhorn, E.; Koopman, D.; Bernsen, R.; Evenhuis, H. (2006). Prevalence of hearing loss in 1598 adults with an intellectual disability: Crosssectional population based study. International Journal of Audiology. 45(11): 660-669.

Schum, R. (2005). Psychological Assessment of Children with Multiple Handicaps Who Have Hearing Loss. Volta Review. 104(4). 237-255.

Sigafoos, J. (2000). Communication development and aberrant behavior in children with developmental disabilities. Education and Training in Mental Retardation and Developmental Disabilities, 35, 168-176.

Stryker, D.S. (1999). Identification of learning disabilities in students who are deaf or hard of hearing: A Bayesian approach. Dissertation Abstracts International Section A: Humanities and Social Sciences. 59(9-A): 3405.

Timehin, C. \& Timehin, E. (2004). Prevalence of hearing impairments in a community population of adults with learning disability: access to audiology and impact on behaviour. British Journal of Learning Disabilities, 32, 128-132.

Tyrer, F., McGrother, C.W., Thorp, C.F., Donaldson, M., Bhaumik, S., Watson, J.M. \& Hollin, C. (2006). Physical aggression towards others in adults with learning disabilities: prevalence amd associated factors. Journal of Intellectual Disability Research, 50(4), 295-304.

Van der Werf, L. J., Goedhart, A. W., Huiberts, S. (1998). Signaleringsplannen, naar minder agressie en dwang in de psychiatrie. Lisse: Swets \& Zeitlinger.

Wehmeijer M.L. et al, (2014). The Oxford Handbook of Positive Psychology and Disability.

Yeates, S. (1995). The incidence and importance of hearing loss in people with severe learning disability: The evolution of a service. British Journal of Learning Disabilities. 23(2): 79-84. 
SUMMARY 


\section{Summary}

Behavioural problems in individuals with both hearing impairments or deafness (HI/D) and an intellectual disability (ID) are common. A literature search was conducted, focused on the prevalence of behavioural problems in people with HI/D or ID and in people with both HI/D and ID.

With one exception little research on behavioural problems in people with a combination of both disabilities was found. Prevalence rates in both other groups (HI/D and ID seperately) vary among the studies. For people with HI/D, differences seem to be related to the composition of the samples, although these studies were aimed on children and younsters. For people with ID, there are differences in the terminology indicating behavioural problems, type and age of the population, the methods of data collection used and the measuring instruments. We also studied as possible risk factors for behaviour problems. In both groups an increase of behavioural problems is found when additional handicaps occur. The existence of ID in children with HI/D and conversely sensory impairment in people with ID form extra risk factors for behavioural problems. Difficulties with communication increase the risk of the occurence of behavioural problems.

Although several risk factors for these behavioural problems are reported, empirical research is needed to gain more insight into direct relations between certain internal and environmental factors and behavioural problems. For this purpose it is necessary to use an instrument with which behaviour can be observed and recorded. We defined six conditions for such a scale. Although we reviewed existing behavioural observation and recording scales on their suitability we did not succeed in finding an appropriate scale that met all our conditions.

Because of this shortage we developed our own Individual Behaviour Observation and Recording Scale (IBORS) which is based on eight dimensions of behaviour and five levels of severity which results in a unique behavioural repertoire of each individual person. With this scale it is possible to define behavioural problems more accurately. Because behaviour at level 3 or higher is challenging and requires therefore active intervention by care-professionals, we proposed to define behaviour representing level 3 or higher as challenging behaviour. We therefore agreed with Emerson et al (2001) and Holden and Gitlesen, (2006) in using this term for describing behavioural problems.

We succeeded in the construction of a scale that meets our criteria and conditions and we carried out an explorative study in inter-assessor agreement. We used two methods to measure agreement. Judgements of behaviour of three people with both $\mathrm{HI} / \mathrm{D}$ and ID were made by two staff- members independently, after having worked a whole shift together. The second method consisted of observing and recording videotaped behaviour of one person with both HI/D and ID by three groups observers: 
familiar professionals, professional outsiders and laymen. In both methods coefficients indicate a fair degree of agreement.

Our next step was to decide which environmental factors should be included in our study. These factors were chosen after carrying out the Delphi method by several professionals who are involved in the daily care of people with both ID and HI/D. These factors were defined in measurable terms. A computer-program was developed to do reliable recordings over longer periods of time of such factors and behaviour according to the IBORS-method, by varying care professionals with different backgrounds.

Data were obtained by recording behaviour on a daily basis during one year for 21 participants with both ID and HI/D. Fourteen are male, seven are female, varying in age from 12.4 to 42 years; mean 26.6, SD 7.27). It was found that $100 \%$ of the participants in this study showed challenging behaviour, although this was not observed every day in each participant. Prevalence rates of episodes with challenging behaviour during a year varied from $1.8 \%$ to $77.3 \%$ of the recording time. On average, the prevalence rate was $28.9 \%$ of the recording time.

The likelihood of challenging behaviour appears to increase proportionally with a decrease in communicative skills as well with a lower level of social independence. We also found that in people with autism spectrum disorder, the prevalence of challenging behaviour was significantly higher than in people without autism spectrum disorder. Furthermore we found a negative correlation between challenging behaviour and age. The level of intellectual disability as well as the level of hearing impairments was not related to the prevalence of challenging behaviour. Because there are several patterns of increasing and decreasing challenging behaviour throughout the day, it is not possible to draw one conclusion on this issue for the whole group.

For almost each participant several environmental factors were found. This showed that the interaction between factors plays an important role, which makes it difficult to isolate the individual influence of separate factors.

Points of concern are made about the amount of staff-members who were involved with the participants and the uneasy situations which seem to occur after alarm-situations. Implications for clinical practice are discussed. 
SAMENVATTING 


\section{Samenvatting}

Bij mensen met zowel een verstandelijke beperking als een auditieve beperking komen veel gedragsproblemen voor. We verrichtten literatuuronderzoek naar de prevalentie van gedragsproblemen bij mensen met een verstandelijke beperking, mensen met een auditieve beperking en mensen met zowel een verstandelijke beperking als een auditieve beperking.

Met uitzondering van één studie bleek er echter geen onderzoek te zijn gedaan naar de prevalentie van gedragsproblemen bij mensen met zowel een verstandelijke beperking als een auditieve beperking. De prevalentiecijfers in beide eerste groepen varieerden sterk. Voor mensen met een auditieve beperking leek dit te wijten aan de samenstelling van de onderzochte groepen, hoewel de studies zich richtten op kinderen en jongeren. Voor mensen met een verstandelijke beperking werden deze verschillen veroorzaakt door verschillen in de terminologie om gedragsproblemen aan te duiden, door het type en de leeftijd van de onderzochte groep, door de manier waarop de gegevens werden verzameld en door de meetinstrumenten die werden gebruikt in de diverse studies.

Ook onderzochten we welke risicofactoren voor het ontstaan van gedragsproblemen worden genoemd. In beide groepen werd een toename van gedragsproblemen gevonden als er sprake was van bijkomende beperkingen. Bij kinderen met een auditieve beperking vormt een verstandelijke beperking een risicofactor terwijl zintuiglijke beperkingen zoals gehoorverlies bij mensen met een verstandelijke beperking extra risicofactoren vormen voor gedragsproblemen. Moeilijkheden met communicatie vergrootte ook het risico op gedragsproblemen. Hoewel verschillende risicofactoren voor gedragsproblemen worden gerapporteerd, is empirisch onderzoek nodig om meer inzicht te krijgen in directe relaties tussen specifieke interne en omgevingsfactoren enerzijds en gedragsproblemen anderzijds. Hiertoe is het nodig om een instrument te hebben waarmee gedrag kan worden geobserveerd en gescoord.

Wij definieerden zes voorwaarden voor een dergelijke schaal. Onderzoek van de bestaande observatieschalen op hun bruikbaarheid, leverde geen geschikte schaal op die aan al onze voorwaarden voldeed. Dit was de reden dat we onze eigen Individuele Gedrags Observatie en Scorings schaal (Individual Behaviour Observation and Recording Scale - IBORS) ontwikkelden. Deze schaal is gebaseerd op acht dimensies van gedrag en vijf niveau's van ernst van het gedrag. De afname van de schaal resulteert in een uniek gedragsrepertoire voor ieder individu persoonlijk. Met deze schaal is het ook mogelijk om gedragsproblemen nauwkeuriger te definiëren. Gedrag dat kenmerkend is voor niveau drie of hoger is zo ernstig dat begeleiders zich genoodzaakt, of "uitgedaagd" voelen tot een actieve interventie om verdere escalatie te voorkomen. Daarom hebben wij voorgesteld om gedrag dat voor een bepaald persoon kenmerkend 
is in niveau drie of hoger te omschrijven als probleemgedrag, ofwel in de internationale traditie "Challenging Behaviour". Daarmee sluiten wij aan bij Emerson et al (2001) en Holden \& Gitlesen, (2006) om deze term te gebruiken voor gedragsproblemen.

We slaagden er zodoende in om een schaal te ontwikkelen die voldeed aan onze voorwaarden en we deden een eerste oriënterend onderzoek naar de interbeoordelaars betrouwbaarheid. We gebruikten daarvoor twee methodes. Twee begeleiders die tegelijkertijd met drie personen met een verstandelijke en auditieve beperking hadden gewerkt, beoordeelden het gedrag onafhankelijk van elkaar. De tweede methode bestond uit het observeren en scoren van het gedrag van één persoon met een verstandelijke en auditieve beperking. De scoring werd gedaan nadat een videotape van ongeveer twintig minuten was geobserveerd. De resultaten van drie groepen beoordelaars (met de betreffende persoon bekende professionals; professionals die bekend waren met de doelgroep maar niet met betreffende persoon en een groep "leken" die privé noch professioneel iets met de zorg voor personen met een verstandelijke en/of auditieve beperking te maken hebben) werden met elkaar vergeleken. Beide methodes resulteerden in een redelijk betrouwbare overeenkomst tussen beoordelaars.

Onze volgende stap was de beslissing welke omgevingsfactoren wij in onze studie zouden betrekken. Deze factoren werden gekozen na de "Delphi-methode" te hebben toegepast door verschillende professionals die betrokken waren bij de dagelijkse zorg van mensen met een verstandelijke en een auditieve beperking. Deze factoren werden in meetbare termen gedefinieerd. Een computerprogramma werd vervolgens ontwikkeld om zowel het gedrag middels IBORS als de omgevingsfactoren over een langere periode betrouwbaar te kunnen registreren.

De gegevens werden verzameld door een jaar lang drie keer per dag het gedrag van 21 proefpersonen met een verstandelijke en auditieve beperking zowel als omgevingsfactoren in het programma in te voeren. Van deze 21 personen waren er veertien mannelijk en zeven vrouwelijk. De leeftijd varieerde van 12.4 tot 42 jaar (gemiddeld 26.6 jaar met een standaardafwijking van 7.27). De resultaten wezen uit dat $100 \%$ van de proefpersonen "Challenging Behaviour" vertoonde, hoewel dat niet elke dag bij elke proefpersoon werd geobserveerd. Prevalentiecijfers van periodes van "Challenging Behaviour" varieerden van $1.8 \%$ to $77.3 \%$ van de observatietijd. Het gemiddelde prevalentiecijfer bedroeg $28.9 \%$ van de observatietijd.

De resultaten wezen uit dat de kans dat "Challenging Behaviour" voorkomt groter wordt als er sprake is van verminderde communicatieve vaardigheden en wanneer er sprake is van een lager niveau van sociale redzaamheid. Ook vonden we een significant hogere prevalentie "Challenging Behaviour" bij proefpersonen met een bijkomende autismespectrum stoornis. Voorts vonden we een negatief verband tussen leeftijd en "Challenging Behaviour". De ernst van de verstandelijke beperking zowel als de mate van gehoorverlies bleek niet gerelateerd te zijn aan de prevalentie van "Challenging Behaviour". Omdat er verschillende patronen zichtbaar waren van toename en afname 
van "Challenging Behaviour" in de loop van de dag is het niet mogelijk om conclusies voor de gehele groep te trekken.

Voor bijna elke proefpersoon werden verschillende omgevingsfactoren gevonden. Dit toont aan dat de interactie tussen factoren een belangrijke rol speelt, waardoor het moeilijk is om de individuele invloed van afzonderlijke factoren te isoleren.

Er zijn een paar punten van zorg betreffende de hoeveelheid begeleiders die waren betrokken bij de proefpersonen en de ongemakkelijke situaties die lijken te ontstaan rond alarm-situaties waar de proefpersonen niet persoonlijk bij betrokken waren. Tenslotte bediscussiëren we implicaties voor de klinische praktijk. 
VALORISATION 


\section{Valorisation}

From clinical practice it has been reported that professional caregivers who work with people with an Intellectual Disability (ID) as well as Hearing Impairment or Deafness (HI/D) are frequently confronted with challenging behaviour. In particular, aggressive incidents such as destructive behaviour aimed at objects or other people and selfharming behaviour are common problems. Since our research question was developed as a result of this serious problem, we can conclude that the results of our study give us several insights and possible opportunities for professionals working in clinical practice with people with both ID and HI/D.

With our study, we made it plausible that, for 20 out of 21 participants, different environmental factors play a role in increasing or decreasing challenging behaviour. For each participant, unique combinations of environmental factors were found. Undoubtedly, internal (i.e. person-bound) risk- factors play an important role as well. For clinical practice, this means that we cannot give specific advice about environmental factors that influence challenging behaviour in people with ID and HI/D in general. The results of our study have, however, given clues for possible environmental factors and internal risk- factors on an individual level. Staff could try to avoid certain environmental clues or signs in order to prevent challenging behaviour. Moreover, staff could consider possible factors by offering their clients (people with both ID and HI/D) explicit choices in, for instance, nutrition when they suspect that a certain foodstuff is possibly related to challenging behaviour.

To achieve knowledge about suspicious factors, professionals could benefit from the IBORS- method. By utilizing this method (descriptions of eight behavioural aspects over five mood- levels of severity) to describe the behaviour of clients in detail, more insight can be gained regarding behavioural patterns of the client. Moreover, specific and differentiated interventions can be identified, based on the level of severity in which a client is observed. If professionals can be facilitated to intervene in an early stage, the chance will increase that aggression- incidents or other mood- escalations can be prevented.

Another advantage of IBORS is that behaviour can be recorded in measurable terms on an ordinal five-point scale. When staff is able to observe and record behaviour over a longer period of time by making use of IBORS, it is possible that certain trends in (challenging) behaviour can be discovered. Moreover, it could be possible to evaluate certain interventions such as a change in medication.

A second practical implication follows from the results of our study into internal risk- factors. A higher level of social independence as well as a higher level of communication abilities seem to be related to a decrease in challenging behaviour. We wholeheartedly support a vision and method of working as described in the philosophy of "Positive Psychology" (Wehmeijer et al, 2014), which explicitly focuses on 
possibilities instead of disabilities. Stimulating "the ability to adapt and self-manage" (Huber, 2011) will increase a feeling of autonomy in people with ID and HI/D. Therefore we strongly support a professional approach in which stimulating social independence and communication is essential.

A third practical implication is that professionals continuously need to be trained in the vision that challenging behaviour is related to and possibly is caused by a lack of communication abilities, and that a priority in their work in caring for people with ID and $\mathrm{HI} / \mathrm{D}$ is to try to understand their motives for certain challenging behaviour by thorough observation.

A specific point of concern exists in situations in which an alarm- signal sounds. We suspect the risk of a vicious circle. According to individual plans, challenging behaviour can be a reason for staff to push the alarm-button. Seven out of 15 participants $(46.7 \%)$ at the residential home in which this alarm- system is used show an increase of challenging behaviour when alarm- situations occur in another part of this home. It is plausible that such situations are stressful for staff as well as for the residents, whether they are directly involved or not. Although we realize that it is much to ask of professional staff- members, this should be an important issue. In daily practice, staff- members who are giving assistance in these situations immediately have to hurry towards the place where they are expected for assistance. After having assisted, they return to their own clients. They should be very much aware that such alarm- situations can be a risk- factor for challenging behaviour.

Another specific point of concern is that the management of this particular home should give serious attention to the fact that so many different staff-members were involved in the daily care of the participants in our study during one year. It is plausible that this is disadvantageously and even harmful for the quality of life for people with ID and HI/D when they are confronted with over 20 different staff-members. It is important that further research will be conducted regarding the reasons staffmembers resign.

Furthermore, it is doubtful if each person with ID and HI/D benefits from the presence of more than three staff-members at the same time. This should be evaluated more critically. 
In summary, with our study we reached the following results:

1. We developed IBORS. With this method professionals have a tool with which challenging behaviour can be defined accurately and specific interventions can be agreed. Behaviour can be monitored and interventions can be evaluated.

2. We developed a digital recording program which could be developed further.

3. We detected several internal risk-factors which are related to challenging behaviour.

4. We concluded that the interaction between several environmental factors plays an important role in relation to challenging behaviour, which makes it difficult to isolate the individual influence of separate factors. However by using IBORS eventually combined with the digital recording program, it is possible to detect which factors play a role on an individual level. 


\section{References}

Huber M, Knottnerus JA, Green L, Horst $\mathrm{H}$ van der, Jadad AJ, Kromhout D, Leonard B, Lorig K, Loureiro MI, Meer JWM van der, Schnabel P, Smith R, Weel C van, Smid H. (2011). How should we define health? BMJ, 343(4163):235-237.

Wehmeijer M.L. et al, (2014). The Oxford Handbook of Positive Psychology and Disability. 
DANKWOORD 


\section{Dankwoord}

Dat niemand een proefschrift in zijn ééntje schrijft is een enorme open deur. Er zijn dan ook in dit proces heel veel aardige, behulpzame en deskundige mensen betrokken geweest.

Op de eerste plaats zijn dat mijn promotor professor Bert Aldenkamp en copromotor dr. Joop Hoekman. Bert, het is toch wel voorgekomen dat ik het lastig vond om na een pauze die soms meer dan een jaar bedroeg, weer contact met je op te nemen. Maar werkelijk altijd was je weer enthousiast ("Héé Meindert leef jij ook nog?!") en onmiddellijk bereid om een afspraak te maken. Na zo'n afspraak, ook al reed ik wel eens voor slechts een half uurtje overleg vanuit het westen naar Heeze of Oosterhout, was ik weer helemaal vol van energie en ideeën. Ik heb het bewonderenswaardig gevonden dat je zo'n enorme "helicopterview" hebt en op elke vraag een adequaat antwoord of zinvolle suggestie kon geven.

Dat ik in contact ben gekomen met co-promotor Joop Hoekman (destijds staflid wetenschappelijk onderzoek bij de Gemiva-SVG Groep) is één van de betere ontmoetingen in mijn carrière, nee, in mijn leven, gebleken. Joop, vanaf het eerste moment ben je enorm stimulerend geweest. Je deskundigheid, maar ook je geduld en je persoonlijke betrokkenheid waardeer ik bijzonder. Zelden heb ik een meer respectvol persoon ontmoet. Ook ben ik je dankbaar voor het feit dat je me hebt voorgesteld aan Bert. Joop en Bert, jullie hebben mij op allerlei vlakken onnoemlijk veel wijsheid geschonken.

Dr. Godfried van den Wittenboer heeft mij in de eerste fase, nog voor zijn pensioen, goed op weg geholpen met de eerste statistische bewerkingen.

Dat dit onderzoek überhaupt is gestart heb ik te danken aan Sjoerd Homminga, destijds coördinator van Weerklank. Hij heeft mij zo "gek" gekregen om, wat naar later bleek vele jaren, aan dit onderzoek te werken. De raad van bestuur van de Gemiva-SVG Groep, met name de heren Arts, Borsboom en Gerding hebben het onderzoeksvoorstel van harte ondersteund en hebben bovendien bemiddeld in het vinden van fondsen zodat ik de eerste jaren twee dagen per week vrijgesteld kon worden van mijn taken als behandelcoördinator.

Voorts dank ik de ouders van de cliënten van Weerklank en Odion die toestemming hebben gegeven dat hun zoon of dochter aan het onderzoek kon deelnemen. Ook dank ik de vele collega's die in de beginfase hebben meegedacht over de eerste opzet alsmede degenen die een jaar lang bereid waren om trouw allerlei observaties in het computerprogramma in te voeren waardoor heel veel gegevens 
konden worden verzameld. Daarnaast hebben meerdere mensen hun bijdrage geleverd aan het oriënterend betrouwbaarheidsonderzoek van IBORS, zoals in hoofdstuk 4 werd beschreven. Mede door al deze mensen is dit proefschrift mogelijk gemaakt.

Ook in de persoonlijke sfeer hebben meerdere mensen mij ondersteund. Op de eerste plaats is dat Johan de Haas, mijn grote neef en held, die het computerprogramma heeft gemaakt waarmee de data werden verzameld. Mijn liefste nicht Imke Harrewijne - de Haas heeft in de beginfase mijn allereerste teksten geredigeerd. Beiden zijn veel te vroeg overleden en ik mis hen enorm, zeker op momenten zoals rond deze promotie.

Collega Ines Sleeboom - van Raaij heeft enerzijds als klankbord en bemiddelaar met de European Society of Mental Health and Deafness gefungeerd en daarnaast ervoor gezorgd dat ik door Niels Veldhuijzen weer een stap verder werd geholpen op statistisch gebied.

Mijn "steenkolen-Engels" is eerst door Dianne Simcock - Hartogh gecorrigeerd maar het leeuwendeel daarvan heeft mijn andere liefste nicht, Sunny Buskermolen, op strenge wijze grondig aangepakt. Beiden ben ik zeer erkentelijk.

Marisca Hageman heeft mij als collega en goede vriendin met heel veel kritische, genuanceerde, maar ook heerlijk ongenuanceerde wake-up opmerkingen en suggesties regelmatig een flinke schop in de juiste richting gegeven.

Mijn oudste zoon Thom heeft me in de laatste fase van het onderzoek geadviseerd met betrekking tot een aantal statistische bewerkingen waarbij ik meerdere malen met grote bewondering (en vaderlijke trots) stond te kijken naar zijn vindingrijkheid.

Corina, al meer dan 30 jaar mijn beste vriend, partner en grote liefde heeft me bovendien als voedingsdeskundige nog eens extra geholpen met hoofdstuk 5 . 
CURRICULUM VITAE 


\section{Curriculum vitae}

Meindert Buskermolen werd geboren op 31 maart 1956 in Leiden. Na de middelbare school behaalde hij aan de Rijkspedagogische Academie te Haarlem in 1978 het onderwijsdiploma voor het basisonderwijs. Tijdens deze opleiding had hij echter al het plan opgevat om na het behalen van het diploma psychologie te gaan studeren. Na zijn kandidaatsexamen volgde hij de specialisatie ontwikkelingspsychologie aan de Vrije Universiteit te Amsterdam. Binnen deze hoofdrichting specialiseerde hij zich verder in de "Hulpverlening aan gezinnen met een Lichamelijk- of Meervoudig gehandicapt kind". Tijdens de laatste twee jaar van zijn studie was hij tevens werkzaam als communicatietherapeut bij Weerklank, een residentiële instelling voor jongeren met een verstandelijke en auditieve beperking te Amsterdam en destijds onderdeel van de Gemiva-SVG Groep. Na zijn afstuderen in 1987 bleef hij werkzaam voor Weerklank en werd hij in 1990 ook behandel coördinator in Weerklank. In Weerklank heeft hij vervolgens in die functie steeds verschillende taken gehad, waaronder het opzetten van de ambulante dienst. In 1999 kreeg hij de vraag vanuit het management van Weerklank en de Gemiva-SVG Groep om onderzoek te doen naar de oorzaken van probleemgedrag bij de bewoners van Weerklank. Dat onderzoek is met dit proefschrift afgerond. Sinds 1998 heeft hij als vrijgevestigd GZ-Psycholoog / Kinder- en Jeugdpsycholoog zijn eigen praktijk (Opmaat-Aalsmeer) waar hij met zeer veel plezier, sinds 2015 inmiddels full-time, werkzaam is. Hij is getrouwd en is vader van vier zoons. Voorts is hij actief als basketballtrainer en -coach en speelt hij als basgitarist in twee bands, waarvan één met zijn zoons. 
